\title{
Space Shuttle Solid Rocket Motor Plume Pressure and Heat Rate Measurements
}

\begin{tabular}{|r|l|}
\hline Journal: & 2012 New Orleans Conferences \\
\hline Manuscript ID: & Draft \\
\hline luMeetingID: & 2227 \\
\hline Date Submitted by the Author: & n/a \\
\hline Contact Author: & Struchen, Leah \\
\hline
\end{tabular}

SCHOLARONE ${ }^{m}$

Manuscripts 


\title{
Space Shuttle Solid Rocket Motor Plume Pressure and Heat Rate Measurements
}

\author{
Wulf von Eckroth, Ph.D., ${ }^{1}$ Leah Struchen, ${ }^{2}$ Tom Trovillion, Ph.D., ${ }^{3}$ \\ Rafael Perez, Ph.D., ${ }^{4}$ and Shaun Nerolich ${ }^{5}$ \\ United Space Alliance, LLC., Kennedy Space Center, FL, 32780 \\ and \\ Chris Parlier ${ }^{6}$ \\ NASA, Kennedy Space Center, FL, 32899
}

\begin{abstract}
The Solid Rocket Booster (SRB) Main Flame Deflector (MFD) at Launch Complex 39A was instrumented with sensors to measure heat rates, pressures, and temperatures on the final three Space Shuttle launches. Because the SRB plume is hot and erosive, a robust Tungsten Piston Calorimeter was developed to compliment measurements made by off-theshelf sensors. Witness materials were installed and their melting and erosion response to the Mach $2 / 4000^{\circ} \mathrm{F} / 4$-second duration plume was observed. The data show that the specification used for the design of the MFD thermal protection system over-predicts heat rates by a factor of 3 and under-predicts pressures by a factor of 2 . These findings will be used to baseline NASA Computational Fluid Dynamics (CFD) models and develop innovative MFD designs for the Space Launch System (SLS) before this vehicle becomes operational in 2017.
\end{abstract}

$\begin{array}{llll} & & & \\ & \text { Nomenclature } & \\ K S C & =\text { Kennedy Space Center } & F E M & =\text { Finite Element Model } \\ M S F C & =\text { Marshall Space Flight Center } & P S D & =\text { power spectral density } \\ U S A & =\text { United Space Alliance, LLC. } & M L P & =\text { Mobile Launch Platform } \\ N A S A & =\text { National Aeronautics and Space Administration } & T & =\text { temperature } \\ S R B & =\text { Solid Rocket Booster } & x & =\text { distance or depth } \\ M F D & =\text { Main Flame Deflector } & k & =\text { thermal conductivity } \\ L C-39 A & =\text { Launch Complex 39A (Pad A) } & c_{v} & =\text { specific heat } \\ S T S & =\text { Space Transportation System ('Space Shuttle') } & \rho & =\text { density } \\ C F D & =\text { Computational Fluid Dynamics } & \alpha & =\text { thermal diffusivity } \\ S L S & =\text { Space Launch System } & & = \\ F O D & =\text { foreign object debris } & & \\ S R M & =\text { Solid Rocket Motor } & & \\ S S M E & =\text { Space Shuttle Main Engine } & & \\ G S E & =\text { ground support equipment fusion } \\ M E T & =\text { mission elapsed time } & & \\ T P C & =\text { Tungsten Piston Calorimeter } & & \\ C O T S & =\text { commercial-off-the-shelf } & & \\ D A Q & =\text { data acquisition system } & & \\ E D M & =\text { Electrical Discharged Machined } & & \\ D L R & =\text { German Aerospace Center } & & \end{array}$

\footnotetext{
${ }_{1}^{1}$ Launch Site Design Manager, Engineering Project Management, USK-800, AIAA Senior Member

${ }^{2}$ Staff Engineer, Strength and Thermal Analysis Dept., USK-841, AIAA Professional Member

${ }^{3}$ Senior Staff Engineer (retired), Technical Analysis Dept., AIAA Senior Member

${ }^{4}$ Staff Engineer, Strength and Thermal Analysis Dept., USK-841, AIAA Professional Member

${ }^{5}$ Staff Engineer, Loads and Dynamics Analysis Dept., USK-841, AIAA Senior Member

${ }^{6}$ Staff Engineer, Mechanical Support Systems Engineering Branch, Mail Stop NE-M6
}

1

American Institute of Aeronautics and Astronautics

http://mc.manuscriptcentral.com/aiaa-mfd12 


\section{Introduction}

$\mathrm{T}$ HE Main Flame Deflectors used at both Launch Complex 39A and B are covered with a refractory concrete that cracks and shatters at liftoff, releasing FOD (Foreign Object Debris), which is both expensive to repair and potentially damaging to ground support equipment. Figure la shows the SRB plume at liftoff during STS-135 and illustrates the two types of fluids causing the extreme environment affecting the MFD. The brownish colored clouds to the sides of the photo are from the Solid Rocket Motor (SRM) combustion exhaust, and the gray clouds in the center foreground are steam from the water deluge sound suppression system and Space Shuttle Main Engine (SSME) exhaust. Figure $1 \mathrm{~b}$ illustrates the Shuttle and Pad A ground structures, including the MFD. Because refractory concrete on the MFD has very little tensile strength, pieces of this material weighing over eighty pounds can liberate and fly hundreds of feet, striking and damaging pad ground structures such as fluid distribution systems. The expensive process of reapplying concrete has become a regular part of the pad refurbishment process after Space Shuttle launches. Elimination of FOD was largely unsuccessful using mechanical systems; the refractory concrete is held to the substrate of the steel deflector by grid steel and steel studs. The Mach 2, $4000^{\circ} \mathrm{F}$ SRM plume filled with aluminum oxide particles causes erosion of the refractory concrete and exposes the steel studs to the severe environment published in NASA Technical Standard GP-1059. ${ }^{1}$ Micro-structural analysis on the steel studs discovered no signs of melting. ${ }^{2}$ A discrepancy exists because, when a simulation of steel is run using GP-1059's ground support equipment (GSE) predicted heat rates, the steel should melt. This anecdotal evidence suggests that the SRB plume's effect on the MFD is not well understood, even though GP-1059 is the overarching technical specification produced by NASA to which engineers refer for obtaining environmental loads on the GSE incurred from Shuttle launches. The environmental loads had never been directly measured. This inconsistency initiated the installation of sensors to measure heat rates, pressures, temperatures, and vibration on the MFD. In addition, steel witness rods were installed in close proximity to the sensors to gather qualitative evidence of the environment.

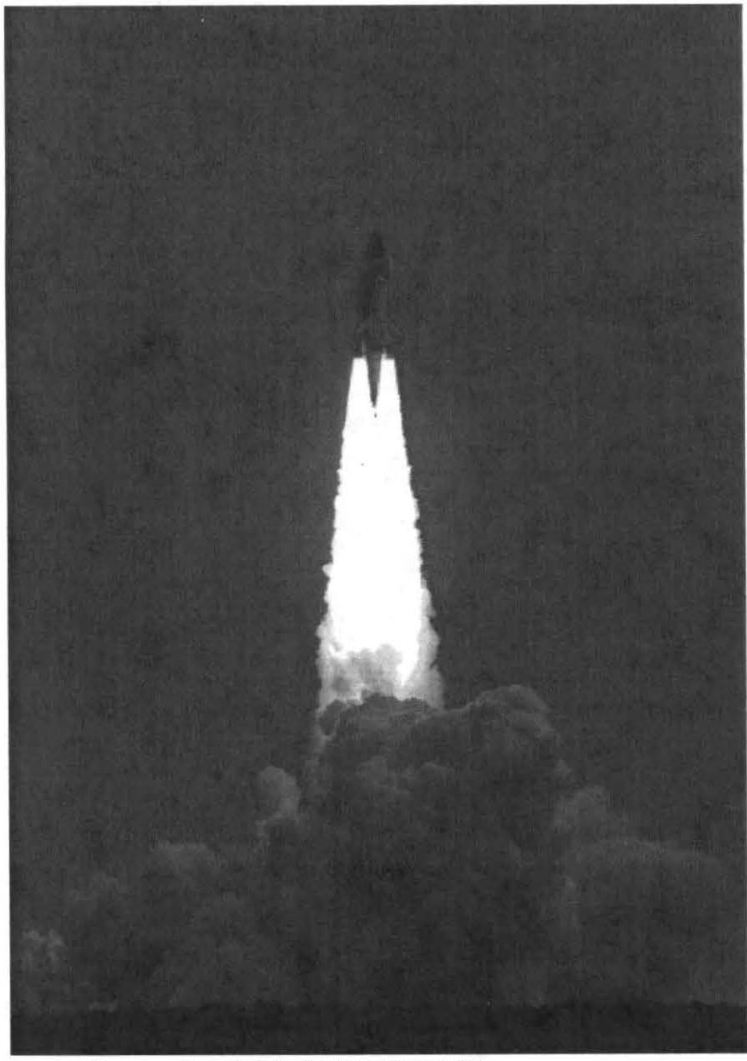

Figure 1: a) STS-135 SRB Plume

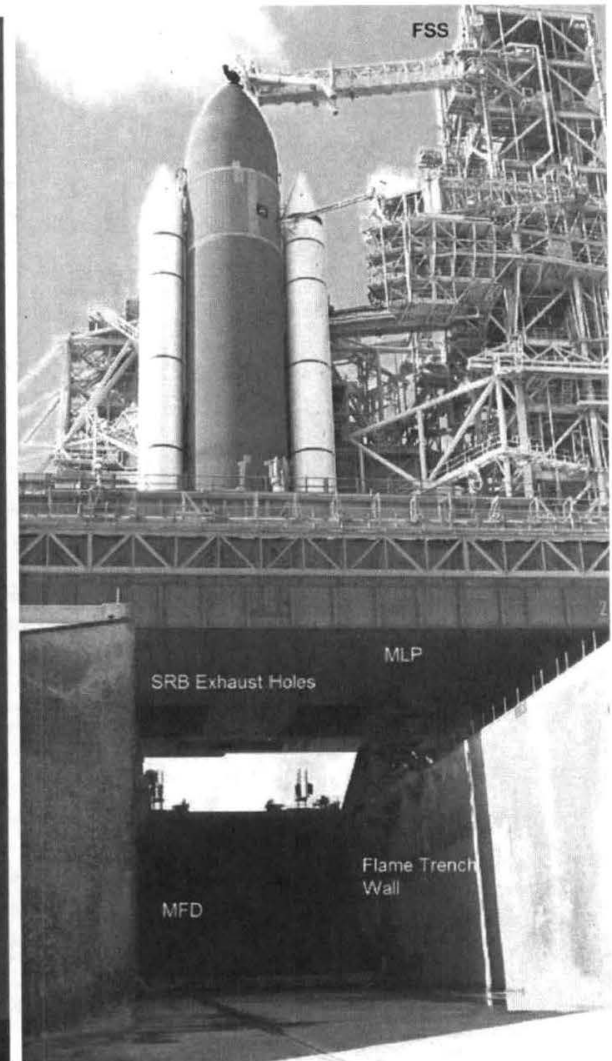

b) Shuttle and Pad A GSE Structures including the MFD (looking south) 


\section{MFD Instrumentation Site Selection}

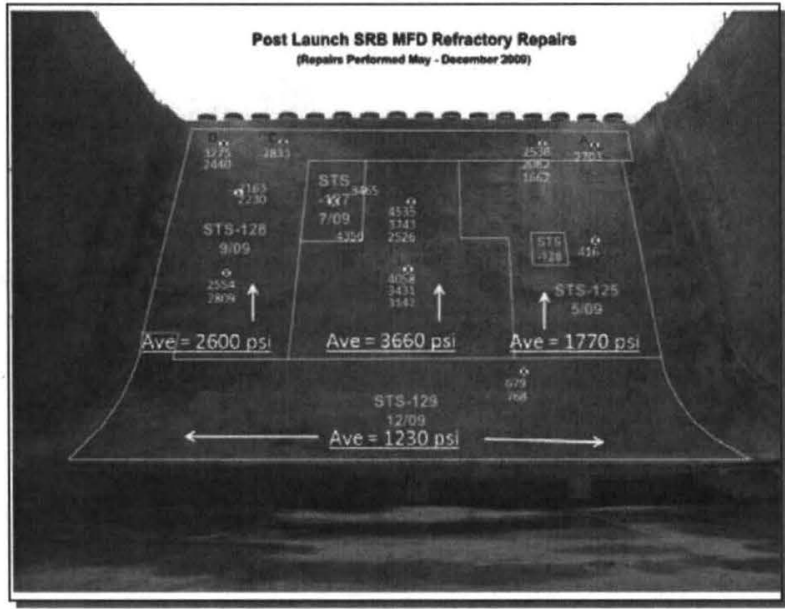

Figure 2: Cored compressive strengths of refractory concrete on Pad A Main Flame Deflector
The refractory concrete along the entire bottom and west (right) side of the deflector displayed very low compressive strengths as seen in Figure 2. When cored specimens were tested from the west side after STS-125 in May 2009, one sample demonstrated a compressive strength as low as 416 psi with an average of 1770 psi. (The specification ${ }^{3}$ for refractory concrete stipulates a compressive strength of 4500 psi at 7 days). Tensile stresses within the refractory concrete are complex and are induced from flexure and vibration of the MFD during launch. Because the tensile strength of the refractory concrete was determined to be less than $10 \%$ of the compressive strength, ${ }^{4}$ it can be seen that low strengths in this material will result in cracking and liberation during the launch event. Because the slope at the bottom of the MFD physically turns the plume from vertical to horizontal, it experiences some of the worst erosion. The west and bottom areas of concrete were replaced before STS-133 in January 2011 because of their low strength and high FOD risk. The MFD before this refurbishment is illustrated in Figure 29.

KSC NASA and USA employees worked with the refractory concrete vendor to develop a concrete installation technique using casting to replace the historic gunning technique in order to improve MFD strength. The water-tocement $(\mathrm{w} / \mathrm{c})$ ratio in refractory concrete greatly influences its compressive strength, and the casting technique better controls the w/c ratio. Furthermore, measurements returned from instrumentation installed flush with the MFD face, within the boundary layer, are dependent on the smoothness of the surface. The formwork left a smooth faceted surface with 0 to $1 / 2$-inch-high horizontal ridges as a result of using 2 -inch-thick by 12 -inch-wide form boards. The KSC engineering community decided the cast surface was acceptable for obtaining these measurements.

Three areas along the west side of the MFD were selected for sensor installation during the concrete refurbishment process based on GP-1059 data. One "sensor suite" installed in each of the three sites is further described in Section III as made up of one Tungsten Piston Calorimeter (TPC), one Commercial-Off-the-Shelf (COTS) set, and one witness rod. Figure 3 presents the plan view of the heat rate contours for the SRB exhaust impingement on the MFD at one second after SRM ignition (defined as mission elapsed time (MET) of $+1 \mathrm{~s}$ ). Directly beneath the SRBs, the very dense contours indicate that a distance of less than ten feet separates the heat rates of 5000 and 1000 $\mathrm{Btu} / \mathrm{ft}^{2}$-sec. In order to capture the governing heat rate, one sensor suite was installed as close as possible to the "K" central contour. The uppermost sensors were actually installed near the " $\mathrm{H}$ " contour, based on access from the back side of the MFD and spacing of the steel structural stiffeners. Two additional sensor suites were installed downhill from the upper set as illustrated in Figure 4. Additionally, a pressure transducer was installed on the centerline of the MFD near the top because this location does not see direct plume impingement and measures acoustic pressure. The upper right corner of Figure 4 shows the MFD sleeve penetrations into which the sensors were inserted. These sleeves are approximately three feet apart. Figure 5 shows the final installation prior to STS-134.

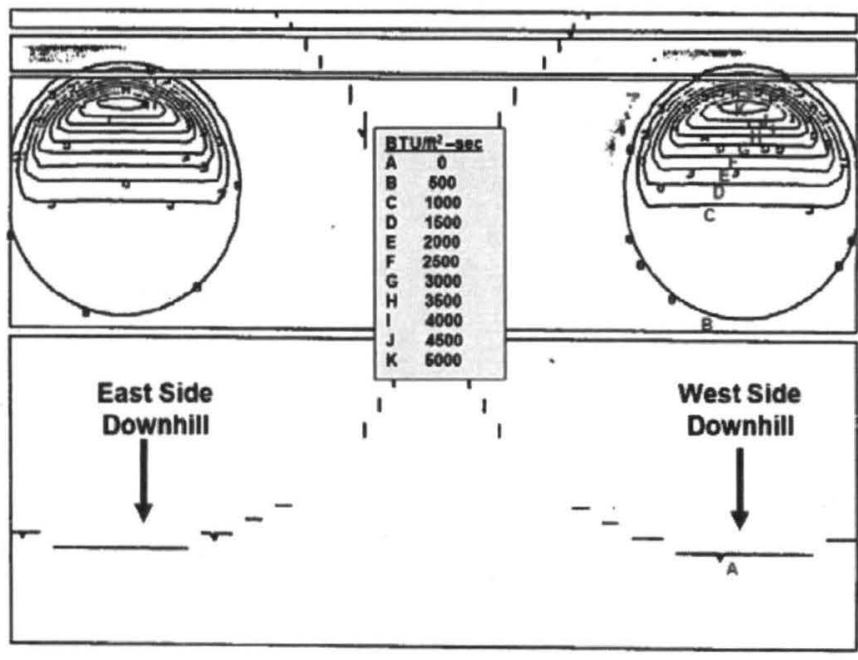

Figure 3: GP-1059 Heat Rate contours from SRB plume impingement at one second after ignition (looking down at the MFD from above)

3

American Institute of Aeronautics and Astronautics 


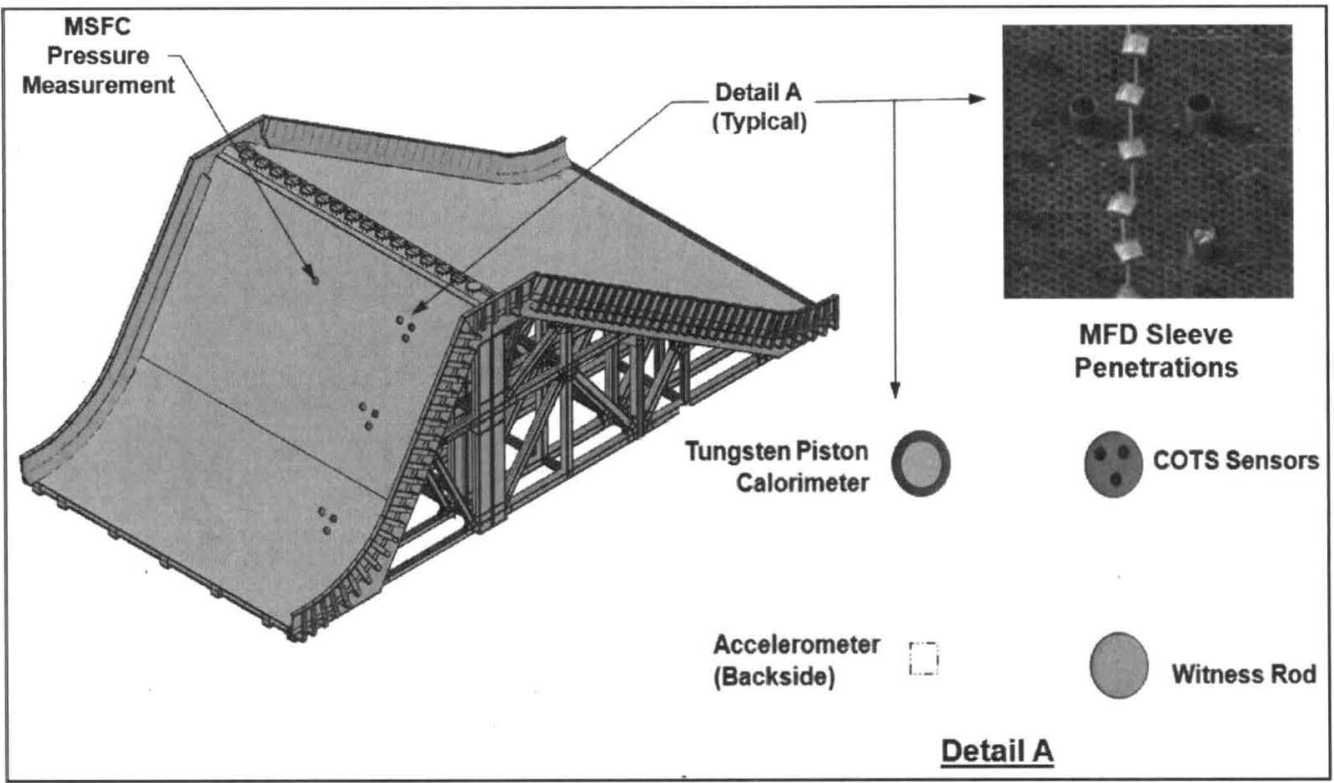

Figure 4: Overall layout of sensors installed on the SRB side of MFD

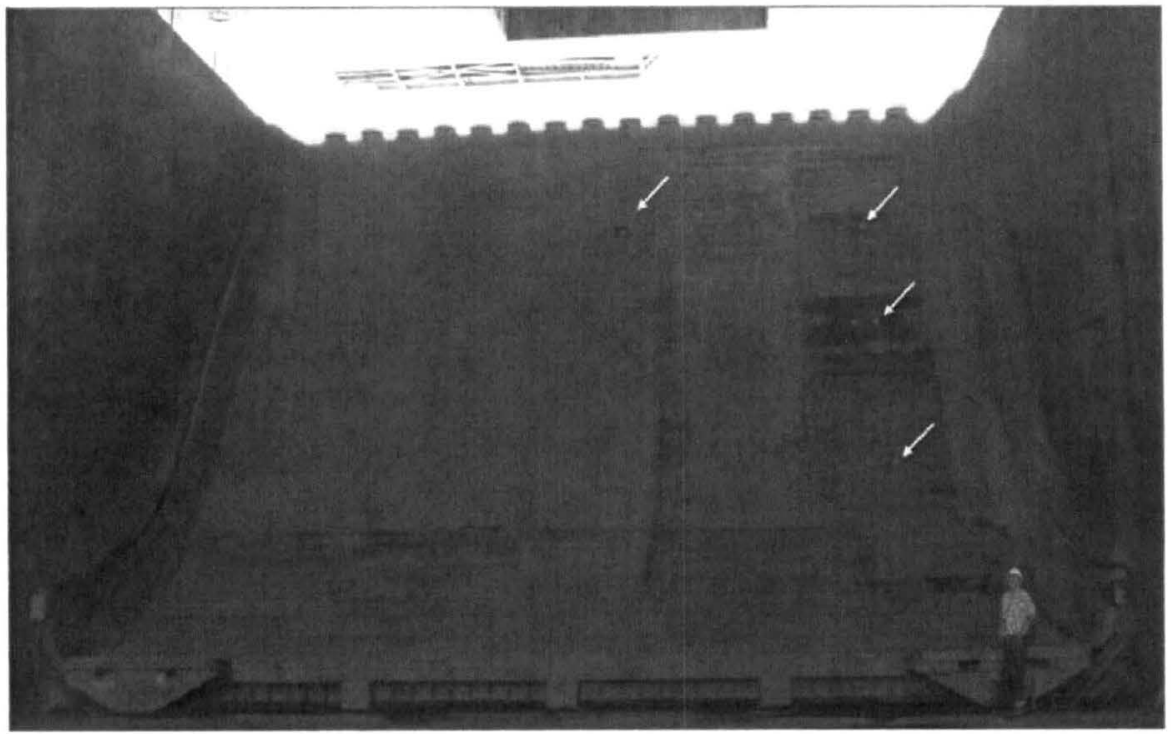

Figure 5. Final sensor installation prior to STS-134. The refractory concrete cast before STS-133 is a different color than the concrete applied by the traditional gunning method

\section{Installed Instrumentation}

\section{A. Commercial-Off-the-Shelf (COTS) Sensors}

NASA has had a long successful history of using COTS sensors in launch environments. The intent of including the COTS products in the design is to provide comparative data to the tungsten piston, thus increasing the confidence in the data. Based on this experience, four types of sensors were procured to measure the plume's extreme environment. The following COTS sensors were used in the testing:

- Medtherm ${ }^{\circledast}$ Calorimeter (upper measurement limit: $4000 \mathrm{BTU} / \mathrm{ft}^{2}$-sec)

- Nanmac ${ }^{\circledR}$ Erodible thermocouple $\left(-191\right.$ to $\left.1414^{\circ} \mathrm{C}\right)$

- $\mathrm{Kulite}^{\circledR}$ or Stellar ${ }^{\circledR}$ pressure transducers (upper measurement limit: 300 and 200 psi respectively)

- $\mathrm{PCB}^{\circledR}$ accelerometers $( \pm 500 \mathrm{~g})$

$$
4
$$

American Institute of Aeronautics and Astronautics 
The Medtherms, Nanmacs, and Kulites or Stellars are installed in a three-inch diameter 304 stainless cap screwed into a stainless housing. Figure 6 depicts the COTS assembly ready for installation. The PCB accelerometers were adhered to the back side of the MFD to measure vibration, and the data acquired from those transducers are not presented in this paper.

The Medtherm calorimeter, shown in Figure 7 prior to installation in the COTS cap housing, includes tubes for water, an independent Type $\mathrm{K}$ thermocouple to measure its body temperature, and electrical leads for the heat rate measurement. All of these connections exit the backside of the housing and are connected to the Ground Measurement System-2 data acquisition system (DAQ) for Pad A. Because the Medtherm body must remain below $400^{\circ} \mathrm{F}$ to accurately measure the heat rate, it was connected to a water cooling system.
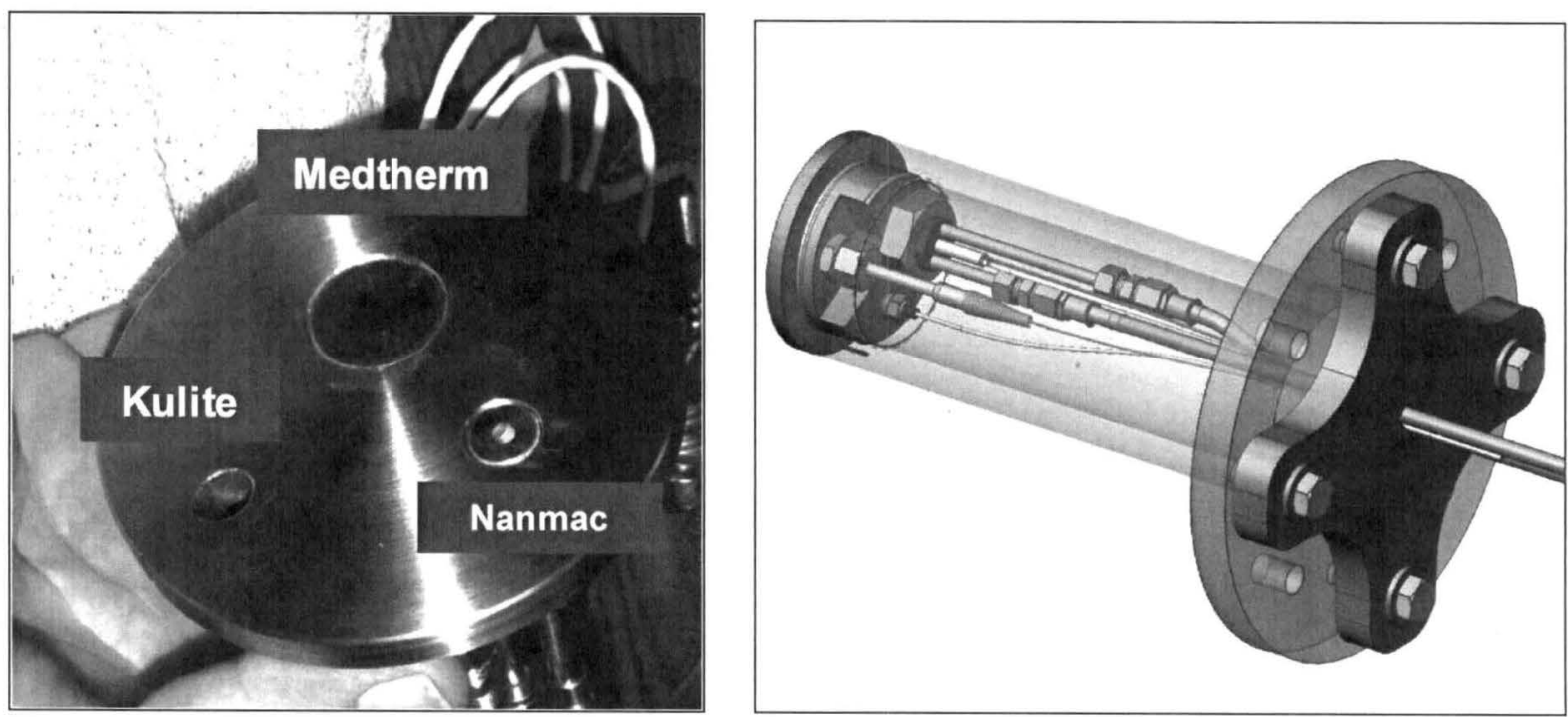

Figure 6. COTS cap with sensors installed

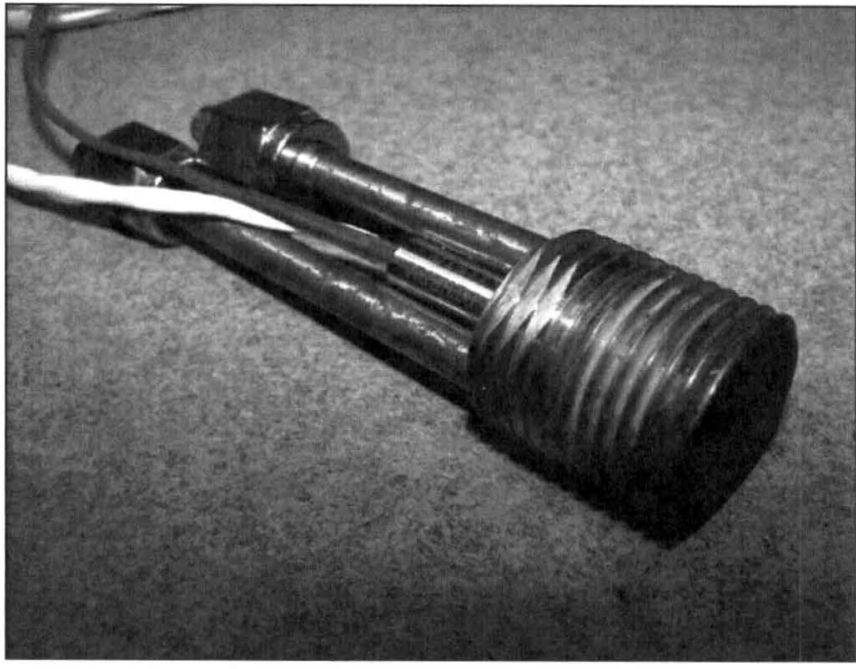

Figure 7. Medtherm Calorimeter
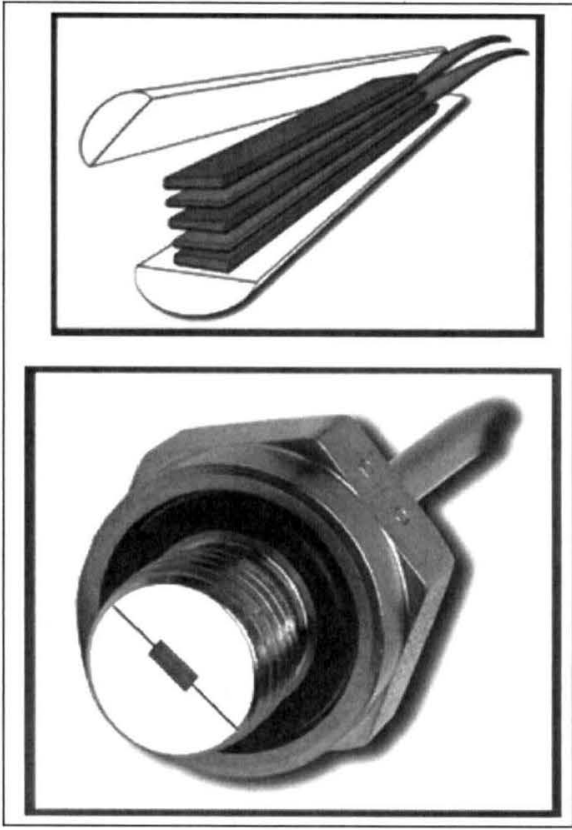

Figure 8. Dissimilar Metallic Layers in the Nanmac Thermocouple

American Institute of Aeronautics and Astronautics 
The Nanmac is an erodible thermocouple. It is comprised of layers of thermocouple metals that make electrical contact as erosion occurs. Small "whiskers" or slivers of metal make contact between the insulated layers of conductors. For STS-133, a Type C Nanmac was installed. Because temperatures were not as high as anticipated the last two launches employed Type K Nanmacs for greater sensitivity to voltage output and higher fidelity measurements. Figure 8 illustrates the layers of metals that erode and create a conduction path for voltage generation.

Kulite pressure transducers were installed for STS-133 and STS-134 with a switch to Stellars in the last flight, which can be compared in Figure 9. Kulites were chosen for their ability to measure both dynamic and static pressures in the acoustic environment of the MFD. Their frequency response of greater than $160 \mathrm{kHz}$ in the expected pressure range allows capture of fast-changing pressure data, such as ignition overpressure. The Kulites accomplish this with a miniature Wheatstone bridge molecularly bonded to, but electrically isolated from, the miniature silicon diaphragm (integrated circuit technology). The silicon diaphragm is thought to be advantageous for resisting the high temperatures of the MFD environment. Review of the data after STS-133 and STS-134 shows false pressure increases after the main plume impingement. This data error is theorized to be caused by thermal drift: the diaphragm of the Kulite heats up and expands, causing a change in resistance of the Wheatstone bridge that is interpreted by the DAQ as false pressure. In hopes of eliminating the data drift, the last flight was instrumented with Stellar pressure transducers. The Stellars have a conventional stain gauge membrane that makes them heavier, more robust, and less sensitive than the Kulites. The added mass allows for more thermal energy absorption before thermal drift occurs. The tradeoff is that the frequency response for the Stellars is $1.5 \mathrm{kHz}$ in the expected pressure range, which is a factor of 100 less responsive than the Kulites. The high natural frequency of the sensors, compared to the relatively low frequencies of the plume and structure, suggests that modal coupling between the transducers and their environment is not

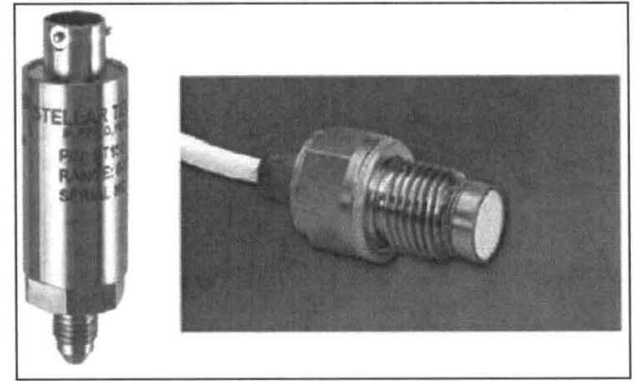

Figure 9. Stellar (left) and Kulite (right) pressure transducers (not to scale) possible.

\section{B. Tungsten Piston Calorimeter (TPC)}

The launch environment is thermally severe and comprised of molten aluminum oxide $\left(\mathrm{AL}_{2} \mathrm{O}_{3}\right)$ being deposited on (or eroding) any structure in the flow field. COTS sensors are not designed for this extreme environment, possibly causing them to erode or melt in the instant after SRB ignition. A robust sensor, the Tungsten Piston Calorimeter, was developed to withstand the plume conditions and supplement the COTS data. Tungsten is used for its hardness and thermal properties. Of all the refractory metals it is the hardest (to resist erosion) and has the highest melting point (to resist the plume's heat). Its thermal diffusivity is similar to aluminum making it an excellent thermal conductor. The TPC has three spring loaded thermocouples touching the bottom of thermal wells in the piston. This thermocouple installation is based on an experimental DLR German Aerospace Center rocket combustion chamber design. ${ }^{5}$ The measured temperatures are used to back-calculate heat rates. The piston is connected via a rod to a load cell to measure the force of the plume on the piston.

Heat rates can be back-calculated by applying fundamental thermal equations to temperatures measured with respect to time and depth in the tungsten piston. Values obtained using this methodology can be directly compared to the Medtherm and are discussed in Section V. Similarly, pressures can be back-calculated by using the area of the piston surface and the load measured by a Strainsert load cell. Values obtained by this calculation can be directly compared to the Kulite or Stellar pressure data. A high degree of confidence is given to measurements that correlate when acquired by more than one method.

The tungsten piston is a cylinder 3 inches in diameter by 3.5 inches long. Because of material availability and production costs, pistons were manufactured from both $99.99 \%$ pure tungsten and an

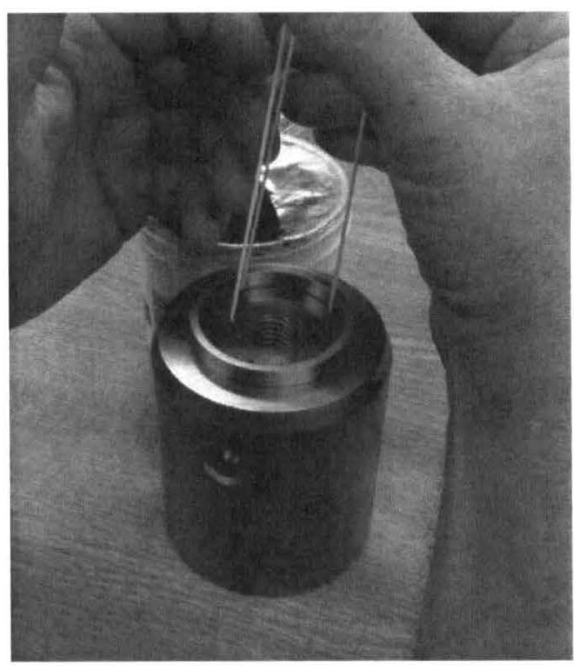

Figure 10. Insertion of thermocouples into a full size prototype steel piston

6

American Institute of Aeronautics and Astronautics

http://mc.manuscriptcentral.com/aiaa-mfd12 
alloy made of $90 \%$ tungsten, $6 \%$ nickel, and $4 \%$ copper. Three thermal wells $120^{\circ}$ apart were Electrical Discharged Machined (EDM) in each piston from the bottom face (the cold side) to near the top (the hot face, exposed to the flame), leaving approximately $0.030,0.060$, and 0.090 inches of metal protecting the thermocouple tip from the plume environment. Type K 0.005 -inch diameter thermocouples enclosed in two-hole ceramic tubes are shown in Figure 10 being installed into the backside of a prototype steel piston. The depths of $0.030,0.060$, and 0.090 inches were chosen to ensure some thermocouples would survive if the plume significantly eroded the top of the TPC. After reviewing the data, tungsten is able to resist SRB plume erosion, and thermal wells closer to the surface can be used in future applications.

Development testing, discussed in Section IV, shows that the tiny air gap between the Type $\mathrm{K}$ metal thermocouple and the metal bottom of the thermal well causes significant resistance to conduction. The solution is to fill the air gap with a material to bond to both metals, enhance conduction, and remain in place during the launch event. Figure 11 illustrates the difference in response of the thermocouples when the air gap is filled with a conductive metal. A heat rate of $500 \mathrm{Btu} / \mathrm{ft}^{2}-\mathrm{sec}$ was applied to three differently installed thermocouples: bare-ended (with air-gap), another with Field's Metal, and one with Sil-Fos ${ }^{\circledR}$ brazing. The Field's metal recorded the highest temperature while the brazed thermocouple recorded the quickest rise in temperature, which is important in a shortduration event. Both offered superior performance over the thermocouple with the air gap. The Field's metal melting point at $144^{\circ} \mathrm{F}$ makes it easy to handle and install but this material is repulsed by the tungsten and the Type $\mathrm{K}$ thermocouple. Field's metal would melt and vibrate free in the launch conditions leaving only an air-gap thermal path. The Sil-Fos ${ }^{\circledR}$ easily wets both the thermocouple and piston and was selected as the material to form a permanent conductive pathway for the heat even when melted. The latent heat of fusion of the melting Sil-Fos ${ }^{\circledR}$ is never observed in the launch temperature measurements because it is such a small amount.

To braze the thermocouples, half of the weld bead of the thermocouple is removed with a grinding wheel under a microscope and replaced with Sil-Fos ${ }^{\circledR}$ brazing. The remade thermocouple is then inserted into the well with a small amount of black flux and a focused acetylene flame is applied to the hot face of the piston to melt the braze. The temperature of the thermocouple is monitored to know when the Sil-Fos ${ }^{\circledR}$ braze reaches its liquidus of $1200^{\circ} \mathrm{F}$, causing the thermocouple and tungsten to bond to the braze and displace the air. A small spring is epoxied to the ceramic protective sheath to force contact between the metals while the piston is thermally expanding, but only a small amount of load can be applied without breaking the ceramic.

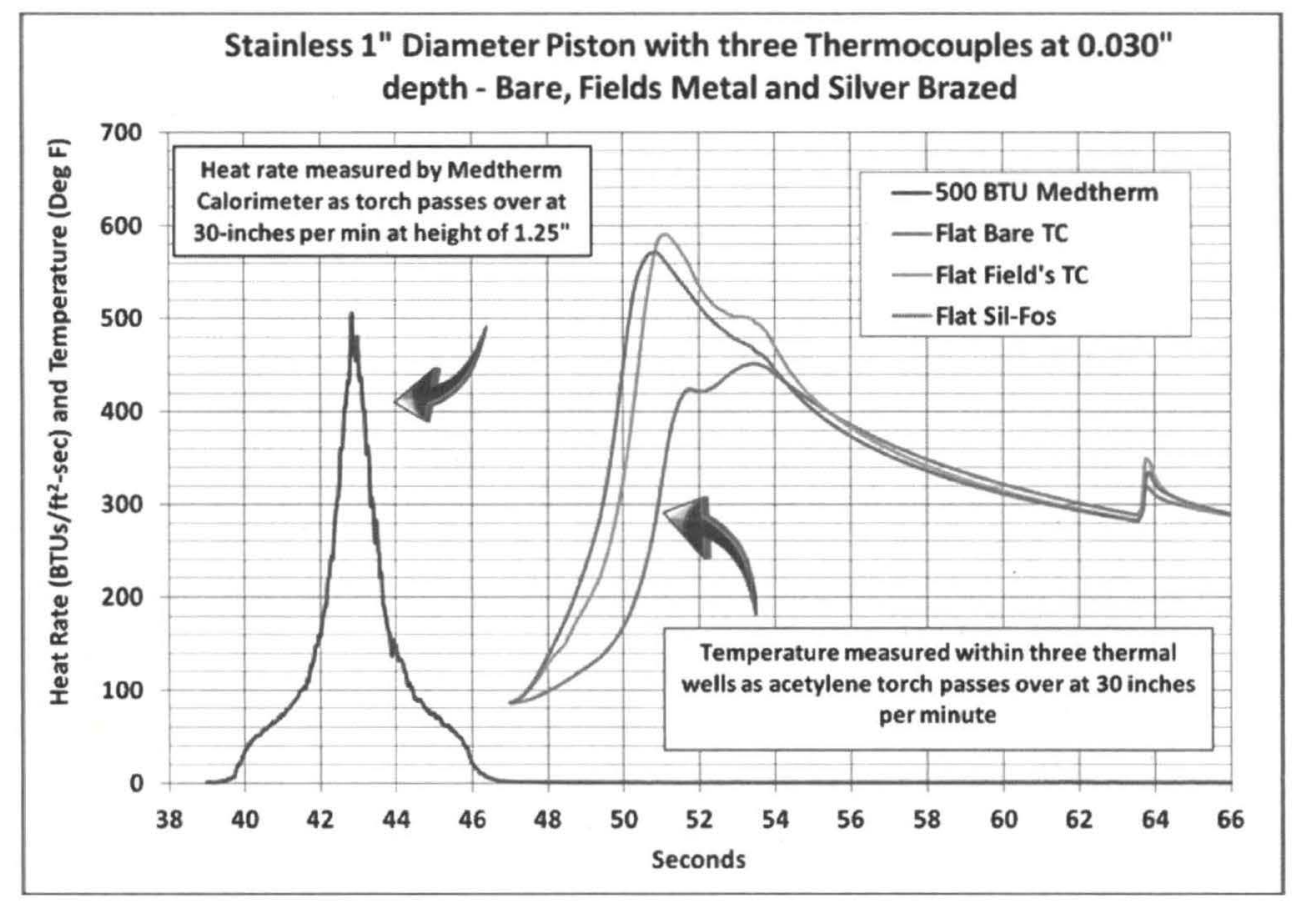

Figure 11. The response of the thermocouples to gap-filler materials 

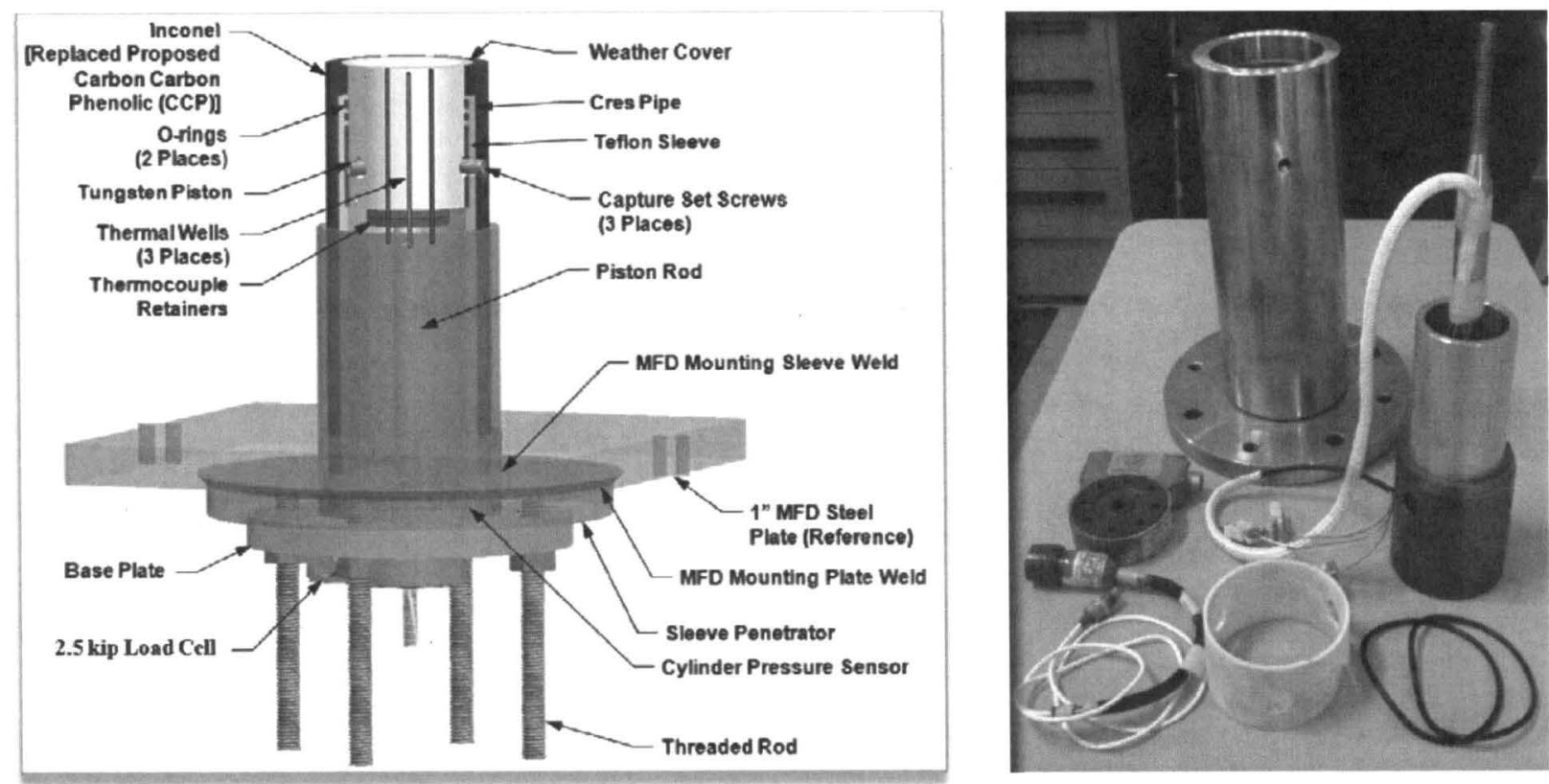

Figure 12. The Design and Parts for the Tungsten Piston Calorimeter

Figure 12 illustrates the details of the Tungsten Piston Calorimeter. The tungsten piston is slid into a 304 stainless housing that contains double O-ring grooves to prevent plume blow-by and a Teflon ${ }^{\circledR}$ bearing for the piston to ride on during plume lateral loading. This inner sleeve is installed in a sacrificial outer housing machined from either A-286 or 17-4PH steel. To prevent direct thermal impingement of the plume on the upper O-ring, three layers of 0.060 -inch thick high-temperature ceramic thread is packed into the gap between the piston and sleeve above the O-rings. A rod connects the piston to a 2.5 kip Strainsert load cell to measure the total plume load. A Kulite pressure transducer is installed in the cavity beneath the piston in the event the O-rings leak and hot gas partially pressurizes the cavity. If this occurs, a correction factor can be obtained to correct the plume pressure calculation for the difference between pressure on the top and bottom faces of the piston. The backside pressure (beneath the MFD) remained close to ambient during the event so no correction factor is needed. The electrical leads for the thermocouples, pressure transducer, and load cell leave the bottom of the sensor and are connected to the Ground Measurement System-2 DAQ.

\section{Witness Rods}

Four-inch diameter witness rods were installed in close proximity to the COTS and TPC sensors for each launch to qualitatively study the effect of the SRB plume on different steel types. 1018 steel was used for STS-134 because it is the material of choice for the exit cones of the SRB separation motors. HY-80 steel rods were installed for STS-133 and STS-135. HY-80 is used because of its high yield and tensile strength, good ductility, atmospheric corrosion resistance, and excellent weldability with reduced preheat. These qualities are desirable for an unprotected steel flame deflector if one were to be proposed for use in the future. The witness rods for STS-135 are shown ready for installation in Figure 13.

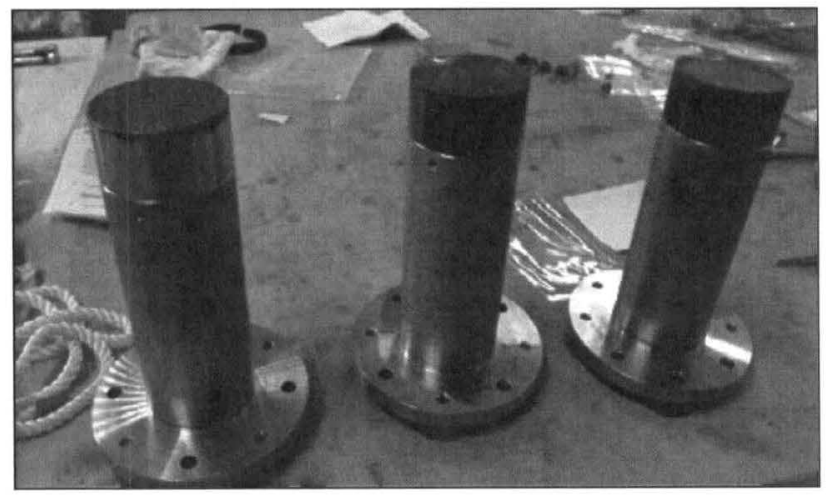

Figure 13. HY-80 witness rods ready for installation 


\section{TPC Validation Tests}

During the development of the TPC, thermal, pressure, and vibration tests were performed to verify the load cell and thermocouples would correctly measure the environment.

\section{A. Thermal Tests}

The thermal tests validated both TPC fabrication methods and the numerical method used to calculate the heat rates from the thermocouple data. One-inch aluminum, stainless steel, and tungsten test articles were used. Over 50 tests were performed using an Oxyacetylene CNC torch as shown in Figure 14a. Two (a $2000 \mathrm{Btu} / \mathrm{ft}^{2}-\mathrm{sec}$ and a 500 $\mathrm{Btu} / \mathrm{ft}^{2}-\mathrm{sec}$ ) Medtherm calorimeters were used to verify heat rates generated by the torch and to verify that the values each Medtherm measured were comparable. Sine wave and square wave heat profiles were applied to the prototype pistons and compared to the response of the Medtherms. The tests proved the importance of springs to hold the thermocouples tightly against the bottom of the thermal well. Filling the air gap between the thermocouple and tungsten thermal well to produce a conductive pathway greatly improved the repeatability of the back calculated heat rates. Finding the correct gap-filler material to 'wet' the thermocouple and tungsten piston, as well as the correct procedure to braze the thermocouples to the bottom of the thermal well, took hours of testing.

The TPC consistently calculated heat rates $20 \%$ less than those values measured by the Medtherms in the oxyacetylene tests. An ANSYS ${ }^{\circledR}$ Fluent model of the plume shown in Figure 14b indicates that it is highly 3dimensional. It was speculated that the small diameter measuring area on the Medtherm calorimeter (approximately 0.050 -inch diameter) was successful at measuring the pinpoint where the maximum heat rate occurs. It was also speculated that the large diameter TPC cannot perform as well with such a 3-dimensional small diameter flame. However, when placed beneath a larger heat source (e.g. the 12-foot diameter SRB plume) it would function as expected. The measured SRB heat rates discussed in Section V supports this assumption.
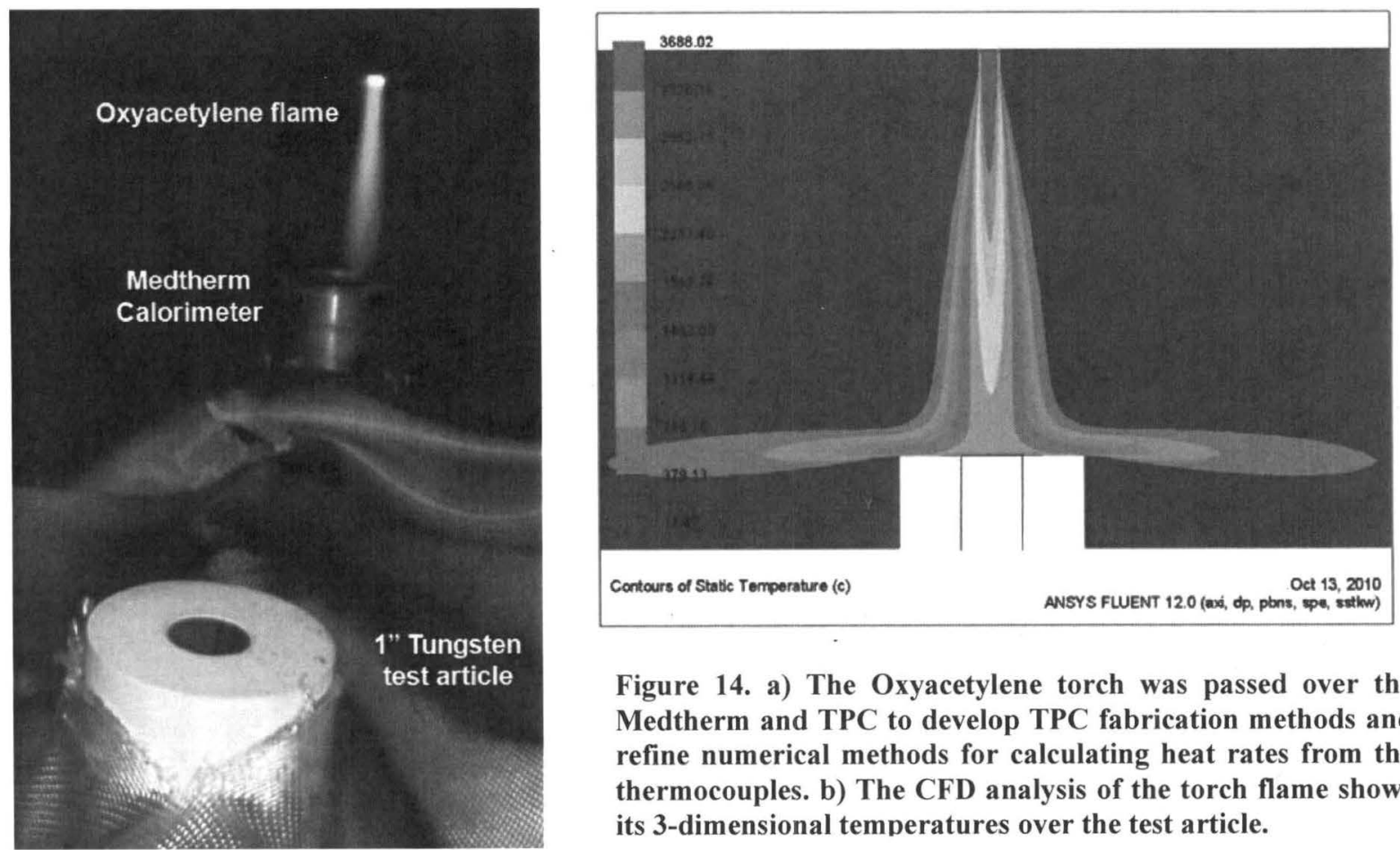

Figure 14. a) The Oxyacetylene torch was passed over the Medtherm and TPC to develop TPC fabrication methods and refine numerical methods for calculating heat rates from the thermocouples. b) The CFD analysis of the torch flame shows its 3-dimensional temperatures over the test article. 


\section{B. Pressure Tests}

Pressure tests were divided into static leak checks and dynamic pressure spikes to compare the 2.5 kip Strainsert load cell to the 0-300 psia Kulite pressure transducer. The tests were performed by pressurizing a cavity above the piston as shown in Figure 15. Leak check pressures (i.e. static pressures) were applied slowly and showed that the piston's O-rings held the internal pressure for the 10-minute duration of the test. The load cell output was converted to pressure and was within two percent of the Kulite reading. To verify the load cell would track a pressure spike similar to the SRB ignition overpressure, a dynamic pressure spike was generated by manually opening a valve in approximately 0.05 seconds. Figure 16 shows the response of the Strainsert load cell as compared to the Kulite pressure transducer. The piston/load cell tracked the pressure pulse within 5 psi on an amplitude pulse of 250 psi. This pressure oscillated within the closed cavity creating a resonate frequency of between 10 and $25 \mathrm{~Hz}$ (depending upon the rapidness of valve actuation). These tests validated the similarity in response of the two pressure measurement methodologies.
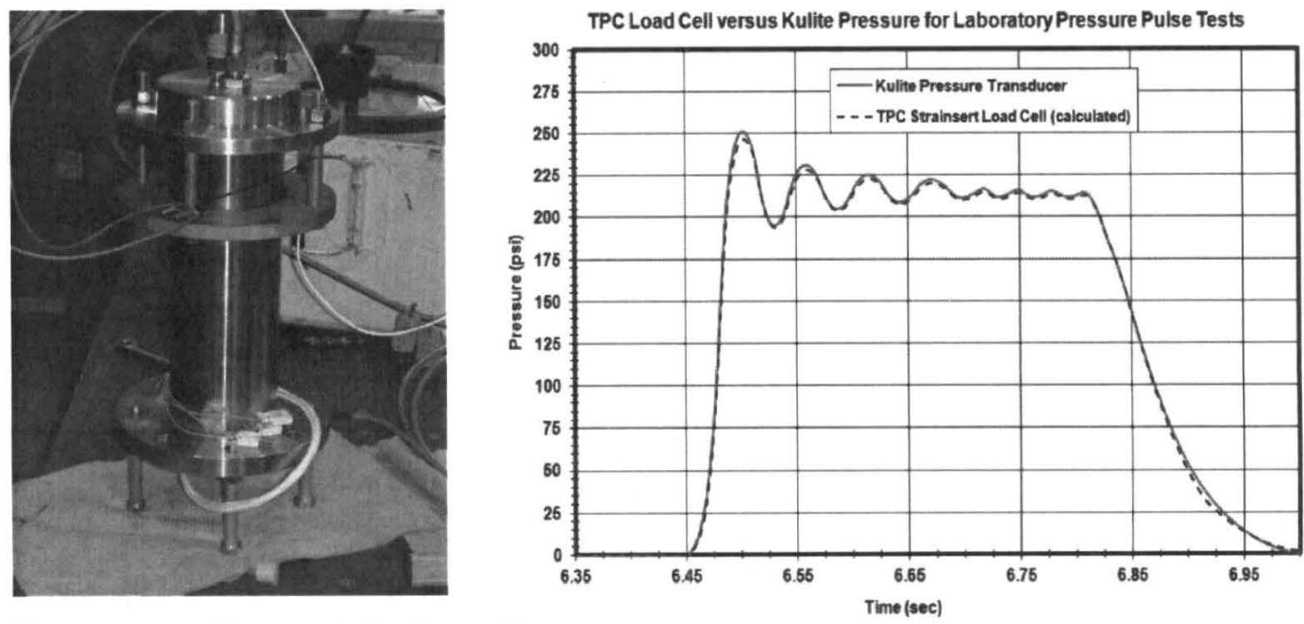

Figure 15. Pressure cavity created above the piston used for static leak check and dynamic

Figure 16. Pressure test on piston/load cell system response testing

\section{Frequency Response Modeling and Vibration Testing}

The structural load into the piston/load cell is a result of two input sources. The first is the transient input from the SRB plume directly while a secondary load can occur from the dynamic response of the MFD, onto which the TPC is hard-mounted, due to its response to the plume. A dynamic analysis was conducted using a FEM of the TPC mounted to the MFD. This analysis investigated the effects of the base excitation of the MFD on the TPC's ability to accurately measure the pressure of the direct SRB plume. The FEM is shown in Figure 17. The force inputs (Power Spectral Densities or PSDs) were derived from the measured pressure and vibration environments, and these derivations are consistent with GSFC-STD-7000. ${ }^{6}$ The PSDs were calculated from both measured pressures on the bottom of the Mobile Launch Platform (MLP) and measured accelerations on the backside of the MFD steel panels directly beneath the location of SRB plume impingement. These graphs are presented in the Appendix as Figure 33. Inspection of the PSDs shows that most of the pressure energy in the plume is below $40 \mathrm{~Hz}$ while all of the peak responses of the MFD PSDs occur below $140 \mathrm{~Hz}$. The FEM found the natural frequency to be approximately $300 \mathrm{~Hz}$.

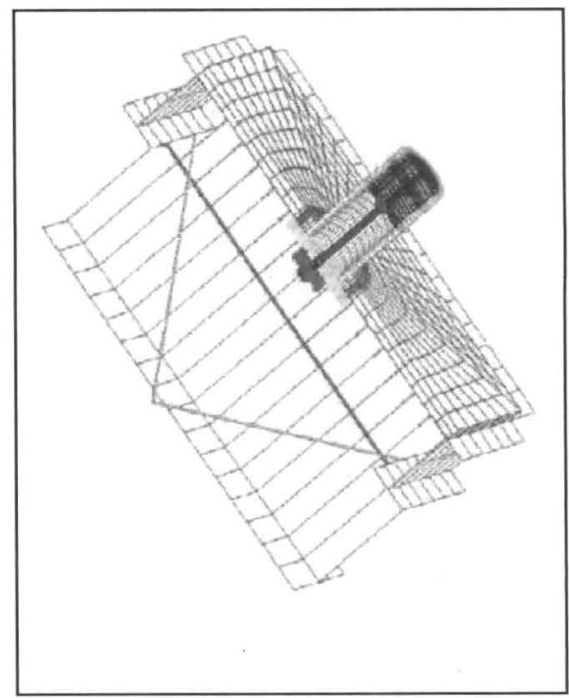

Figure 17. FEM of TPC with MFD structure used for dynamic modeling 
Because it was determined that the effects of base excitation were negligible, the assembly was vibration tested to determine the natural frequency of the piston/load cell system and to ensure the structure would remain intact for three launches. Random and sine sweep vibration tests were performed in accordance with KSC-STD-164B, Environmental Test Methods for Ground Support Equipment. ${ }^{7}$ The input PSDs were modified slightly to accommodate the Unholtz-Dickie Shaker table's capabilities. Figure 18 shows an assembled TPC (with a steel piston) mounted to the Unholtz-Dickie during a vibration test. The sine sweep tests showed that the resonant frequency of the piston/load cell subsystem to be $280 \mathrm{~Hz}$, as Figure 19 shows while testing. Neither the plume's energy content below $40 \mathrm{~Hz}$ nor the MFD's frequency response of $140 \mathrm{~Hz}$ will excite the TPC since it has a measured natural frequency of $280 \mathrm{~Hz}$. It was concluded that the piston should be dominantly loaded by the plume, and the filtered data presented supports this finding.

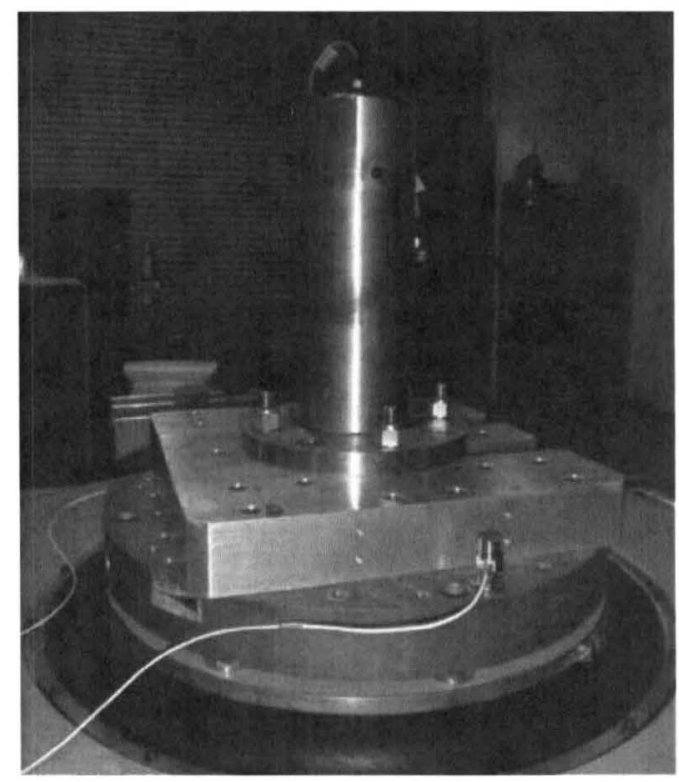

Figure 18. TPC installed on UnholtzDickie Shaker during vibration test

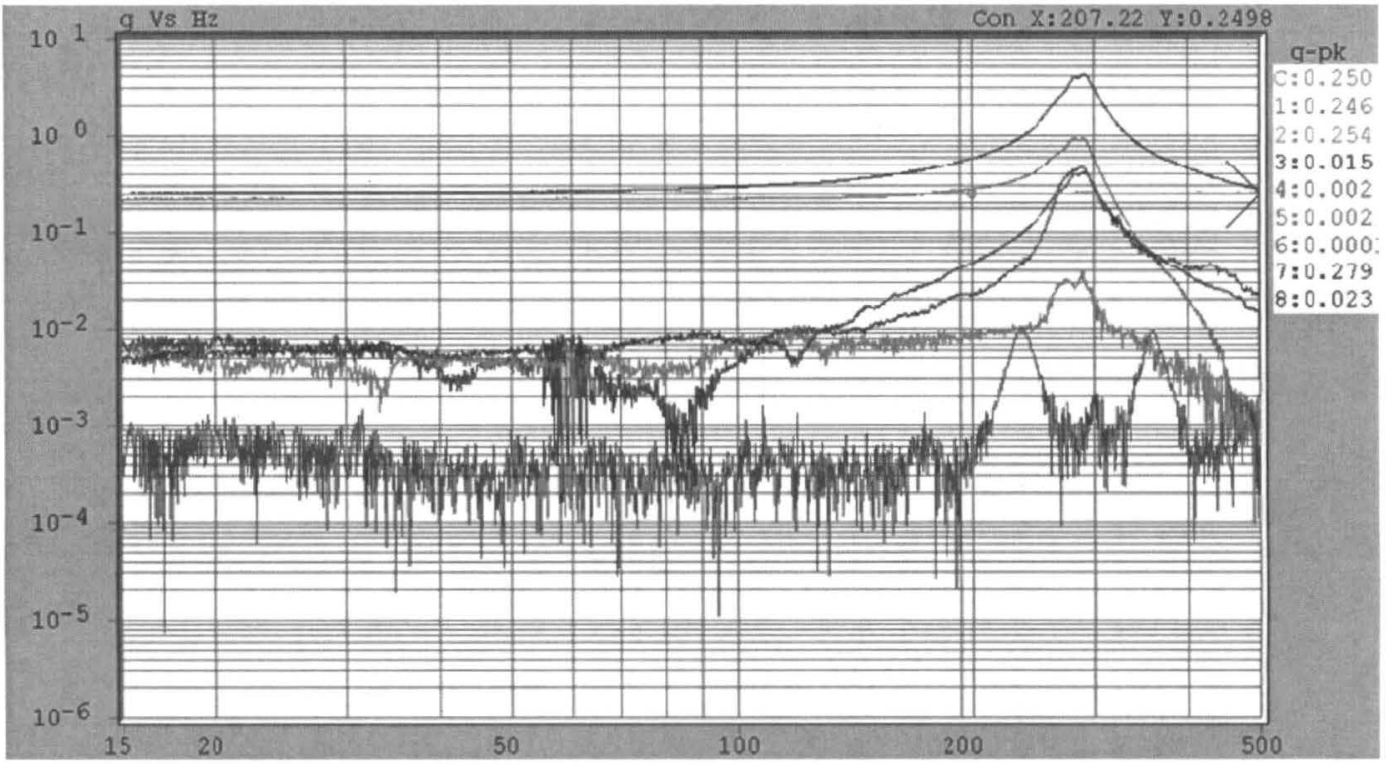

Figure 19. Sine sweep test on TPC showed the resonant frequency of the piston/load cell subassembly to be $280 \mathrm{~Hz}$ 


\section{Results}

\section{A. Plume Pressure}

The pressure measurements from the Kulites and the Stellars returned similar pressure curves for the three launches. The peak values were over twice as high as those reported in GP-1059. Figure 20 compares Strainsert load cell and Stellar pressure transducer data for the three locations on the MFD for the last launch. To arrive at this summary, the raw data from the load cell and the Kulites and Stellars are processed to filter out the high frequency acoustic and vibration signals. Raw data for the pressure transducers and load cell are recorded at $9600 \mathrm{~Hz}$. The raw ASCII data are analyzed using Mathworks ${ }^{\circledast}$ MATLAB software's built-in butter and filter functions that create a Butterworth lowpass filter set at $50 \mathrm{~Hz}$. This limit is used because PSDs from previous launches identified that most of the plume's energy lies below $40 \mathrm{~Hz}$. The filtered data are then averaged over 48 points $(0.005 \mathrm{~s})$ to reduce the number of data points to a manageable quantity without erasing any pressure events. As presented in Figure 20, the data are time-shifted to the right by $0.005 \mathrm{~s}$ because of the averaging algorithm. Finally, the processed Strainsert force data are divided by the area of the exposed piston surface $\left(7.07 \mathrm{in}^{2}\right)$ to calculate pressure.

The pressure graph from STS-135 shown in Figure 20 represents the only complete pressure measurement for an entire launch event. Thermal drift occurred in the pressures recorded by the Kulites installed for STS-133 and STS134 , indicating a loss of measurement accuracy later in the event (after the peak pressure occurred). There is high confidence that the peak pressures were successfully measured for all three launches when these readings are compared to the Strainsert data.

Aside from the $160 \mathrm{psig}$ short-duration ignition overpressure pulse that occurs around MET $+0.3 \mathrm{~s}$, the maximum pressure recorded is over $70 \mathrm{psig}$ on the STS-135 upper location. Upper locations for STS-133 and STS-134 using the Kulites recorded maximum pressures of around 60 psig. GP-1059 cites a maximum pressure of $30 \mathrm{psig}$, a significantly lower value used as the historic design limit. The middle location, just 20 feet downhill from the upper, recorded the plume pressure decreasing by half and matches GP-1059's prediction. The bottom location records still lower pressures as expected. Unexpectedly, between MET $+0.5 \mathrm{~s}$ and $3 \mathrm{~s}$, the bottom location measured negative pressures, indicating that the shape of the MFD surface, coupled with the Mach 2 plume creates a partial vacuum. About three seconds after liftoff, the bottom location pressure increases to about $18 \mathrm{psig}$, indicating that the SRM plume is directly impinging on the lower MFD face as it traverses north during takeoff. These data show that pressures return to ambient around MET +4 seconds, indicating the duration of the main launch event as it applies to the MFD structure.

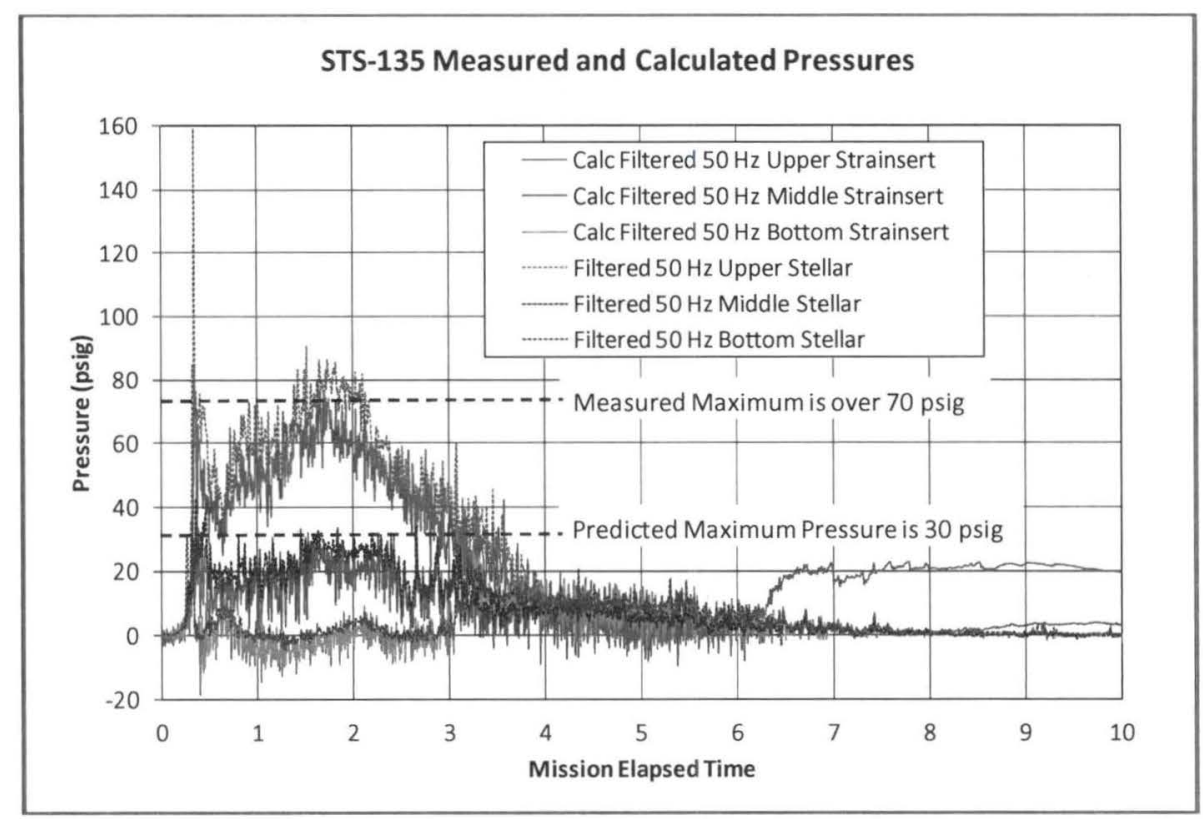

Figure 20. STS-135 Pressures at the Upper, Middle, and Lower Sensor Locations of the Main Flame Deflector

American Institute of Aeronautics and Astronautics 


\section{B. Acoustic Pressure}

Acoustic pressure is primarily a consideration for payloads and ground support equipment. During the launch of STS-1, the reflected ignition overpressure pulse severely loaded Columbia's wings and control surfaces. ${ }^{8}$ One modification after STS-1 was the installation of water bags across the opening of the SRB engine exhaust holes to provide mass dampening for the reflected ignition overpressure pulse. For the last three flights one Kulite pressure transducer was mounted on the MFD centerline, 55 feet from the SRB nozzle exit plane, as shown in Figure 5. A typical observation after each launch is that spray paint applied to the refractory concrete in this region of the MFD remains almost untouched from the plume. Therefore the pressure measured at this location is considered to be almost all acoustic. Figure 21 shows the peak acoustic pressure around 15 psig with a sustained average for two seconds at around 10 psig (notice the units on the $y$-axis are psi absolute). Linear acoustic laws are not valid below a

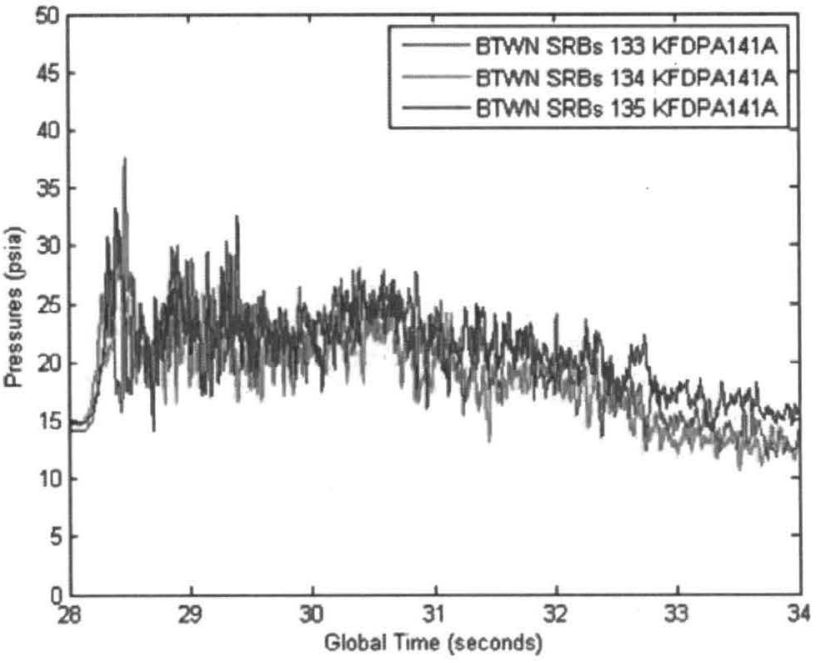
200 foot radius from the centerline of the rocket (assuming spherical spreading). The measured launch data lead to a major finding that in the very near-field acoustic levels increase dramatically rather than saturate or decrease. The data suggest that the near-field acoustic levels are $10 \mathrm{~dB}$ higher than linear acoustic laws predict. ${ }^{9}$ These near-field values are valuable for improving rocket acoustic and vibro-acoustic models used at Kennedy Space Center.

\section{Temperatures}

The Nanmac erodible thermocouples are installed flush with the surface of the COTS assembly cap and are exposed to the direct plume impingement. Directly measuring temperatures using this methodology is difficult considering that the top location didn't record the complete event for any of the three launches, failing after MET $+0 \mathrm{~s}, 1.5 \mathrm{~s}$, and $3.3 \mathrm{~s}$ respectively. The middle location recorded the temperatures for the entire event for all three launches while the lower Nanmac was successful for only STS-134 and STS-135. For much of the temperature rise in the first few seconds of launch, all three Nanmac locations experience similar temperatures. The maximum temperature recorded from any launch, $2160^{\circ} \mathrm{F}$, occurs in the top location at MET $+3.24 \mathrm{~s}$ just before the thermocouple fails during STS-135 as seen in Figure 22. Shortly after this time, the middle and bottom locations show decreasing temperature, and at the top location, the slope of the temperature is not increasing when it fails, indicating temperature is not rising. Therefore the maximum temperature of a complete top location data set is expected to be not much higher than $2160^{\circ} \mathrm{F}$. This suggests that a boundary layer is protecting the Nanmac thermocouple (and MFD surface) when compared to GP1059's predicted SRM plume temperatures of $4000^{\circ} \mathrm{F}$. Factors contributing to the formation of the boundary layer include the sound suppression system water, the supersonic plume speed, and the undulations in the MFD surface.

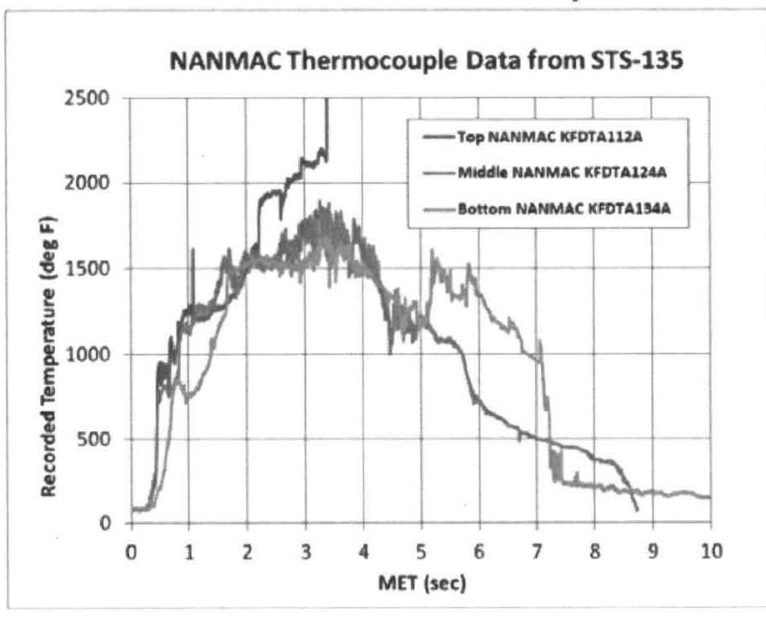

Figure 22. Nanmac temperatures for Top, Middle, and Bottom locations for STS-135 


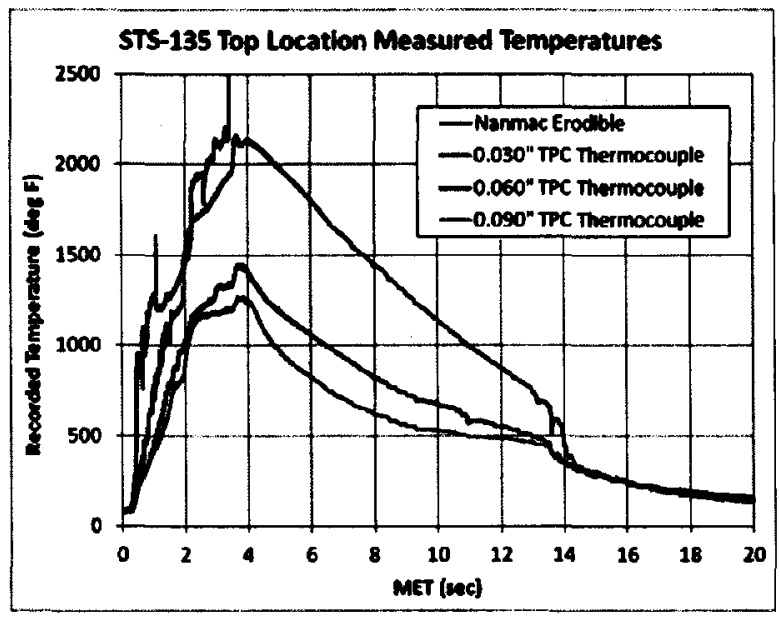

Figure 23. Nanmac and TPC thermocouples for the STS-135 Top location

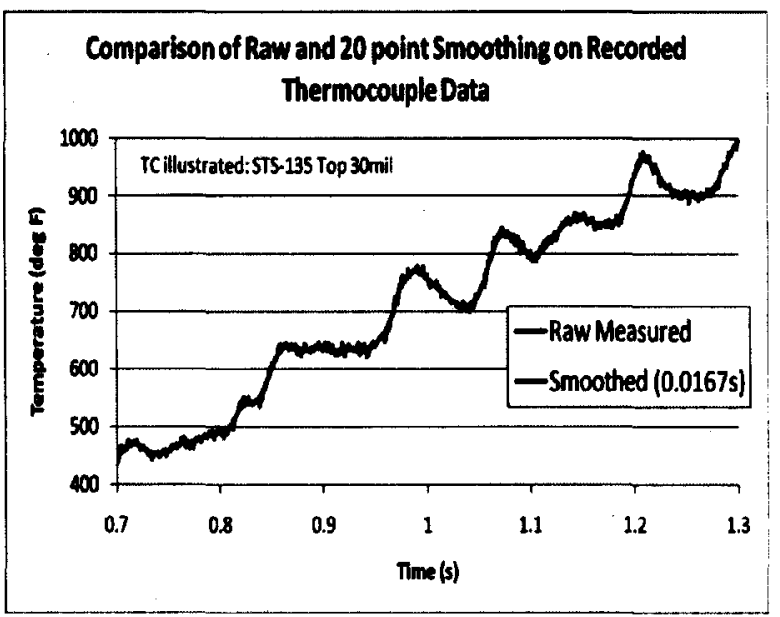

Figure 24. 20-point running average to minimize the signal noise for MATLAB heat rate processing

The temperatures in Figure 22 and Figure 23 are graphed using raw data acquired at $1200 \mathrm{~Hz}$. Before processing the data with MATLAB to calculate heat rates, they have to be smoothed with a 20-point running average, illustrated in Figure 24. Without this simple smoothing to minimize the signal noise, the calculated heat rates are hashy and unusable. The 20 point $(0.0167 \mathrm{sec})$ running average preserves the nuances in the temperature fluctuations and only minimizes the signal noise so heat rates can be accurately calculated.

Figure 23 compares the top Nanmac's temperature to the temperature profile within a tungsten piston. The temperatures are recorded by thermocouples inserted at distances approximately $0.030,0.060$, and 0.090 inches from

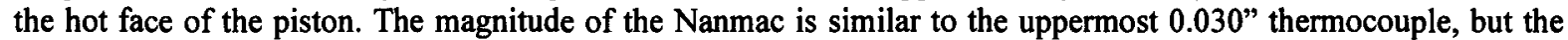
TPC records the temperatures at a delayed time. This illustrates the thermal diffusivity: the time it takes to conduct the plume heat through the solid tungsten to the thermocouples in the thermal wells. The heat rate calculation described in the subsequent section back-calculates a surface temperature from the depth of the thermocouple, accommodating for this apparent time delay. An inspection of the STS-135 calculated piston surface temperatures shows that the 0.030 " thermocouple calculates a surface temperature close to the Nanmac values, but the deeper thermocouples calculate lower surface temperatures than measured. Interestingly, though it is close to the Nanmac in temperature, the STS-135 top TPC 0.030 " thermocouple shown in Figure 23 calculates out-of-family high energy content compared to other top location Medtherm and TPC thermocouples (see Appendix Table A1).

The 0.030" thermocouple in each piston was oriented uphill for STS-134 and STS-135. This thermocouple absorbs the majority of the three dimensional and erosion heating. During launch, the aluminum oxide particles contained in the SRB combustion products scour the surface of the MFD. The particles significantly erode the leading edge of the piston housing sleeve. Piston sleeve erosion values can be found in Table A1 in the Appendix. As the sleeve erodes, it heats due to friction, heating the adjacent piston. Furthermore, as the sleeve erodes it exposes the leading edge of the TPC itself to the plume, shown in Figure 30. This creates a 3-D heating situation and allows the temperature of the tungsten near the 0.030 " thermocouple to increase faster than if it were top-loaded only. A faster temperature increase results in higher calculated heat rates. The temperature should increase faster as the launch event continues and the piston sleeve erodes more. This does occur between MET+2-4s in Figure 23. Seen in Figure 34 in the Appendix, the heat rates resulting from this temperature increase are $30 \%$ higher than calculated by the other two thermocouples, which are less affected by 3-D heating. The temperatures recorded by the uphill thermocouples in all three locations appear to be artificially high.

\section{Heat Rates}

The TPC is a simple instrument with three thermocouples embedded at various depths near the heated surface of a tungsten cylinder. Heat rates are calculated from the measured transient temperatures using a numerical model that assumes one-dimensional heat flow into a 3-inch-long solid block with a known initial temperature. The piston surface temperature is calculated knowing the depth of the thermocouple, and the transient heat rate at the piston surface can be calculated using the thermal diffusion equation in Equation 1. The material properties can be lumped together as the thermal diffusivity $(\alpha)$ in Equation 2 . The material properties used ${ }^{14,13}$ are an average of the 
properties found during a literature survey for tungsten and tungsten alloy. The numerical solution only allows for constant properties although they are found in the literature as a function of temperature.

$$
\begin{aligned}
& \frac{\partial T}{\partial t}=\frac{k}{\rho c_{v}} \frac{\partial^{2} T}{\partial x^{2}} \\
& \alpha=\frac{k}{\rho c_{v}} \\
& \mathrm{k}=\text { thermal conductivity }\left(\frac{B t u}{f t-h r-{ }^{-} F}\right), \rho=\text { density }\left(\frac{i b_{m}}{f t^{2}}\right), c_{v}=\text { specific heat }\left(\frac{B t u}{l b_{m}-^{-} F}\right), \alpha=\text { thermal diffusivity }\left(\frac{f t^{2}}{h r}\right) \\
& \text { For pure tungsten }{ }^{14}, \mathrm{k}=80 .\left(\frac{B t u}{f t-h r-{ }^{-} F}\right), \rho=1203\left(\frac{l b_{m}}{f t^{2}}\right), c_{v}=0.033\left(\frac{B t u}{l b_{m}-^{-F}}\right), \alpha=2.015\left(\frac{f t^{2}}{h r}\right)
\end{aligned}
$$

The initial temperature condition is assumed to be a uniform ambient temperature, the average of the three thermocouples' data recorded before MET+0s. The back surface of the solid block is assumed to be adiabatic: a perfectly insulated surface where heat flow is defined as zero. According to a simulation of the piston using GP1059 heat rates, during the short duration launch event the heat will not penetrate to the back surface of the 3-inch tungsten piston, making it appear to be a semi-infinite thermal problem. In reality, any lost heat from the back surface would be negligible compared to the high heat rates on the hot surface. The measured thermocouple temperatures within the piston are used as the top surface boundary condition.

The desired surface heat flux is calculated from the time and space derivatives in the diffusion equation. The numerical model to solve Eq. 1 is programmed in MATLAB using a Gaussian substitution routine. A backwards substitution using the adiabatic boundary condition produces the piston interior temperatures for the next time step. At each time step, the numerical solution back-calculates the surface temperature that causes the measured temperature reading. The measured thermocouple temperatures are used as the initial guess for the temperature of the surface node as the numerical solution iterates to calculate the surface temperature. The difference between the surface node (to which the measured temperature is applied) and the temperature of the node nearest to the specified thermocouple depth (at $\mathbf{0 . 0 3 0}, \mathbf{0 . 0 6 0}$, or $\mathbf{0 . 0 9 0}$ inches) is added to the surface node temperature for the next iteration. The temperature profile through the piston is recalculated and the iteration process continues about 5-10 times until the temperature difference is minimal.

Further refinement of the algorithm is possible based on the assumptions made to develop the numerical solution, although these are minor corrections considering the many generalizations made in the algorithm. The constant temperature properties can be replaced with textbook temperature-varying properties. Because the thermal properties of tungsten vary among sources, the tungsten or alloy can be thermally tested to measure accurate properties for the particular hardware. The one-dimensional assumption simplifies the inherent three-dimensional nature of the block with thermocouple holes drilled into it. A simulation of a piston with GP-1059 heat rates shows a small temperature variation across the bottom of the thermal well itself, where the thermocouple tip rests. The missing thermal mass causes a slight increase in thermal well temperatures, creating a 3-D effect, which could be modeled with the numerical solution. Precisely locating the thermocouple in the bottom of the well, where the temperature is highest, would ensure a more precise measurement of the environment.

Of the possible heat rate data sets from three TPC thermocouples and one Medtherm in each of three locations, STS-135 returned the most complete set of successful data without significant data dropout. Temperatures cannot be directly compared to determine environment temperature or heat rate. At greater distances from the hot face, the thermocouple will read lower temperatures, as in Figure 23. Heat rate is a description of change in temperature, and the numerical solution adjusts for the depth of the thermocouple in its calculation. Sample heat rate profiles over the duration of the launch event are shown in Figure 25 and Figure 26 to compare the effectiveness of the heat rate measurement types (Medtherm vs. TPC). Qualitatively, the measurements are in-family, lasting about four seconds with heat rate spikes occurring at random intervals throughout the event. The qualitative difference between the sensor types is that the Medtherm is better able to record the quick spikes of heating. It has a smaller thermal mass and quicker response time. The TPC records some of these spikes, indicating they are real phenomena, but it is an instrument better suited to recording the general thermal energy content from the launch. To quantitatively compare the heat rate profiles, the measurements can be integrated to find the area under the curve, which is the energy per unit area that the plume imparts to the sensor. This integrated energy content summarizes the overall thermal effect of the launch on the MFD.

Because it is water-cooled and remains at a constant temperature, the Medtherm records a cold-wall heat rate. As the TPC's surface temperature increases from $80^{\circ} \mathrm{F}$ to $2000^{\circ} \mathrm{F}$, the difference in temperature between the plume and the surface decreases. This decrease in temperature difference decreases the flow of energy into the piston, and

15

American Institute of Aeronautics and Astronautics

http://mc.manuscriptcentral.com/aiaa-mfd12 
consequently the calculated heat rates should be slightly lower than those measured by the Medtherm. The TPC hotwall heat rates were never corrected to compare to the Medtherm cold-wall heat rates. The results show that even though the Medtherm heat rates were expected to be conservative, they are in-family with the TPC heat rates. The MFD surface behaves as a hot-wall system, and future designs can use the hot-wall heat rates without a problem.

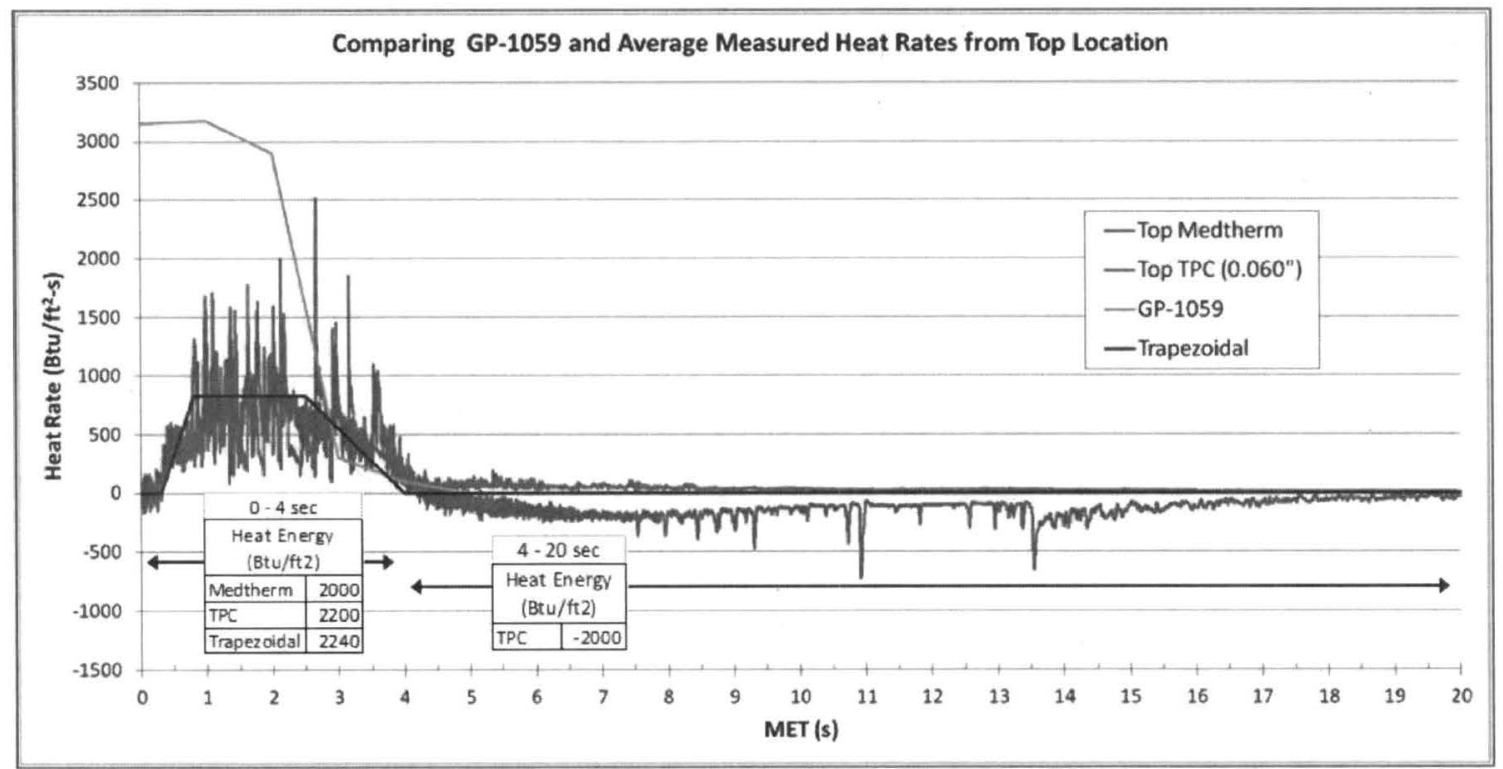

Figure 25. Similar Energy Content-Containing Heat Rates from STS-135 and the Overall Average versus GP-1059

Quantitatively, the Medtherm and TPC recorded similar heat rates. A sample of two heat rate profiles measured during STS-135 at the top location of the MFD are plotted in Figure 25; the blue line is the Medtherm calorimeter and the purple line is the heat rate calculated from the TPC thermocouple at a depth of 0.060 ". Integrating over the entire 20 seconds of TPC data results in nearly zero energy transferred. The temperatures in Figure 23 return almost to ambient when the data collection ends at MET $+20 \mathrm{~s}$. The energy summaries listed on Figure 25 show that the sum of the thermal energy into the piston in the first four seconds $\left(+2200 \mathrm{Btu} / \mathrm{ft}^{2}\right)$ roughly equals the energy lost $(-2000$ $\mathrm{Btu} / \mathrm{ft}^{2}$ ) as the piston cools after launch, seen in the small negative purple spikes from MET +4 to 20 s. The SRB travels far enough away from the MFD in the four seconds after SRM ignition that the sound suppression system water deluge can cover the surface of the TPC sensors and cool them quickly.

Inspection of Medtherm and TPC heat rate and pressure data from multiple launches shows that the majority of the MFD heating event is over around $4 \mathrm{~s}$. Therefore, MET $+4 \mathrm{~s}$ is defined as the ending boundary for all mathematical integration to calculate thermal energy content. The temperatures recorded by the tungsten pistons shown in Figure 23 have a negative slope after four seconds, meaning that the heat added to the piston by the plume has become small.

The areas under the heat rate curves of the Medtherm and TPC in Figure 25 respectively contain 2000 and $2200 \mathrm{Btu} / \mathrm{ft}^{2}$ of heat energy input

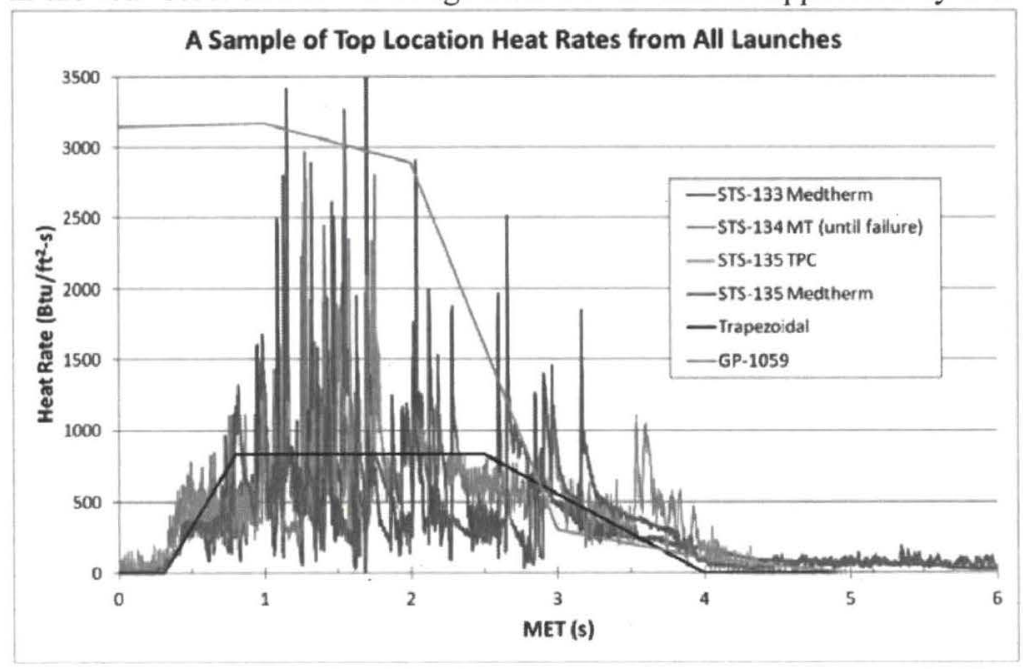

Figure 26. Heat Rates measured for the Top Location for three Shuttle Launches are $28 \%$ of the GP-1059 Predicted Value

16

American Institute of Aeronautics and Astronautics 
from launch. The trapezoidal-shaped black line in the figures contains $2240 \mathrm{Btu} / \mathrm{ft}^{2}$ of energy, which is representative of the average energy content of all the sensors at the top location. (Table A1 in the Appendix is a summary chart of the energy content into each sensor.) The blue, purple, and black lines in Figure 25 represent the same amount of energy. This simple trapezoidal profile illustrates how little energy is contained in the shortduration, high-heat-rate spikes. The total heat applied to the MFD in the trapezoidal profile is about $28 \%$ of the area under the orange curve, which is the heating predicted by GP-1059.

As illustrated by the orange lines in Figure 25 and Figure 26, GP-1059 publishes a heat rate that remains for the entire launch event at a magnitude similar to the heat rate spikes, describing an unrealistic situation with sustained high heat rates. The area under the GP-1059 curve contains $8000 \mathrm{Btu} / \mathrm{ft}^{2}$, which is 3.5 times greater than the average heat content measured during three launches and illustrated by the trapezoidal profile. When first developed in the $1960 \mathrm{~s}$, this curve was likely based on the known heat content of molten aluminum oxide $\left.\left(\Delta \mathrm{H}_{\mathrm{f}}=465 \mathrm{Btu} / \mathrm{lb}\right)\right)^{16}$

Why does GP-1059 describe an unrealistically high average heat rate? Detailed examination of the thermal spikes acquired by the Medtherm/TPC shed light on the physical aspects of the plume. Data from the STS-133 middle Medtherm calorimeter are presented in Figure 28 as an example of a typical heat rate profile. The plume is comprised of a gas phase and aluminum oxide particles (or particle phase). These spikes are the accretion (or freezing) of the aluminum oxide slag onto the sensor. The curves indicate slag accretion, conductive heating, liberation, and erosion sequences during the plume impingement event as described by the letters in Figure 27, which is a detailed look at one spike from Figure 28. The heat transferred to the substrate from the plume is constantly changing. The center of the impingement site on the MFD is approximately 55 feet from the nozzle exit plane at ignition. This distance allows the plume to expand and accelerate, causing the gas portion of the plume to cool. The particle portion of the plume, the $\mathrm{Al}_{2} \mathrm{O}_{3}$ particles (or 'slag'), has a higher thermal mass and remains in the molten state

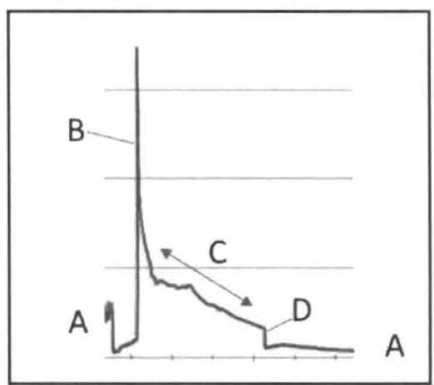

Figure 27. Detailed profile of a heat rate spike, typical of each sensor and launch before impinging on the MFD. The heat still contained in the slag is transferred to the substrate as the heating spike (B). The rapid reduction in heat rate (descent portion of the $\mathrm{B}$ spike and $\mathrm{C}$ ) is the tapering off of the heat rate as the solidified slag in contact with the substrate cools through conduction. As the slag cools, it becomes more brittle. The MFD's vibration liberates the slag from the substrate as seen by the rapid drop in heat rate (D) back to the "floor" (A). Once the protective layer of slag is liberated, the substrate is exposed to erosion and convective heating from the gas phase of the plume.

The heat rate floor identified in Figure 28 (about $350 \quad \mathrm{Btu} / \mathrm{ft}^{2}-\mathrm{s}$ ) appears to be the same order of magnitude as the heat rates from the gaseous portion of the SRB plume as presented in Figure 7-15 in GP-1059 (600 Btu/ft'-s). ${ }^{2}$ In fact, all five successful Medtherm readings from the top and middle locations show a similar heat rate floor of 300-350 Btu/ $/ \mathrm{ft}^{2}$-s. However, when integrating over the 4-second event, the top calorimeters measured a different energy content

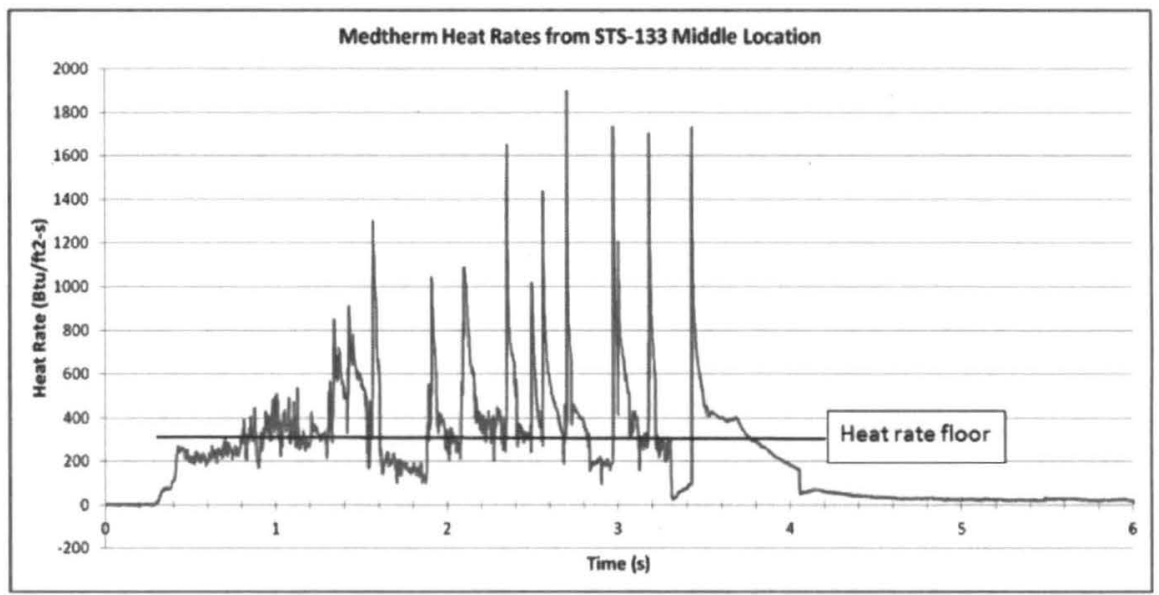

Figure 28. Heat rate data that show the sudden freezing of the slag with the corresponding rapid rise in heat rate. The heat rate floor is around $350 \mathrm{Btu} / \mathrm{ft}^{2}-\mathrm{s}$ than the middle location, the additional energy coming from more slag impinging at the top. This is expected because the top location was designed to be directly beneath the plume at ignition. The spikes from the slag impingement correlate with the particle portion of the plume as presented in Figure 7-15 in GP-1059. Figure 26 shows that GP-1059 envelopes the slag spikes. The authors of that document did not have the advantage of actually measuring the short duration of the heat loading from the spikes. While the details of the heat transfer mechanism are open to interpretation, the overall energy can be summarized by the trapezoidal profile shown in Figure 25. 


\section{E. Witness Material Evaluation}

Historically, the SRB plume erodes the refractory concrete exposing the heads of the $1 / 2$-inch diameter Nelson ${ }^{\circledR}$ Studs to the environment. The studs are part of the mechanical system that holds the refractory concrete to the Main Flame Deflector. As discussed in Section II, during the MFD repair process many of these studs were removed and metallurgically examined to discover that melting of the steel did not occur. ${ }^{2}$ This discrepancy suggested further investigation was valuable with larger diameter specimens. Three 4-inch diameter steel witness rods were installed in close proximity to the COTS and TPC sensors to gather qualitative data on the environment. The STS-133 and STS-135 launches exposed HY-80 steel to the plume while the STS-134 launch exposed 1018 steel. In addition, other metals used for housing the TPC and COTS sensors, A-286, 17-4PH and 304 stainless, were also examined. Pure tungsten pistons were used on STS-133 and STS-135 whereas tungsten alloy pistons made of $90 \% \mathrm{~W}-6 \% \mathrm{Ni}-$ $4 \% \mathrm{Cu}$ were used on STS-134. The applicable material properties and the response of the various metals to the plume are summarized in Table 1. Only the responses of the witness materials for the top location are discussed because this location experiences the most severe thermal/erosive environment. A matrix detailing the complete list of materials installed for each launch can be found in Ref. 9. A complete evaluation of the witness materials exposed to lesser heat rates in the middle and bottom locations on the MFD are covered in the references. ${ }^{10-12}$

Table 1: Witness Material Properties and their Response to the SRB plume for the Top Sensor Location

\begin{tabular}{|c|c|c|c|c|c|c|c|c|c|}
\hline \multirow{2}{*}{\multicolumn{2}{|c|}{$\begin{array}{c}\text { Witness Materials } \\
\text { Top Location }\end{array}$}} & \multirow{2}{*}{\begin{tabular}{|c|} 
Density \\
$\mathrm{lb} / \mathrm{ft}^{3}$
\end{tabular}} & \multirow{2}{*}{\begin{tabular}{|c|} 
Specific he at \\
Btu/lb-F \\
\end{tabular}} & \multirow{2}{*}{\multicolumn{2}{|c|}{\begin{tabular}{|c|} 
The rmal conductivity \\
Btu/hr-ft-F \\
\end{tabular}}} & \multirow{2}{*}{\begin{tabular}{|c|} 
Thermal diffusivity \\
$\mathrm{ft}^{2} / \mathrm{hr}$ \\
\end{tabular}} & \multirow{2}{*}{$\begin{array}{c}\text { Melting Temp } \\
\operatorname{deg} \mathbf{F}\end{array}$} & \multirow{2}{*}{ Response } & \multirow{2}{*}{$\begin{array}{c}\text { Erosion } \\
\text { inches } \\
\end{array}$} \\
\hline & & & & & & & & & \\
\hline \multirow{2}{*}{ Steels } & 1018 & 490.8 & 0.116 & 30.0 & - & 0.527 & $2600-2800$ & Eroded & 0.384 \\
\hline & HY 80 & 483.8 & 0.110 & 22.0 & - & 0.413 & 2595 & Eroded & $0.079 / 0.225 *$ \\
\hline \multirow{3}{*}{ Stainless Steels } & 304 & 493.2 & 0.114 & 8.6 & (a) $80 \mathrm{degF}$ & 0.153 & $2552-2642$ & Melted & $0.244 / 0.340^{*}$ \\
\hline & A286 & 494.0 & 0.110 & 8.7 & @300 degF & 0.159 & 2550 & Melted & $0.189 / 0.205^{*}$ \\
\hline & $17-4 \mathrm{ph}$ & 487.3 & 0.108 & 10.3 & @300 degF & 0.196 & $2552-2624$ & Melted & 0.42 \\
\hline \multirow{2}{*}{ Tungsten } & Pure (99.99\%) & 1203.1 & 0.033 & 84.4 & @ $500 \mathrm{degF}$ & 2.126 & 6192 & Slight erosion & $0.000 / 0.012^{*}$ \\
\hline & Alloy $(90 \% \mathrm{~W}-6 \mathrm{Ni}-4 \mathrm{Cu})$ & 1059.3 & 0.031 & 56.6 & (a) $500 \mathrm{deg} F$ & 1.724 & $5430-5790$ & Eroded & 0.231 \\
\hline
\end{tabular}

* For two launches

Table 1 indicates that thermal diffusivity (Eqn. 2) affects whether the material exhibits melting and/or erosion when exposed to the plume at the top location. Erosion values for all the steels, including the stainless, and the tungsten alloy were between 0.1 " and 0.4 " per launch. The steels with high thermal diffusivity did not melt whereas the stainless steels with lower diffusivity did. Erosion of the steels varies between launches and there is no evidence that any type of steels eroded less than any other (even when considering that melting should cause an increase in erosion). The $99.99 \%$ pure tungsten installed in the top location exhibited a minimal amount of erosion. For STS133 and STS-135, both the top and middle pure tungsten pistons cracked, such as seen in Figure 30, either due to thermal stress from the initial sudden plume impingement or the sound suppression system water rapidly cooling the piston after the event. The erosive response of the $90 \%-6 \%-4 \%$ tungsten alloy was similar to steel for unknown reasons although the thermal diffusivities are similar. Both the pure and alloy tungsten pistons displayed similar hardnesses in lab tests so the difference is not

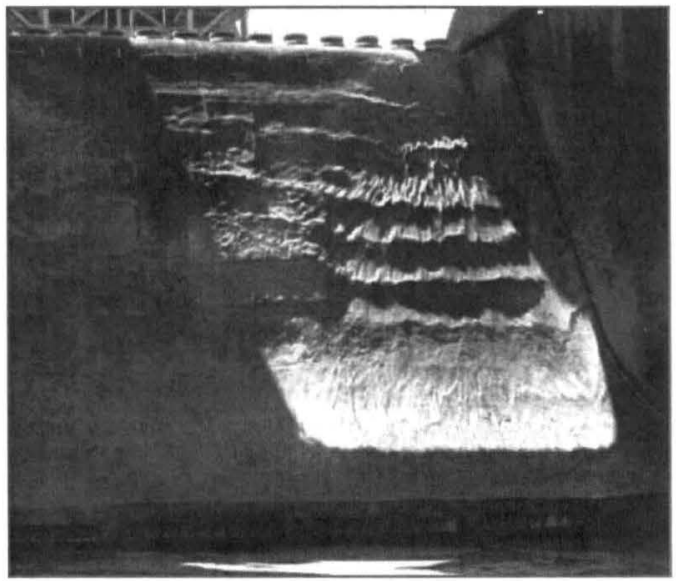

Figure 29. The scallops created by the SRB plume on the refractory concrete reveal the turbulence of the boundary layer 
Depending upon where the witness rods are installed with respect to the undulations on the MFD, erosion of these metals is very difficult to predict. The complexity of the boundary layer and subsequent formation of concrete scouring ridges caused by a number of Shuttle launches are shown in Figure 29, photographed prior to the STS-133 MFD refurbishment. The scallops highlighted by the shadows and sunlight are left in the refractory concrete from the SRB plume and reveal the turbulence of the boundary layer as the plume flows down the MFD surface. For this study, the west side of the MFD refractory concrete was initially smooth except for 0.5 -inch high casting ridges from the formwork as discussed in Section II. The COTS sensors, TPC, and witness rods were initially installed into a surface of the MFD seen in Figure 5 that was much smoother than in Figure 29. After only three launches the beginning of similar scouring was observed.

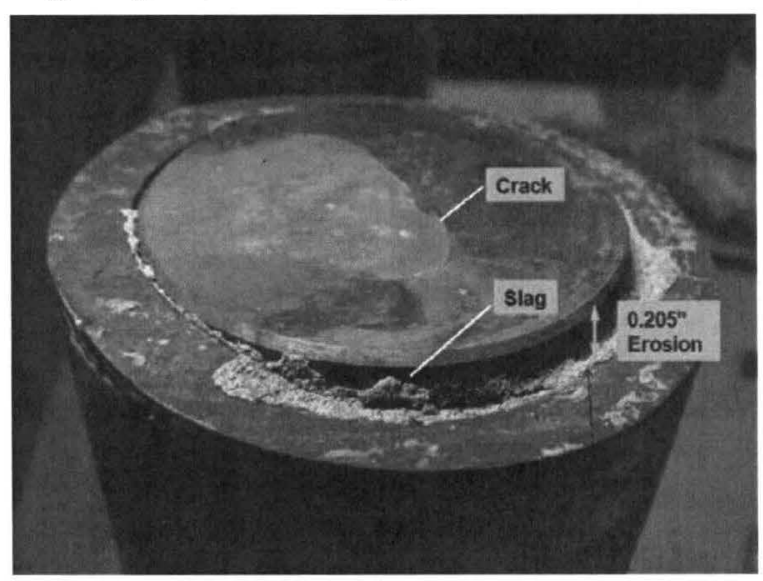

Figure 30 shows the top tungsten piston and its A-286 stainless sleeve after the launch of STS-135. The housing displayed signs of melting: dendrites and distorted grain structure. An accompanying 0.2 " of erosion occurred on the uphill side of the sleeve (to the right in the photo) whereas the piston did not erode at all. This erosion exposed the leading edge of the piston to 3-D heating from the plume as discussed in Section V.D. The crack in the center of the piston is evidence of thermal shock loading. Slag is seen deposited on the piston and housing and in the groove between the piston and the sleeve.

During STS-133, the top COTS cap made of 304 stainless eroded and melted a maximum of 0.244 " on the leading edge, shown in Figure 32. The Medtherm calorimeter survived the launch with minimal damage. In comparison, Figure 31 shows the 304 stainless steel top COTS cap from STS-134, where the Medtherm was destroyed. Metallography showed that the 304 stainless

Figure 30. Top TPC and Sleeve after STS-135

melted and resolidified. The water cooling lines on the Medtherm calorimeter were exposed by the erosion of the COTS cap as identified in Figure 31. Water was injected into the atmosphere at 150 psig. This water formed a protective layer over the COTS housing downstream from the injection hole. This protection scheme is used by the Stennis B-1 Space Shuttle Main Engine (SSME) test stand. ${ }^{13}$ At that test stand water is injected through numerous holes to protect the steel flame deflector from the SSME exhaust.

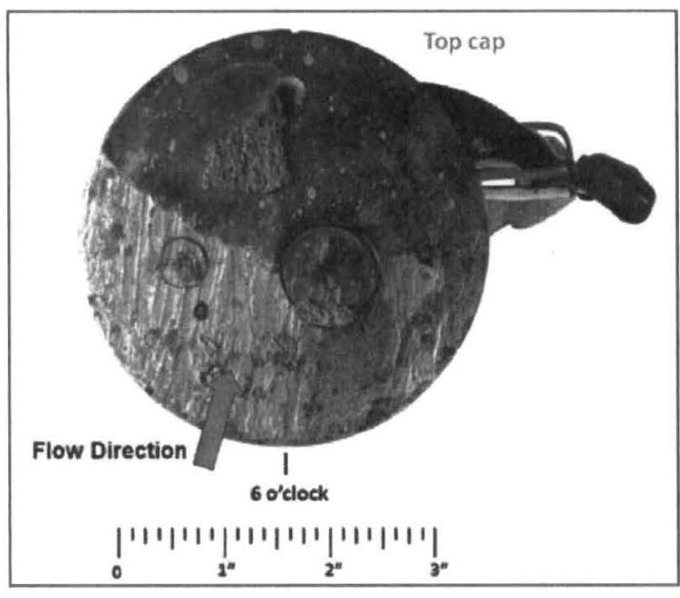

Figure 32. STS-133 melting and erosion of the top COTS cap. The Medtherm Calorimeter survived the event with minor erosion.

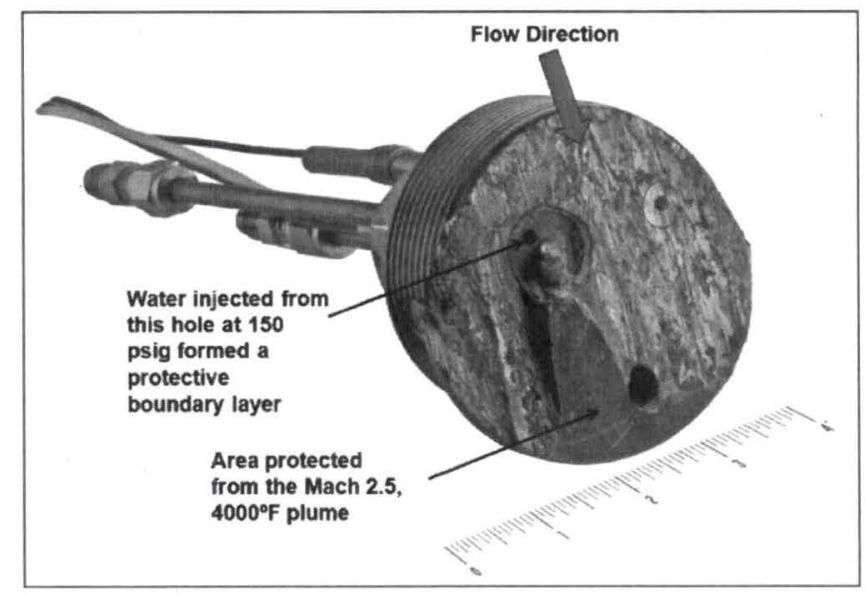

Figure 31. STS-134 Top COTS cap with sensors still installed. Erosion of the Medtherm sensor was so severe that it exposed the water cooling tube. Water was injected into the boundary layer, protecting the 304 stainless downstream. 


\section{Conclusions}

1) A robust Tungsten Piston Calorimeter (TPC) was successfully designed and fabricated to measure heat rates and pressures beneath the Space Shuttle SRB plume. Thermocouples were successfully brazed to the bottom of the TPC thermal wells producing a repeatable sensor with relatively good response for heat rate calculations. Data returned by both the TPC and Medtherm calorimeters indicate that the maximum heat rates from the SRB on the Main Flame Deflector were measured with a high degree of confidence.

2) Future designs of the TPC should install the thermocouples as close as possible to the hot face. Erosion of the TPC sleeve will cause 3-D heating of the thermocouple nearest the exposed leading edge. This will produce more heating in that region of the piston with corresponding higher calculated heat rates.

3) The COTS sensors performed better than expected. They should be considered for measuring other solid rocket motor plumes.

4) Data returned by both the Strainsert load cell and Kulite/Stellar pressure transducers indicate that the maximum impingement pressures from the SRB on the Main Flame Deflector were measured with a high degree of confidence.

5) It was determined that the KSC specification ${ }^{1}$ used for quantifying the MFD thermal and pressure environment over-predicted heat rates by a factor of 3 and under-predicted pressures by a factor of 2 .

6) The reason the specification ${ }^{1}$ overpredicted the heat rates on the MFD is because the short duration of the thermal spikes from the $\mathrm{Al}_{2} \mathrm{O}_{3}$ slag was unknown. The Medtherm and TPC identified these short duration spikes.

7) No witness material (except pure tungsten) was able to withstand the plume without some degree of erosion. Materials with low diffusivities have a propensity to melt. However, the heat rates measured by the TPC and Medtherm calorimeter were a fraction of the value published in the KSC specification, ${ }^{1}$ which may be the reason the Nelson ${ }^{\circledR}$ Studs and steel witness rods do not melt. Water injected to form a boundary layer will protect the substrate from the erosive effects of the plume.

8) Data acquired from this study are important contributors for the calibration of the Computational Fluid Dynamic (CFD) Models used to generate pressures, temperatures, kinetic energies, and flow visualization fields. Accurately modeling the SLS plume is an important factor in designing the Flame Trench and Main Flame Deflector for the Space Launch System. 


\section{Appendix}

The following figures are the power spectral densities for the acceleration measured on the MFD beneath the plume and the pressure measured on the bottom of the MLP, respectively.
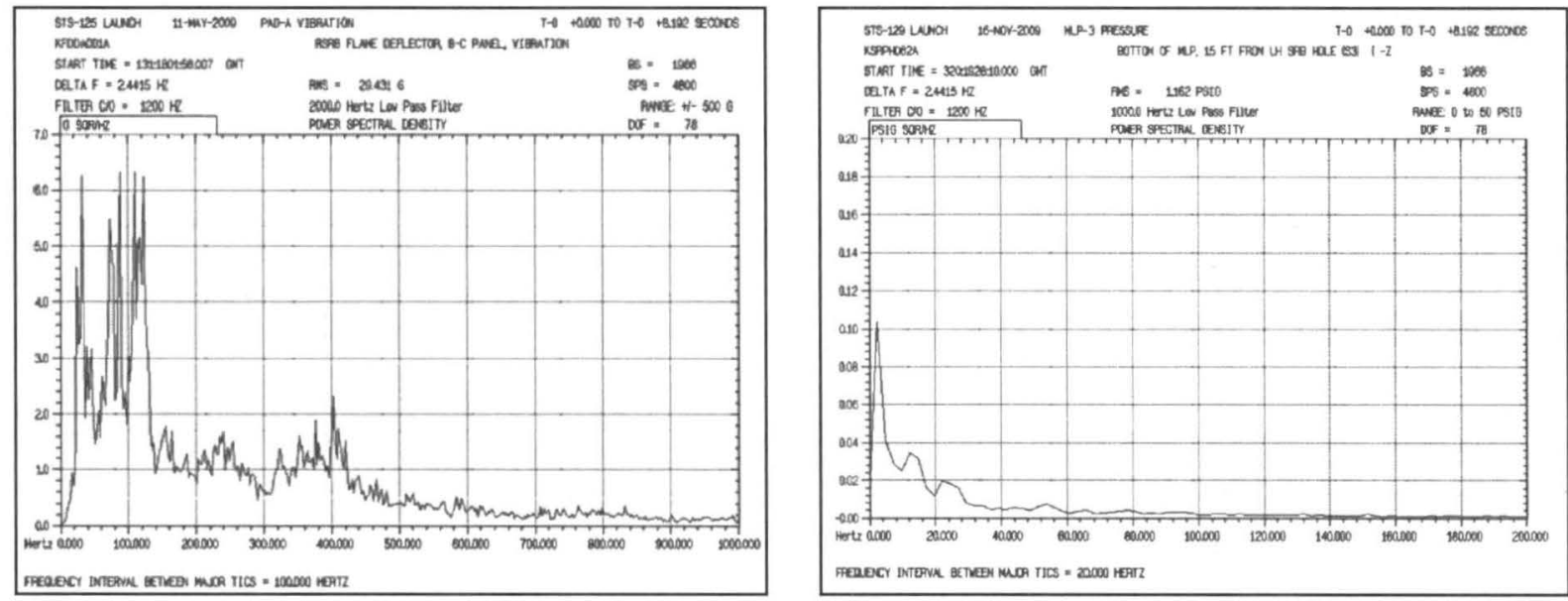

Figure 33. STS-125 and STS-129 PSDs used as input for the FEM Dynamic Analysis described in Section IV.C

The following table and figure are referenced in Sections V.C and V.D. The heat rate curve from each sensor is integrated to quantify the amount of thermal energy measured during the launch event. The valid measurements for each location are averaged to find the Avg value, to summarize the amount of energy content at each location on the MFD. The heat affecting the bottom location is less than half the heat at the top. The Medtherm measured heat rates are similar to the heat rates calculated from the TPC temperatures. The erosion on the uphill-oriented piston housing sleeve is included to quantify the erosive effect of the SRB plume.

Table A1: Energy Contained in Heat Rate Profiles of Each Sensor with Erosion Amount Heat Input into Each Sensor for 0-4.0 sec (Btu/ft2)

\begin{tabular}{|c|c|c|c|c|c|}
\hline & Sensor/Erosion & STS-133 & STS-134 & STS-135 & Avg \\
\hline \multirow{5}{*}{ Top } & Medtherm & 1860 & $\mathrm{x}$ & 2000 & \multirow{4}{*}{2240} \\
\hline & TPC $0.030 "$ & $x$ & $x$ & 3140 & \\
\hline & TPC $0.060 "$ & $x$ & $x$ & 2200 & \\
\hline & TPC $0.090^{\prime \prime}$ & $x$ & $x$ & 2020 & \\
\hline & Piston Sleeve Erosion & $0.189 "$ & $0.420^{\prime \prime}$ & $0.205^{\prime \prime}$ & $0.271^{\prime \prime}$ \\
\hline \multirow{5}{*}{ Middle } & Medtherm & 1360 & 1420 & $\mathrm{x}$ & \multirow{4}{*}{1660} \\
\hline & TPC $0.030^{\prime \prime}$ & 1560 & $x$ & 2100 & \\
\hline & TPC $0.060 "$ & 2200 & 1740 & 1520 & \\
\hline & TPC 0.090" & $x$ & 1760 & 1260 & \\
\hline & Piston Sleeve Erosion & $0.183^{\prime \prime}$ & $0.236 "$ & $0.195^{\prime \prime}$ & $0.205^{\prime \prime}$ \\
\hline \multirow{5}{*}{ Bottom } & Medtherm & 1040 & 940 & 940 & \multirow{4}{*}{960} \\
\hline & TPC $0.030 "$ & 780 & 1140 & 1080 & \\
\hline & TPC $0.060^{\prime \prime}$ & 800 & 930 & 830 & \\
\hline & TPC $0.090^{\prime \prime}$ & 1300 & $x$ & 830 & \\
\hline & Piston Sleeve Erosion & $0.116^{\prime \prime}$ & $0.146^{\prime \prime}$ & $0.153^{\prime \prime}$ & $0.138^{\prime \prime}$ \\
\hline
\end{tabular}




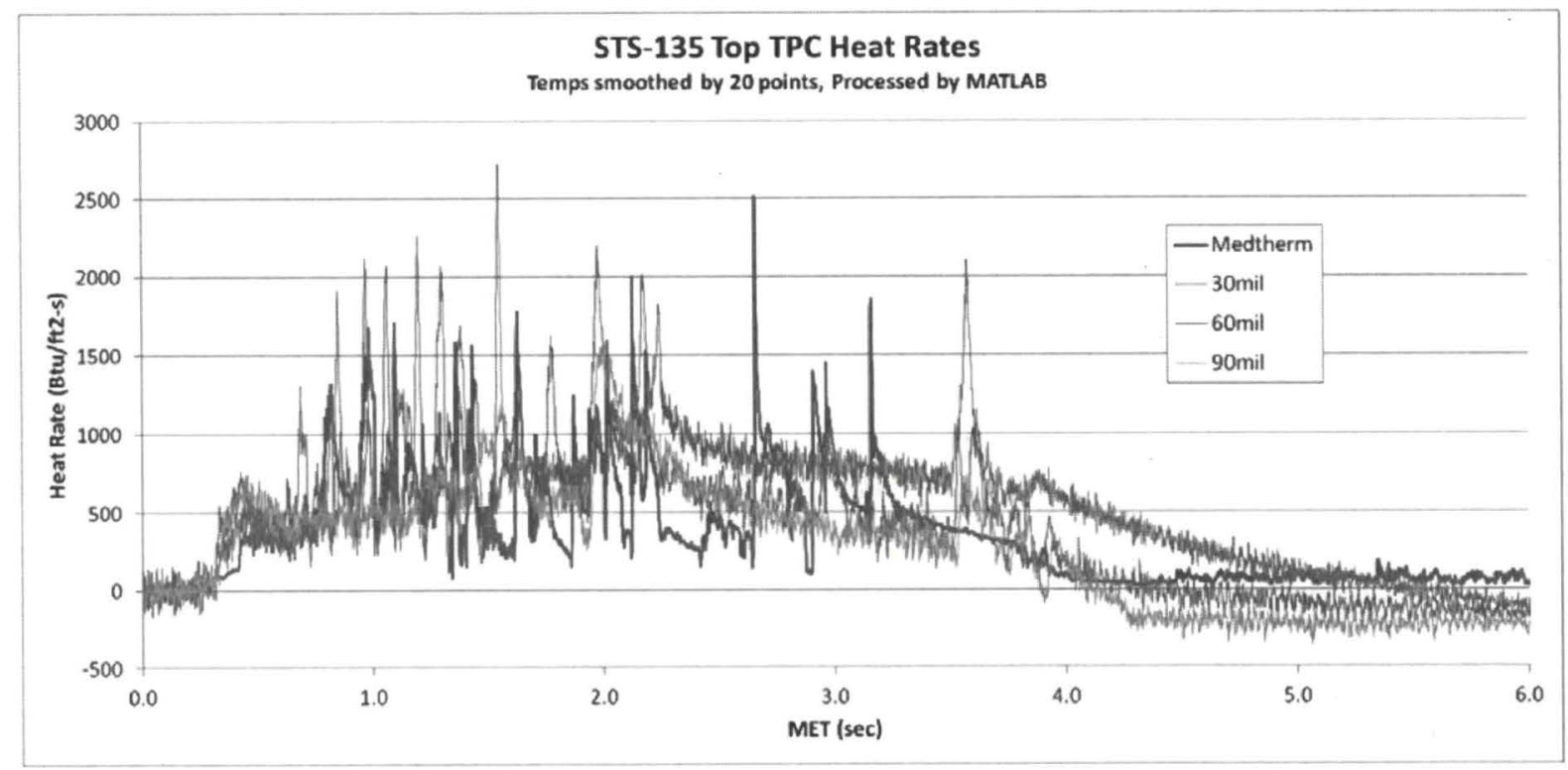

Figure 34. Heat Rates from STS-135 Top Location show the 0.030" thermocouple calculates a higher heat rate compared to the 0.060 " and 0.090 " thermocouple and Medtherm

\section{Acknowledgments}

The authors would like to thank Jose Perez-Morales, NASA Pad Senior Project Manager, for providing the funding for this study. Ken Page, Charles Gardener, Armand Gosselin, Frank Walker, Sathish Sounderrajan and Gabor Tanacs, (all with USA FL) provided valuable concepts for design, testing and fabrication of the COTS and TPC sensors. Erica Bruno of USA SSP Systems Engineering (Houston, TX) filtered the load cell and pressure data. Steve Marek with Lucas-Milhaupt (Cudahy, WI) provided an assortment of brazing materials that were tested and one was eventually incorporated as the thermocouple gap-filler material. Kevin Anetsberger with Midwest Tungsten Service (Willowbrook, IL) worked hard to get the machined tungsten pistons to the launch site in order to support these last three launches. Victoria Long and Peter Marciniak of NASA Materials Science Laboratories (KSC) provided the metallurgical analysis on the witness materials. These are just a few of the eighty people that worked on fabrication, test, installation, and processing the data for this project.

\section{References}

1"Environment and Test Specification Levels Ground Support Equipment For Space Shuttle System Launch Complex 39, Thermal and Pressure," GP-1059 Volume IV, John F. Kennedy Space Center, Engineering Development Directorate, April 13, 1992, pp. 1-779.

${ }^{2 *}$ Failure Analysis of Main Flame Deflector Nelson Studs," KSC-MSL-2009-0297, NASA Engineering Directorate, Materials Science Division, Kennedy Space Center, FL, October 2, 2009, pp 1-7.

${ }^{3 "}$ Specification for Refractory Concrete," KSC-SPEC-P-0012, Kennedy Space Center, April 23, 1979, pp. 11.

4"Properties of Refractory Concrete in Tension and Compression," KSC-MSL-2009-0336, NASA Engineering Directorate, Materials Science Division, Kennedy Space Center, FL, November 13, 2009, pp. 17.

${ }^{5}$ Suslov, D.I., Arnold, R., and Haidn, O. J., "Investigation of Two Dimensional Thermal Loads in the Region Near the Injector Head of a High Pressure Subscale Combustion Chamber," $47^{\text {th }}$ AIAA Aerospace Sciences Meeting, Orlando, FL, AIAA paper 2009-450, 5-8 January 2009, pp.1-10.

${ }^{6 " G e n e r a l ~ E n v i r o n m e n t a l ~ V e r i f i c a t i o n ~ S t a n d a r d ~(G E V S) ~ F o r ~ G S F C ~ F l i g h t ~ P r o g r a m s ~ a n d ~ P r o j e c t s, " ~ G S F C-S T D-~}$ 7000, NASA Goddard Space Flight Center, Greenbelt, MD., April 2005, pp. 1-151.

${ }^{7 "}$ Standard for Environmental Test Methods for Ground Support Equipment," KSC-STD-164B, Engineering Development Directorate, July 6, 1992

${ }^{8}$ Arenas, J. P., and Margasahayan, R. N., "Noise and Vibration of Spacecraft Structures," Ingeniare, Revista chilena de ingeniería, Vol. 14, No 3, 2006, pp. 251-264. 
${ }^{9}$ Eckroth, W., Struchen, L., Perez, R., Nerolich, S., Sounderrajan, S., Page, K., Bruno, E., "STS-133, 134 and 135 Pad A SRB Main Flame Deflector (MFD) and MLP Launch Environment," KSC-91000-12209, Kennedy Space Center, FL (to be published June 2012).

${ }^{10 "}$ "Post STS-133 Evaluation of Main Flame Defector Witness Materials," KSC-MSL-2010-0344, NASA Engineering Directorate, Materials Science Division, Kennedy Space Center, FL, July 6, 2011, pp 1-14.

${ }^{11 "}$ Post STS-134 Evaluation of Main Flame Defector Witness Materials, KSC-MSL-2011-0148, NASA Engineering Directorate, Materials Science Division, Kennedy Space Center, FL, November 18, 2011, pp 1-13.

${ }_{12 "}$ Post STS-135 Evaluation of Main Flame Defector Witness Materials," KSC-MSL-2011-0149, NASA Engineering Directorate, Materials Science Division, Kennedy Space Center, FL, November 18, 2011, pp 11-13.

${ }^{13}$ Sachdev, J. S., Ahuja, V., Hosangadi, A., and Allgood, D. C. "Analysis of Flame Deflector Spray Nozzles in Rocket Engine Test Stands," 46 4 th AIAA/ASME/SAE/ASEE Joint Propulsion Conference \& Exhibit, Nashville, TN, paper AIAA 2010-6972, 25-28 July 2010, pp. 1-10.

${ }^{14}$ Yih, S. W. H., "Properties of Pure Metals: Tungsten," Properties and Selection: Nonferrous Alloys and Special-Purpose Materials, ASM Handbook, Vol. 2, ASM International, 1990, pp. 1099-1201

${ }^{15} \mathrm{CMW}$ Inc., "CMW 1000 Tungsten Nickel Copper Alloy Properties," URL: http://www.cmwinc.com/tungsten-alloys.php\#1000

${ }^{16}$ Gaskell, D. R., Introduction to the Thermodynamics of Materials, $4^{\text {th }}$ ed., Taylor \& Francis, New York, 2003, pp. 587. 
28th AIAA Aerodynamic Measurement Technology, Ground Testing, and Flight

Testing Conference, New Orleans, LA

GT-04, Ground Testing Advancements and Simulations II

\section{Space Shuttle Solid Rocket Motor Plume Pressure and Heat Rate Measurements}

27 June 2012

Leah Struchen

Engineering Analysis - Strength and Thermal

United Space Alliance, LLC

Kennedy Space Center, FL 


\section{Overview}

- The brittle refractory concrete that covers the Solid Rocket Booster (SRB) Main Flame Deflector (MFD) at the Shuttle launch pads can shatter at launch

- Liberation of concrete damages launch pad infrastructure

- FOD generation is undesirable

- Before redesigning the Main Flame Deflector's thermal protection system to prevent FOD, the environment had to be measured (primarily heat rates and pressures)

- Two sets of sensors were installed to measure this harsh environment

- Tungsten Piston Calorimeter (innovative design for this environment)

- Commercial off-the-shelf sensors

- Data presented will show that the specification used for the design of the MFD thermal protection system over-predicts heat rates by a factor of 3 and underpredicts pressures by a factor of 2 . 


\section{Location of the Main Flame Deflector Beneath Shuttle}

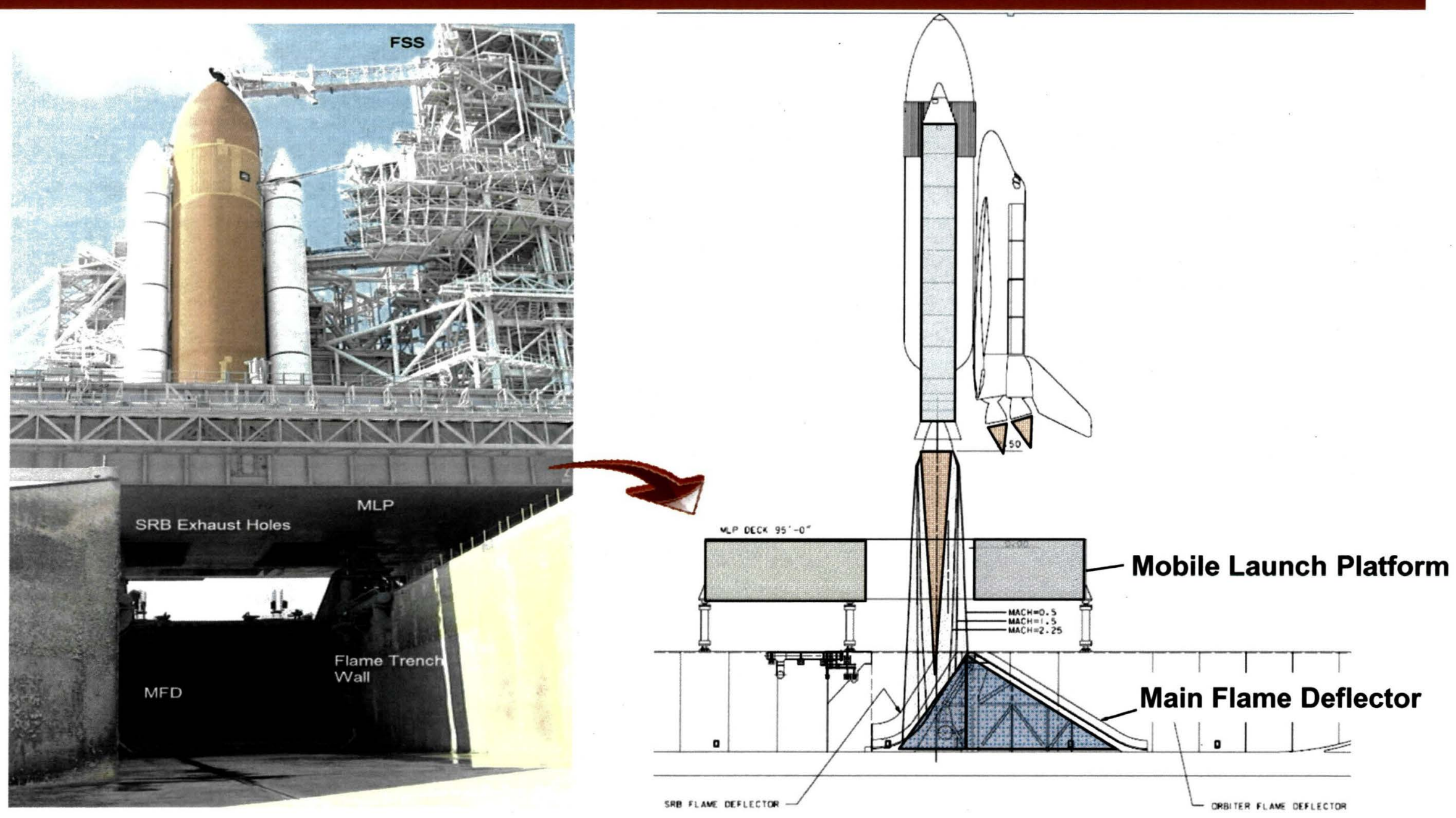

- Plumes from Solid Rocket Boosters on the Space Shuttle are directed at a refractory concrete-covered deflector - called the Main Flame Deflector (MFD)

- During launch the refractory concrete is liberated and causes Pad damage 


\section{Shuttle Launch / Debris Movies}

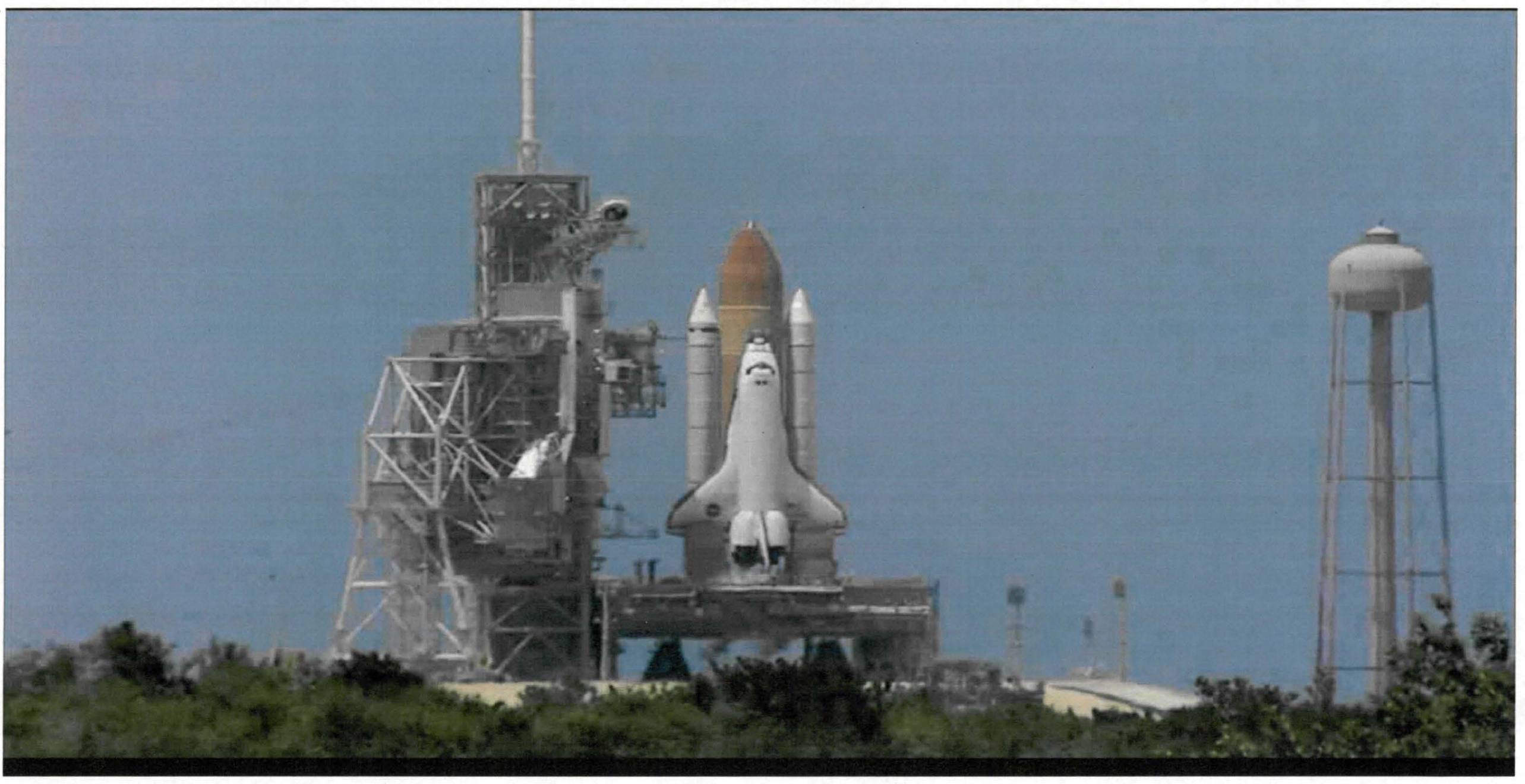




\section{SRB Plume Dynamics (CFD from Marshall Space Flight Center)}

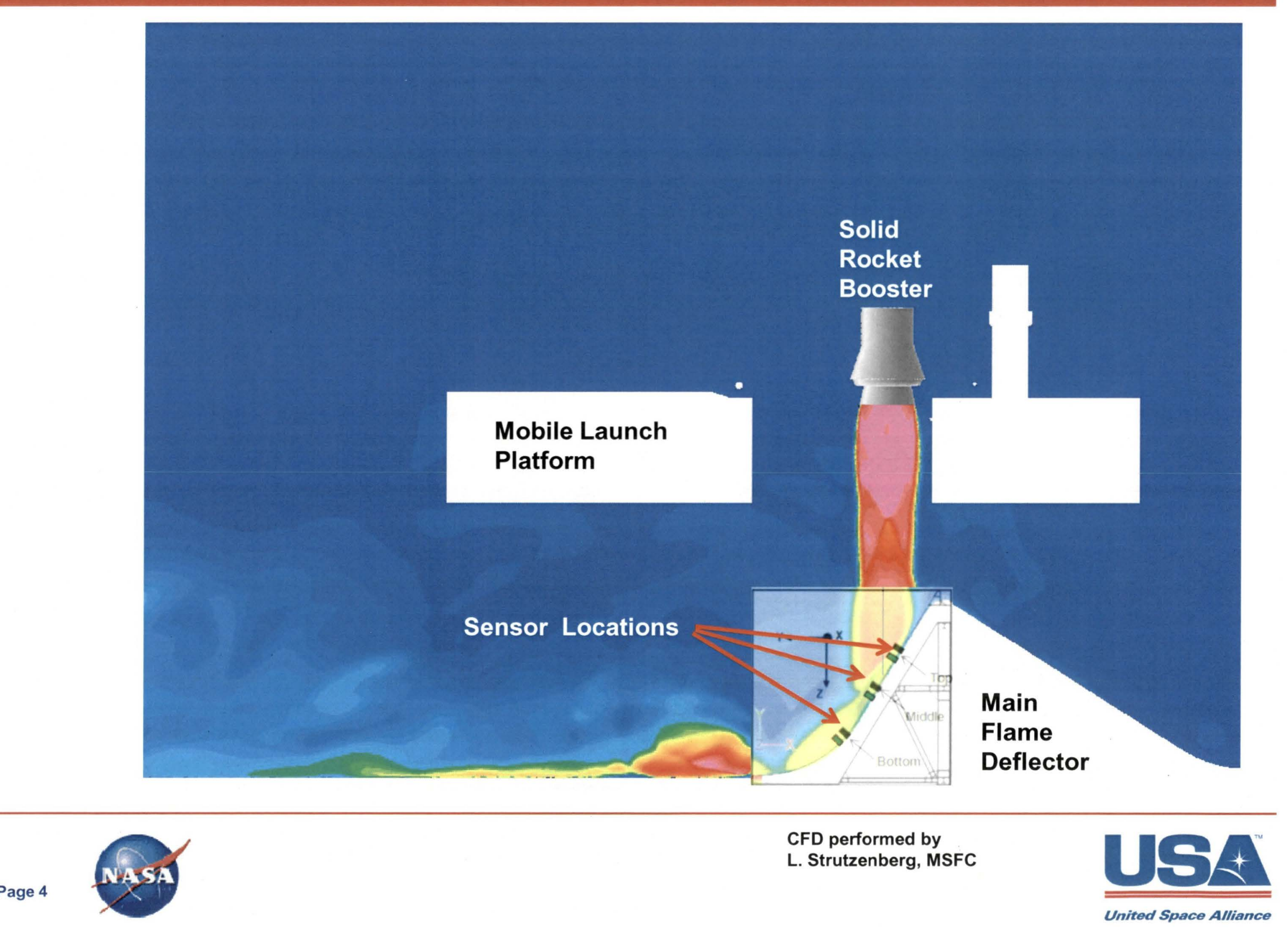




\section{SRB Plume Visualization by Mach Number}

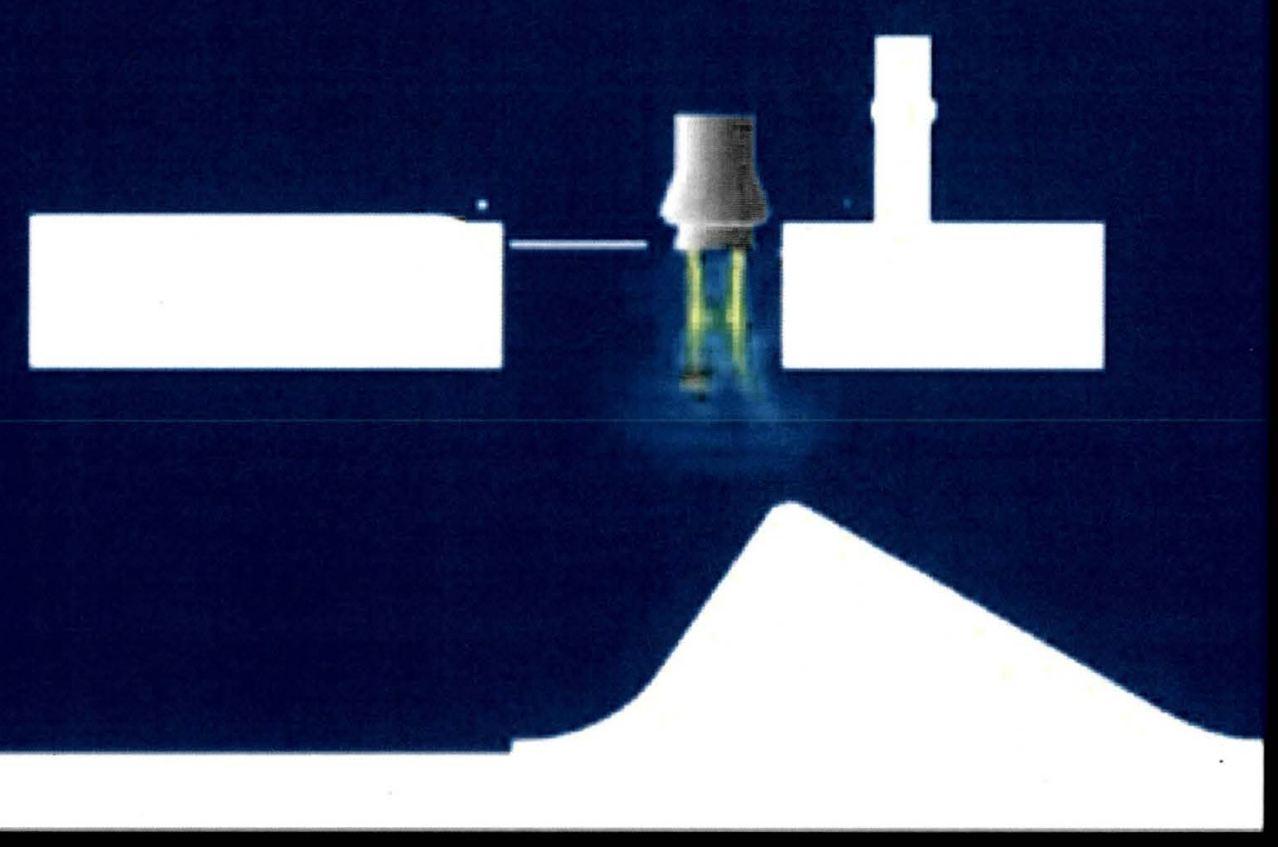




\section{Sensor Locations on Main Flame Deflector}

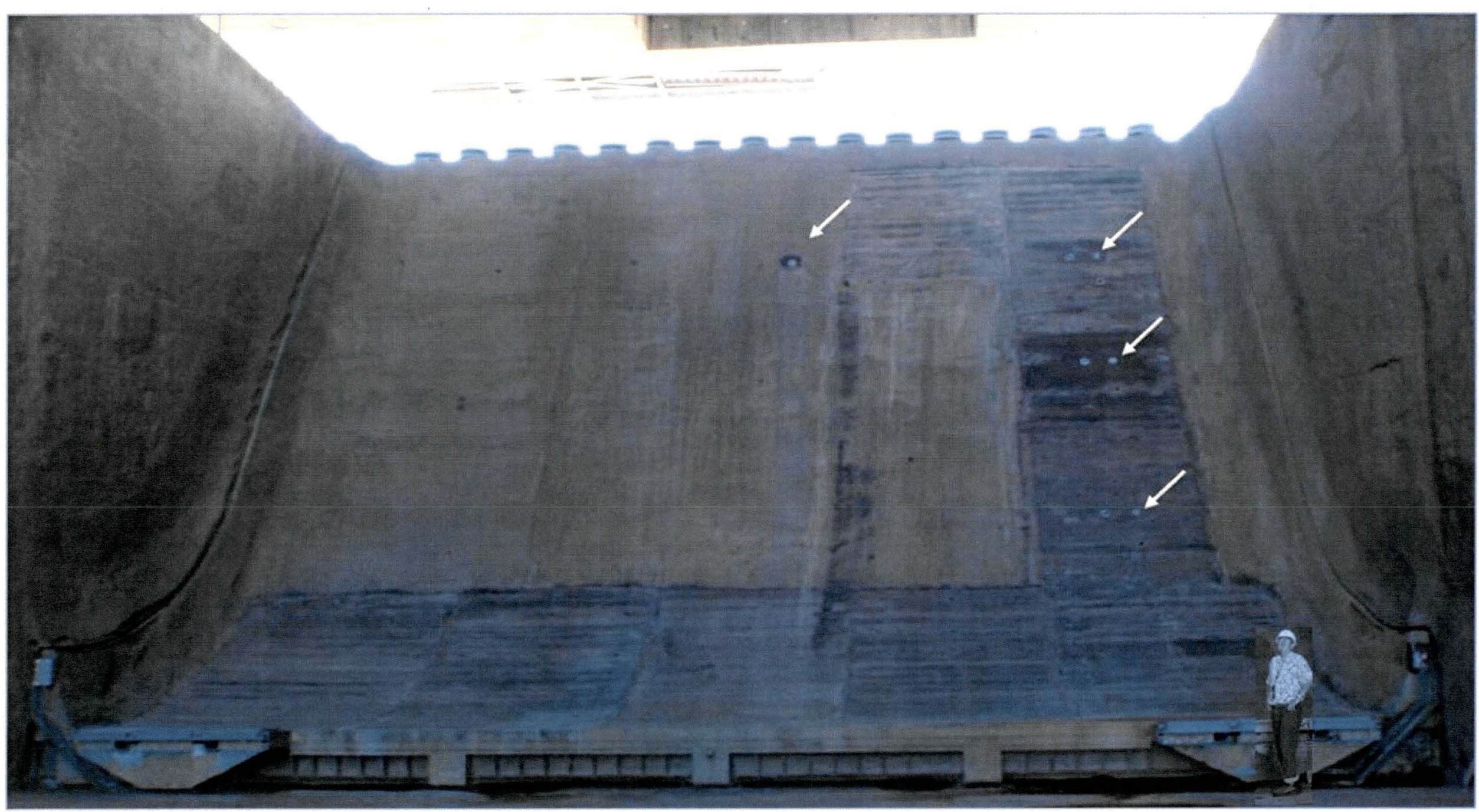

- Photograph of relatively smooth surface of Refractory Concrete prior to launch 


\section{Erosion Undulations formed by the Plume}

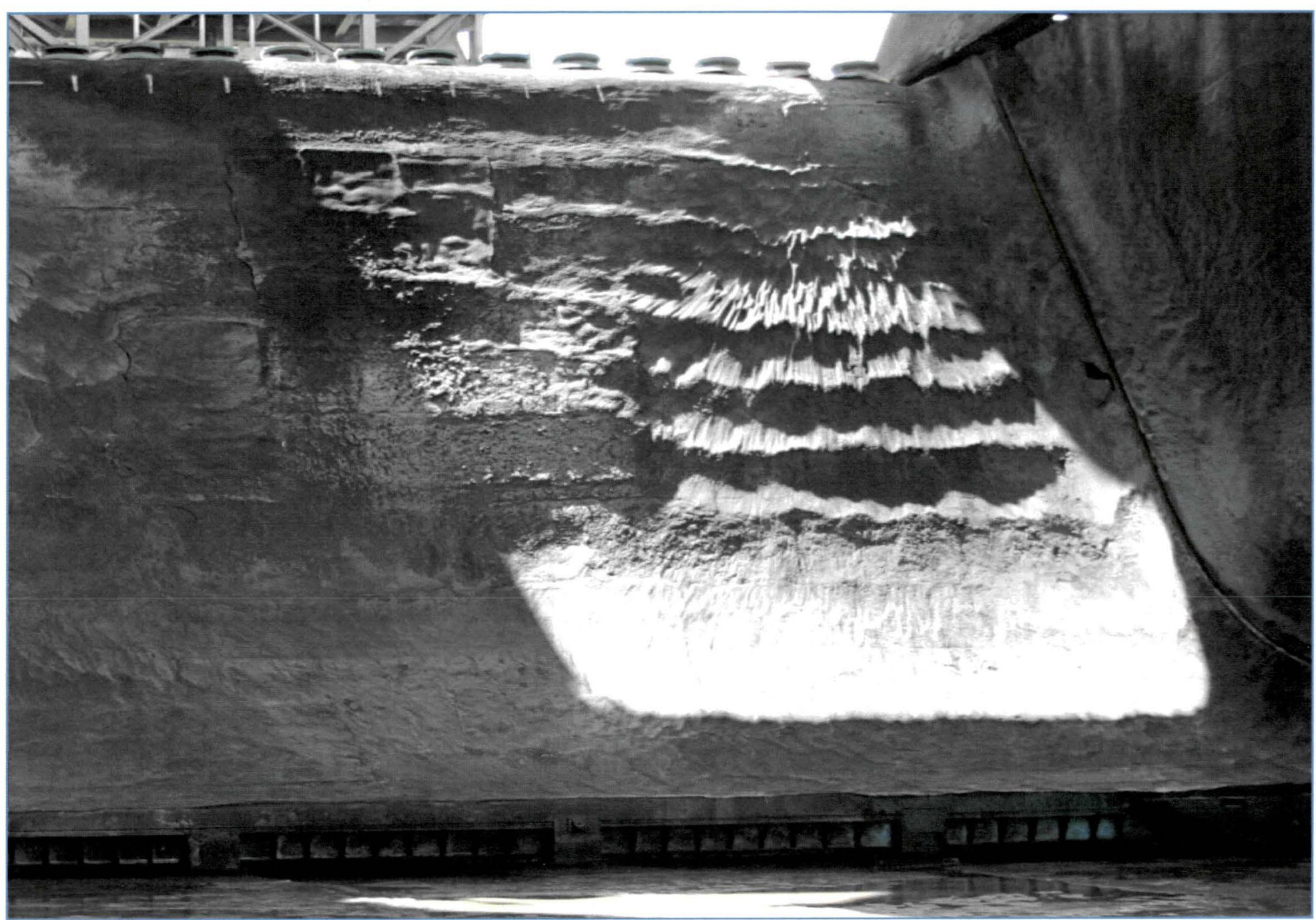

- Erosive pattern after several launches is a testament to the complexity of the flow in the boundary layer 


\section{Methodology}

- To optimize protection of the Main Flame Deflector, the environment was measured

- NASA Specification GP-1059 predicts boundary layer environment

- The boundary layer environment has never been measured

- Measurements on the last three Shuttle launches

- Heat rates

- Temperatures

- Pressures

- Witness materials - quantify erosion of metals subjected to SRB plume

- Dual-path approach to data acquisition

- Commercial-off-the-Shelf (COTS) sensors

- Tungsten Piston Calorimeter was developed 


\section{Main Flame Deflector Sensor Arrangement}

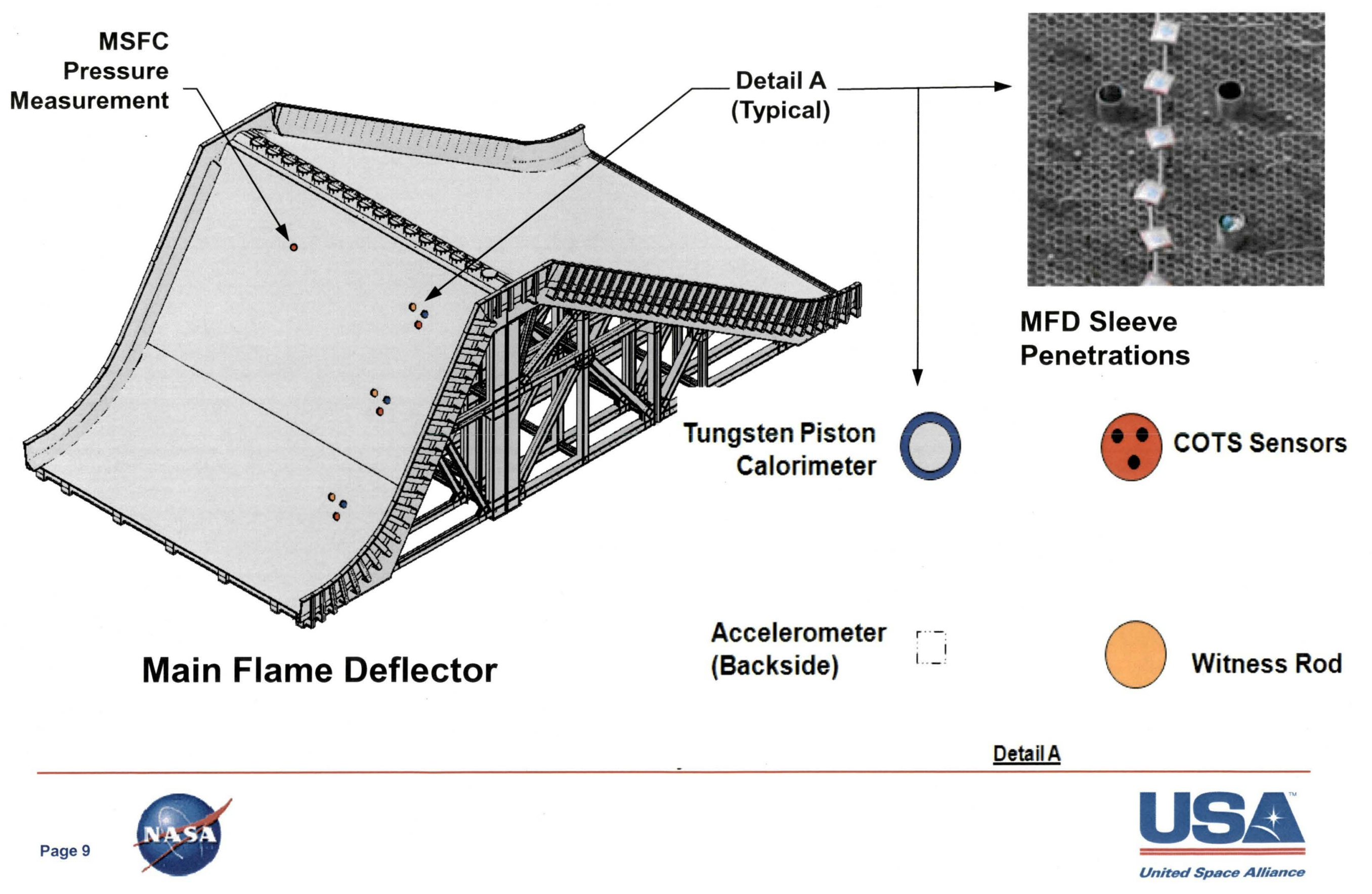




\section{Components of the Tungsten Piston Calorimeter}
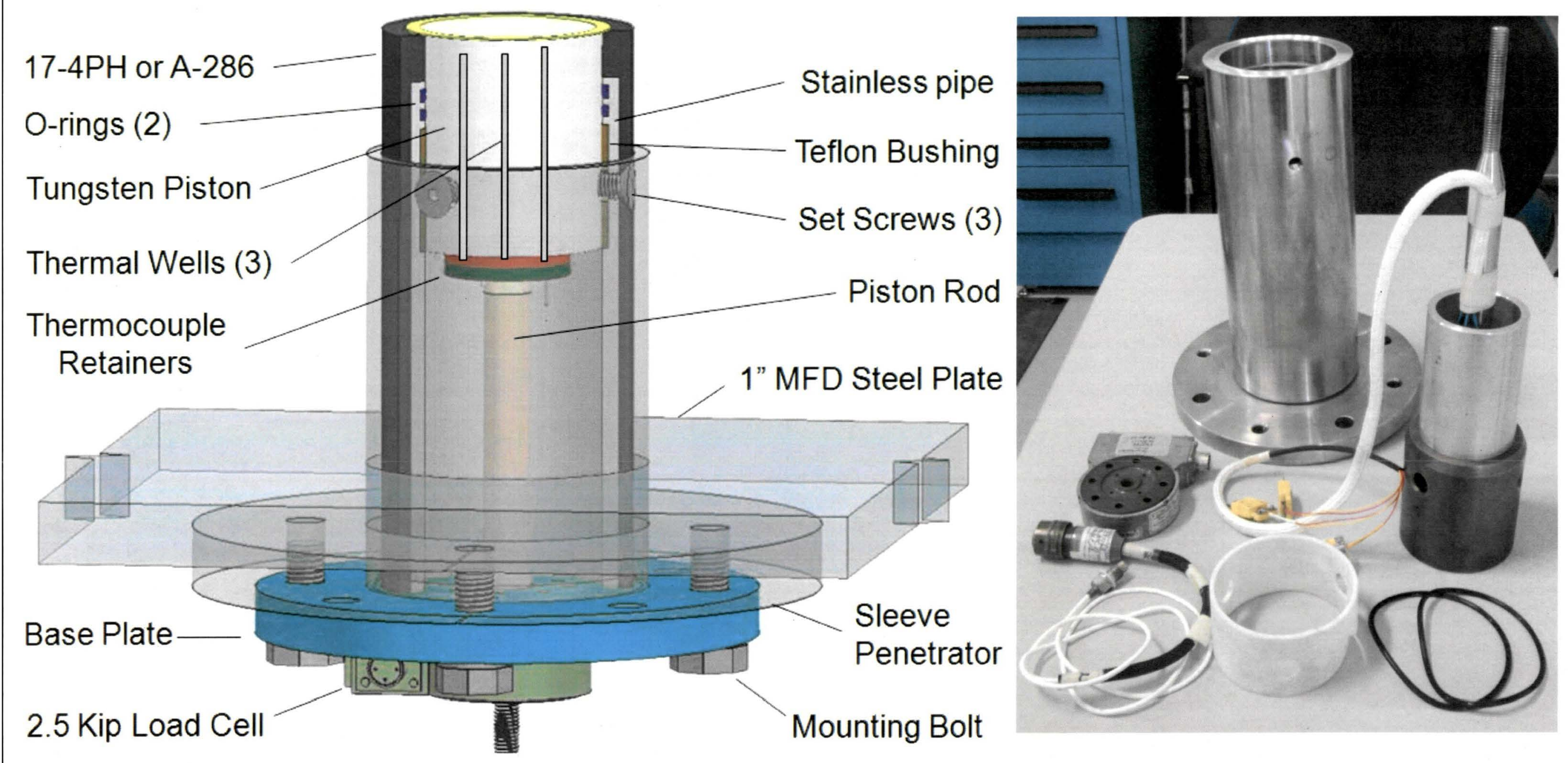


\section{Dynamic Modeling}

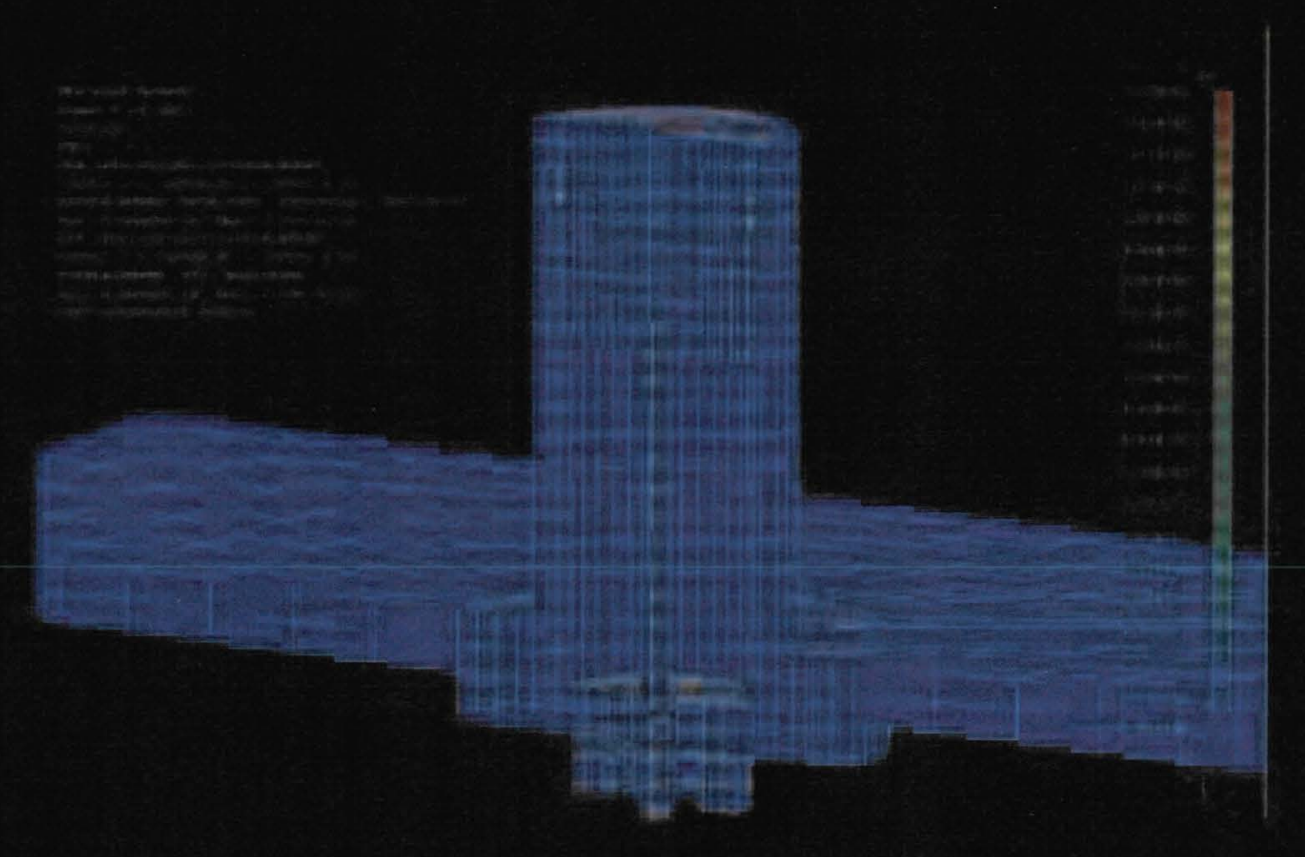




\section{TPC Development Testing}

- Thermal tests using Oxyacetylene torch

- Developed thermocouple embedment method

- Refined heat rate calculation algorithm

- Pressure

- Static for O-ring leakage

- Dynamic for response of load cell versus pressure transducer

- Vibration and Modeling

- Would the load cell accurately measure the pressure of the SRB plume?

- FEM Modeling verified load cell would work - sufficient frequency separation

- Shaker was used to vibrate Tungsten Piston Calorimeter for structure integrity and verify natural frequency

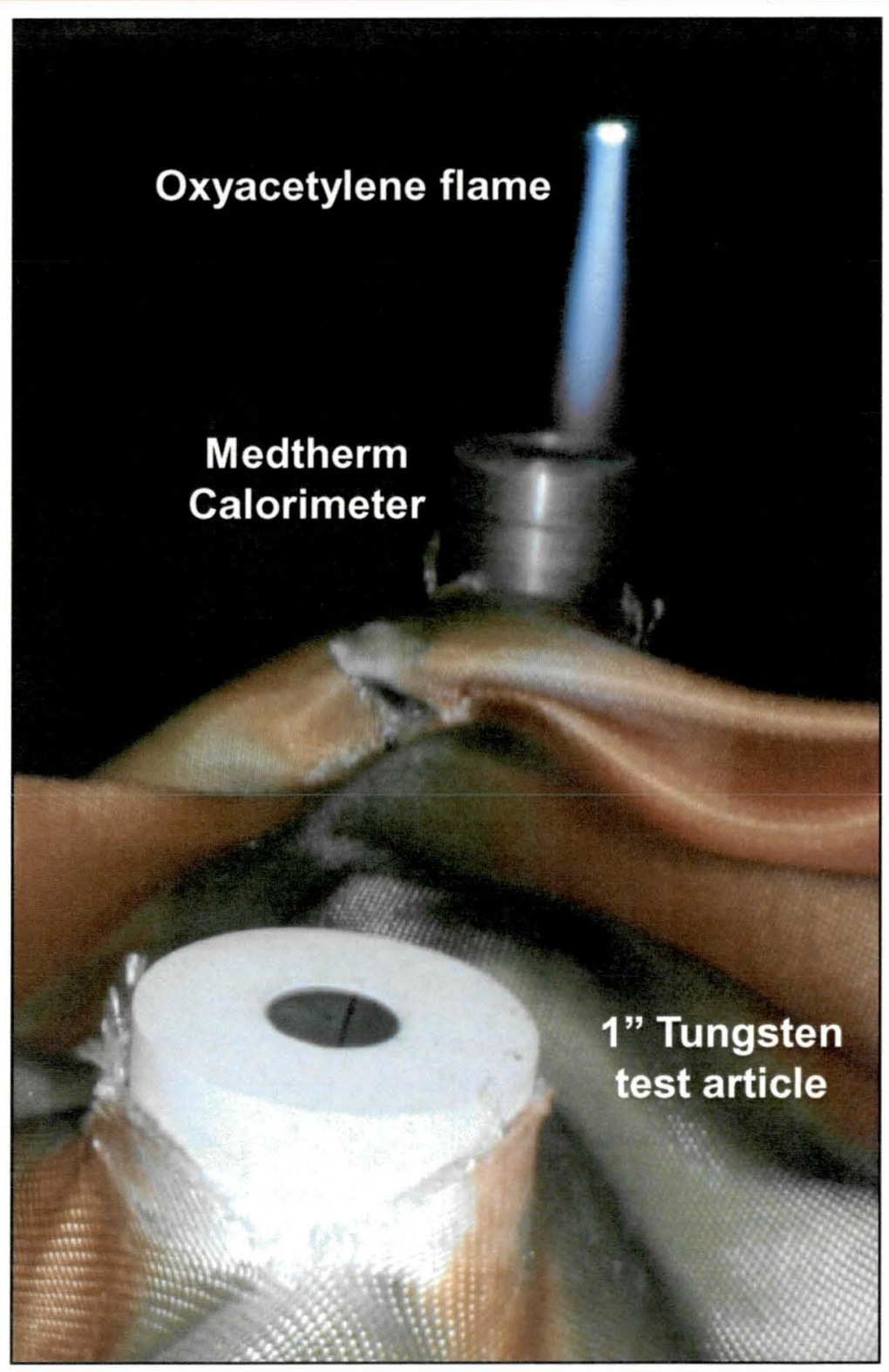




\section{Silver Brazed Thermocouples Thermal Wells}

- Thermocouples are adhered to the bottoms of the thermal wells using Silver braze

- The silver brazing provided a metallic conductive path for the heat transfer and made the calculated heat rate repeatable

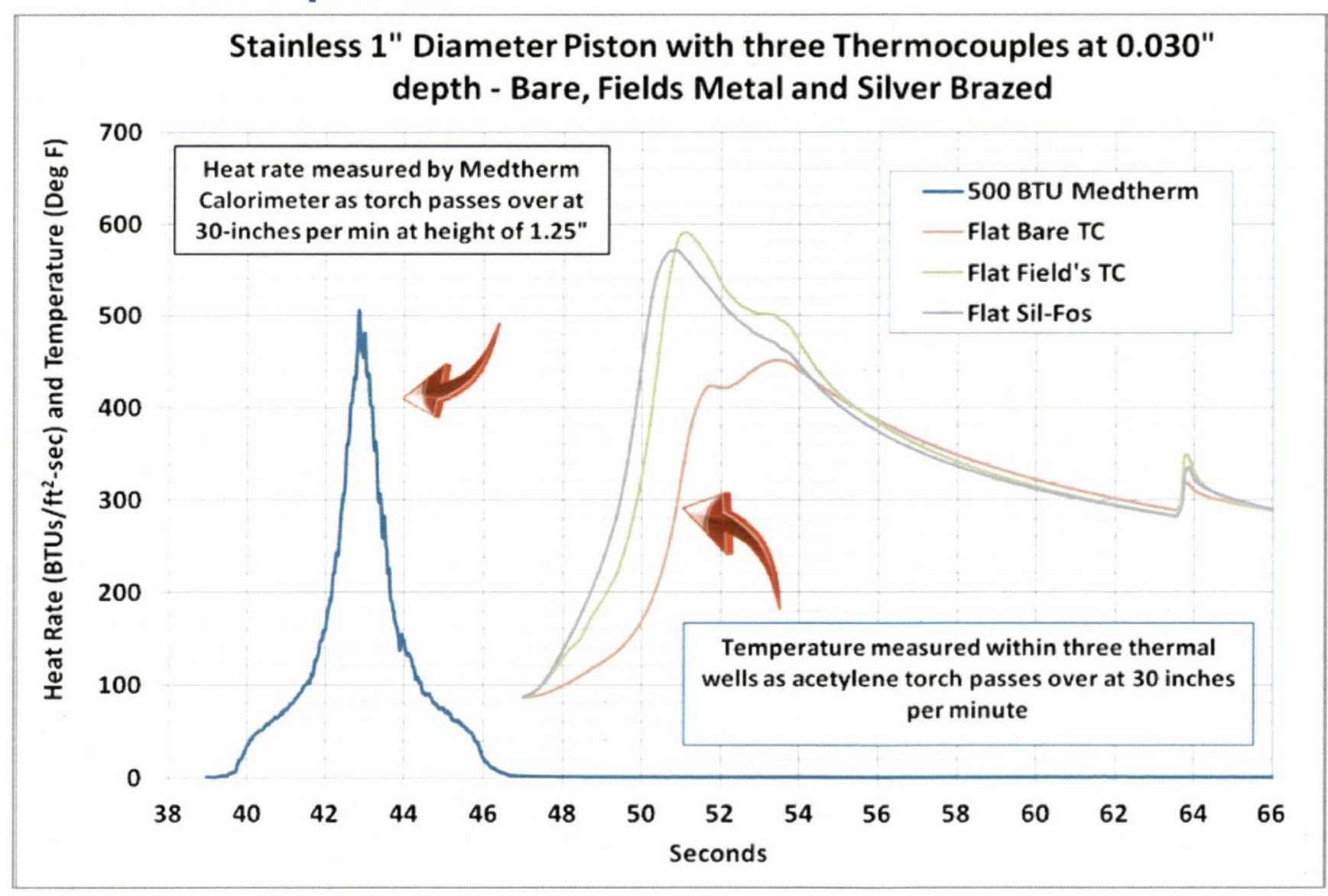

\section{Original weld bead}

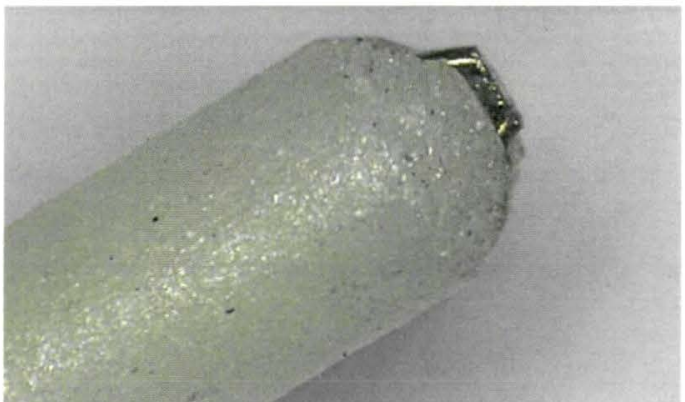

One-half weld bead removed

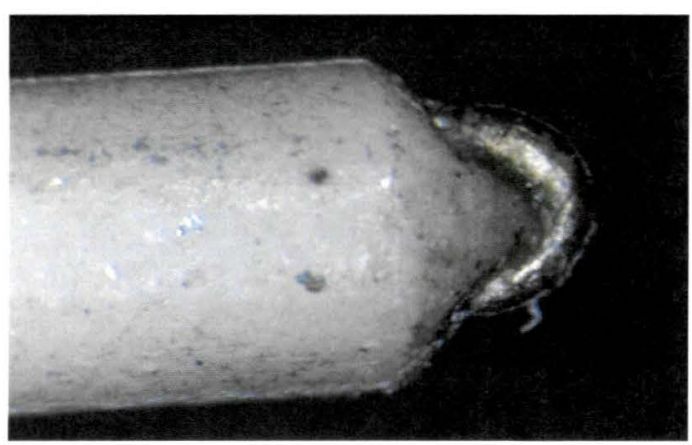

Silver Brazing applied 


\section{Dynamic and Static Pressure tests}
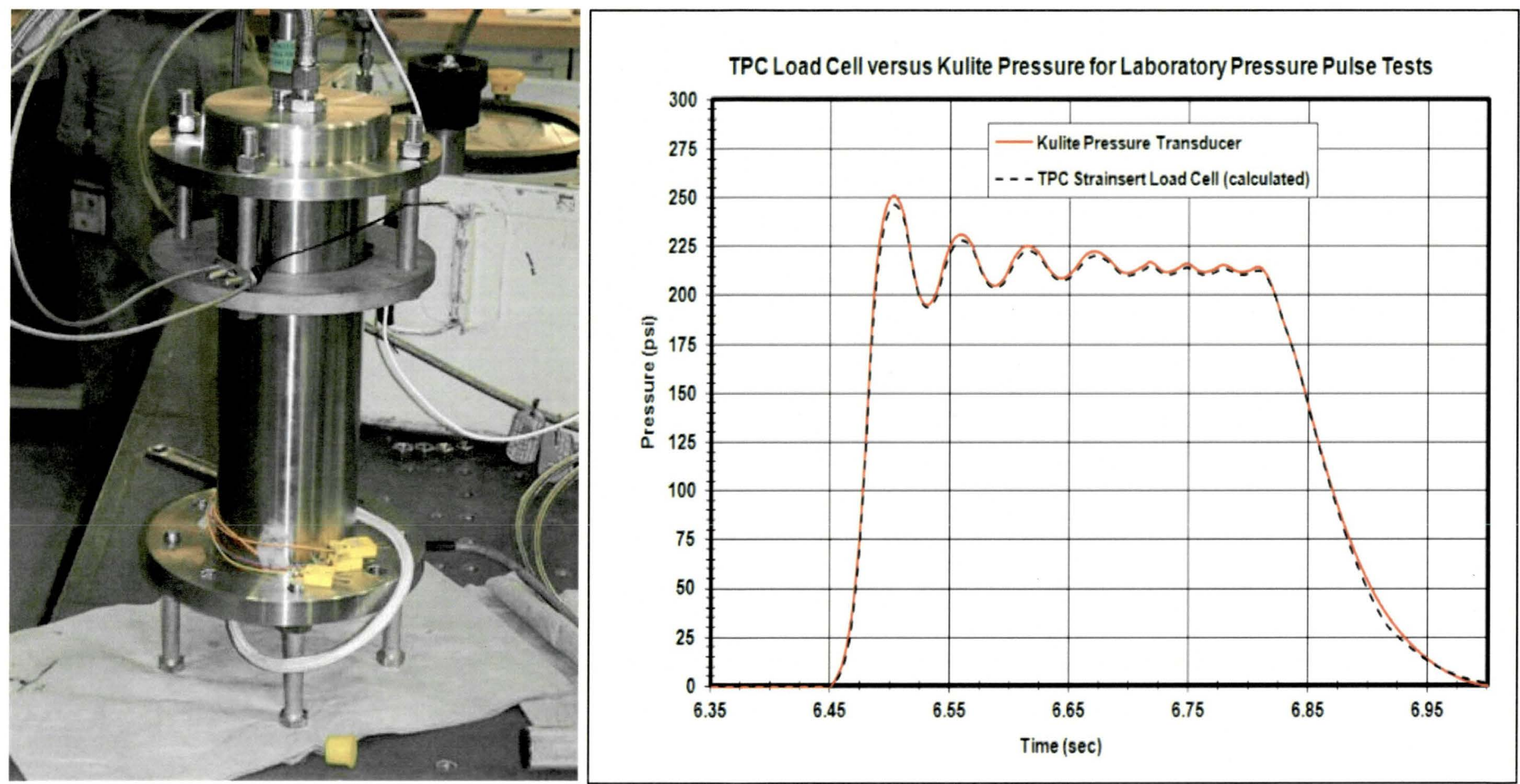

- Excellent correlation between the load cell and the pressure transducer during development testing 


\section{COTS and Witness Rod Assemblies}

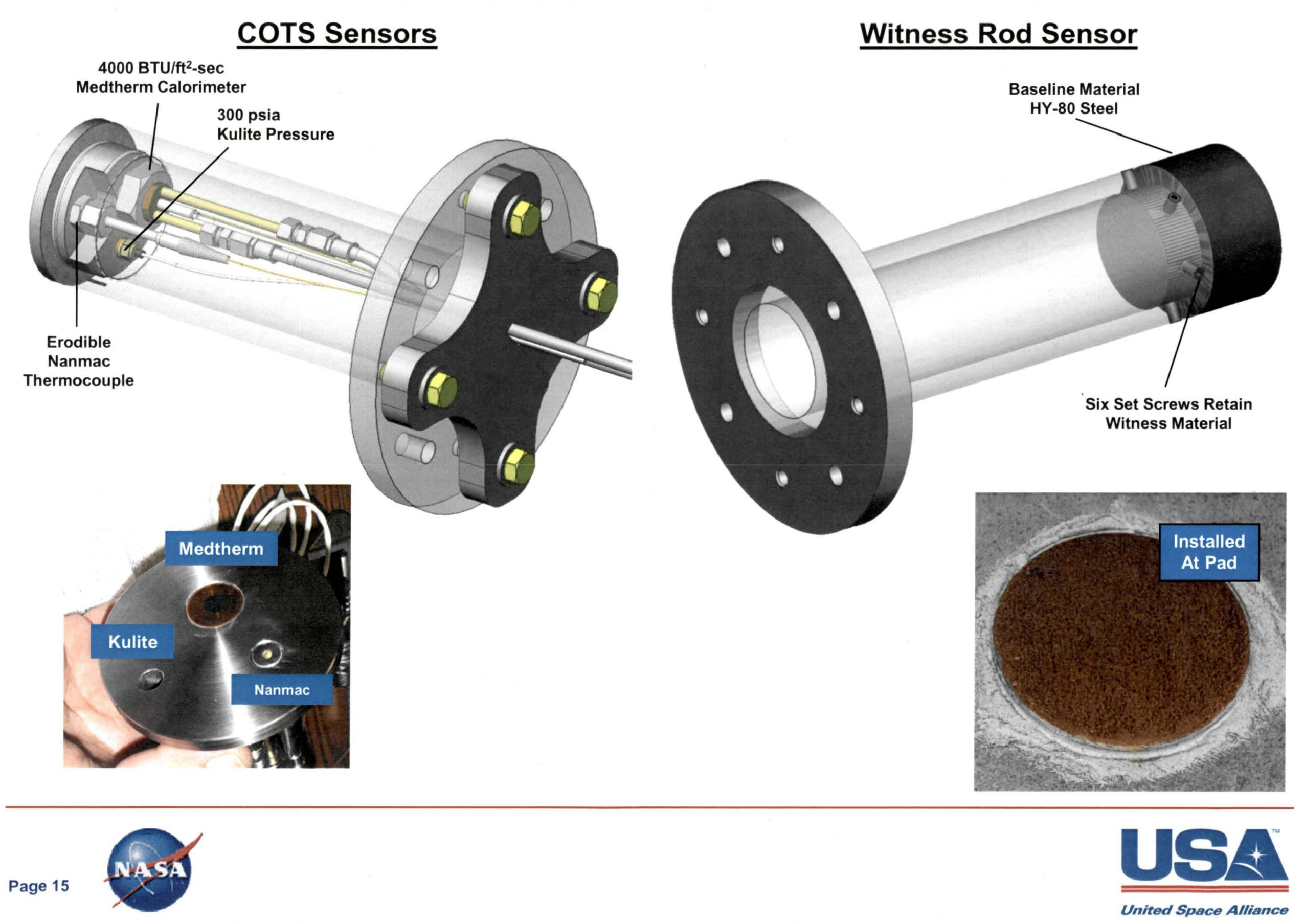




\section{STS-135 Pressure Results (load cell vs. pressure transducer)}

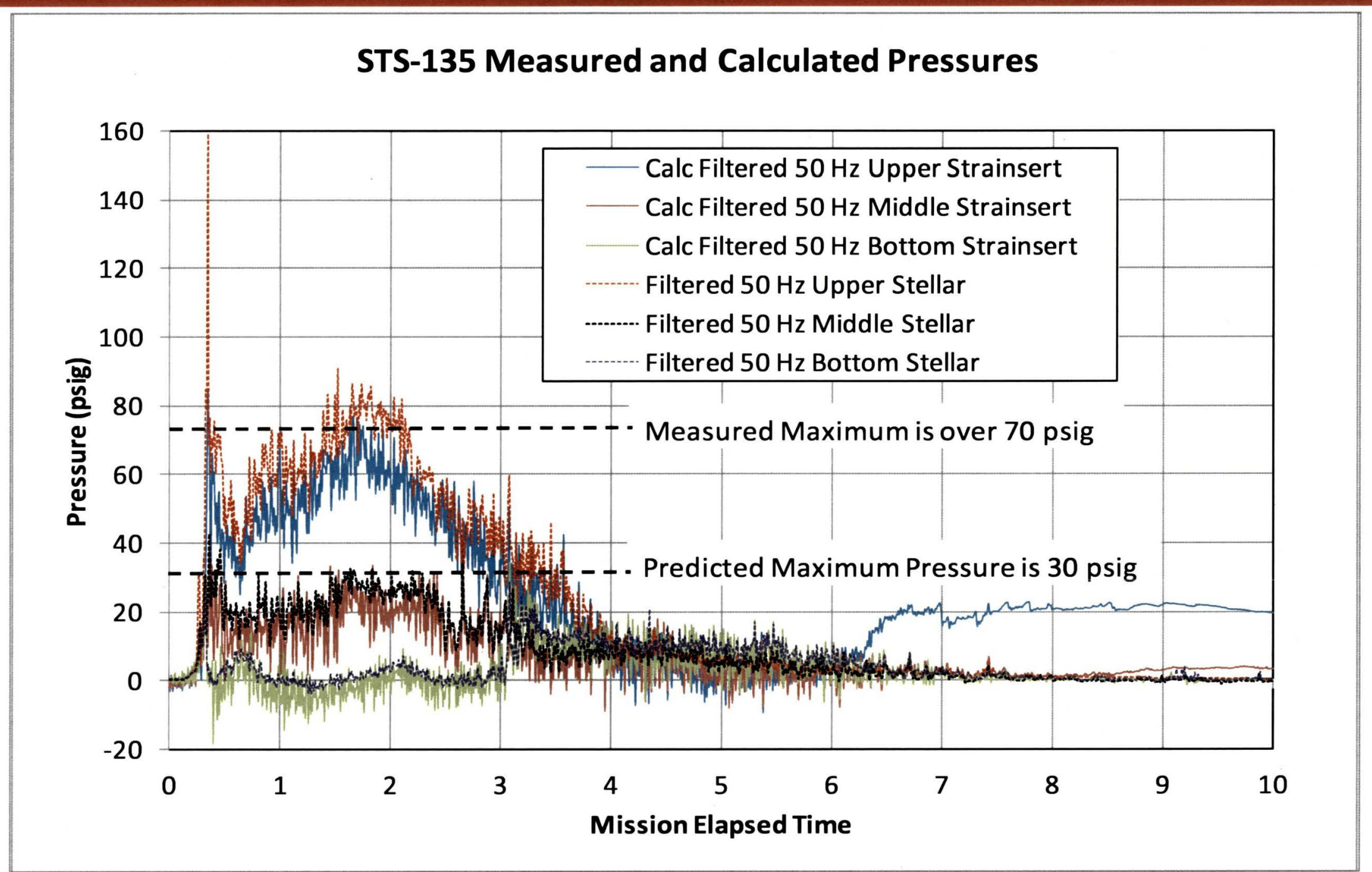

- Upper location: measured pressures were twice those predicted in GP-1059

- Measured pressures at the middle locations were in line with GP-1059 


\section{Heat Rates Measured using the Medtherm Calorimeter}
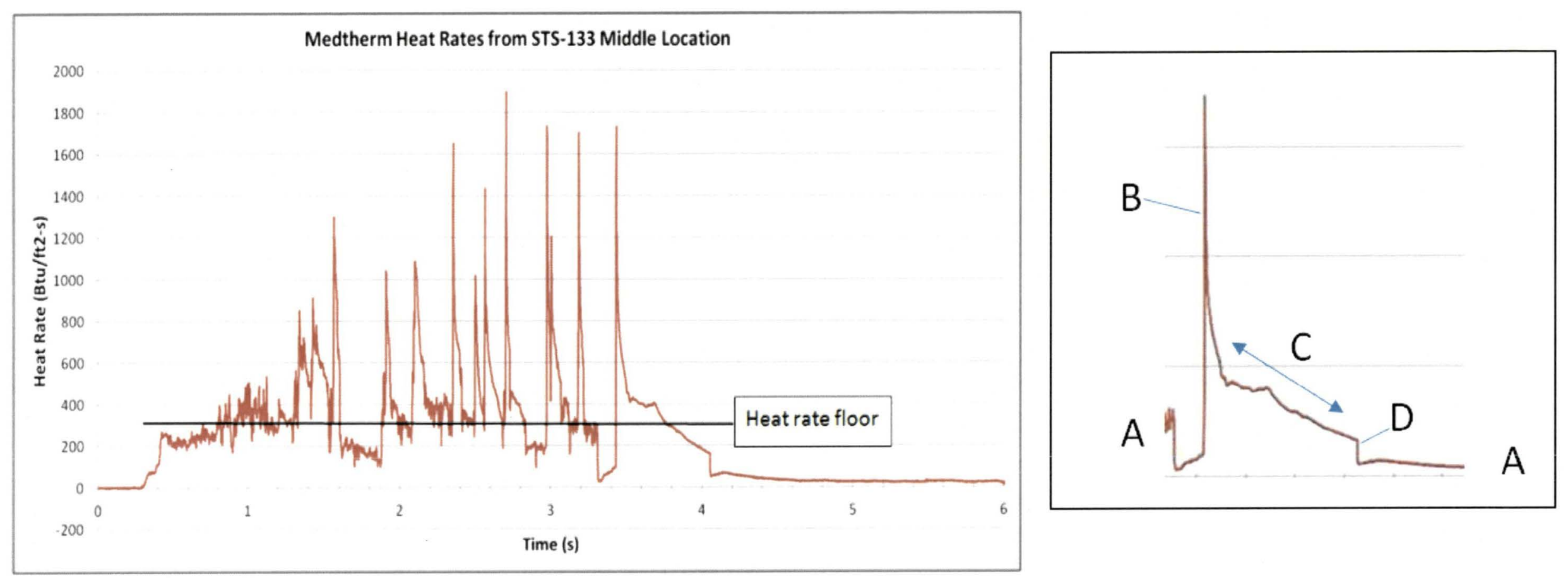

- Gaseous portion of SRB plume provides a heat rate baseline via convection ("Heat Rate floor")

- Aluminum oxide particulate portion of plume deposits on sensor and deflector; heating the substrate via conduction

- The aluminum oxide 'slag' portion of the plume causes the heat rate spikes 


\section{STS-135 Top Piston - Embedded Thermocouple Data}

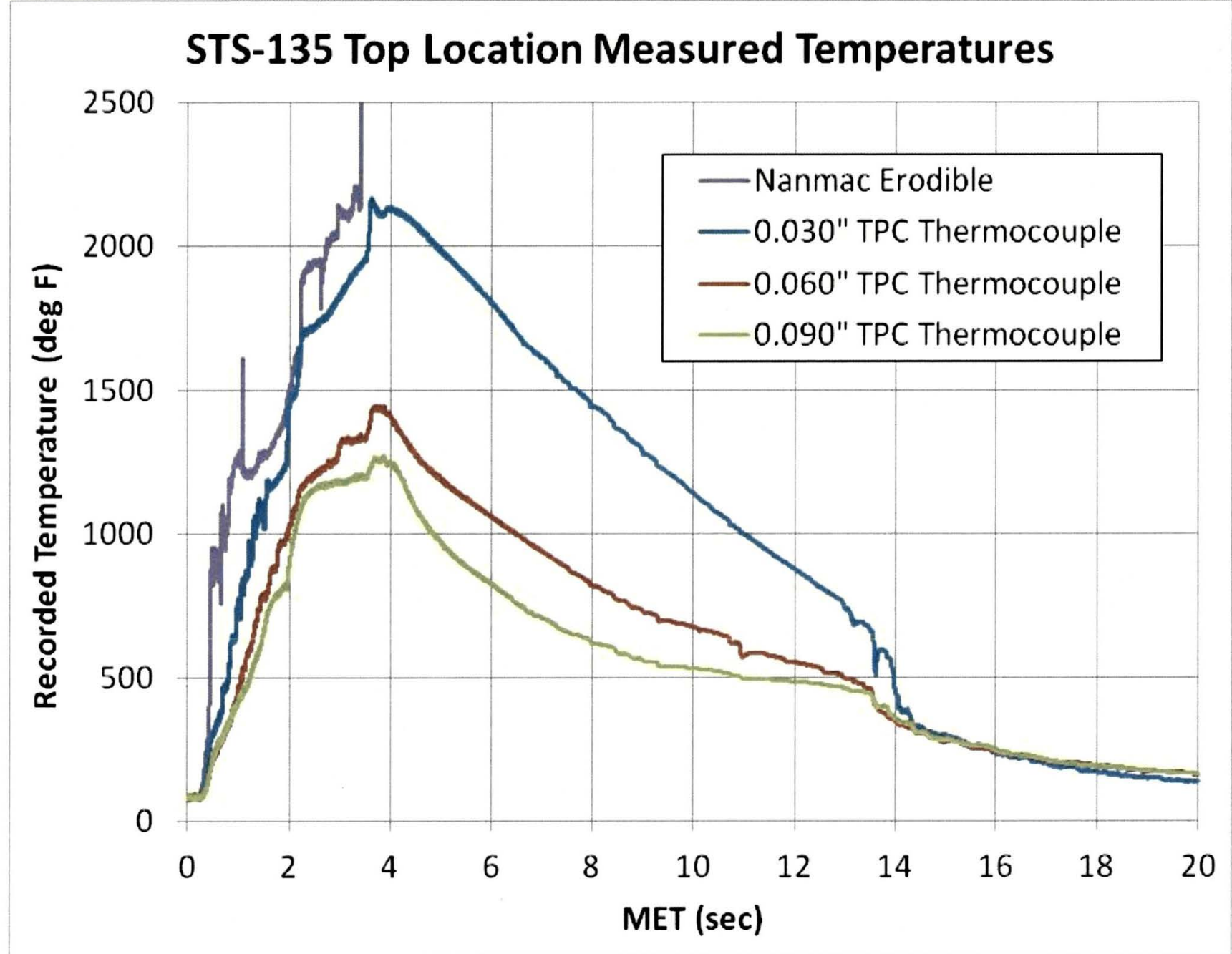

- Three thermocouples embedded in the TPC are processed to calculate heat rates 


\section{Medtherm \& Calculated Heat Rates for Top Location STS-135}

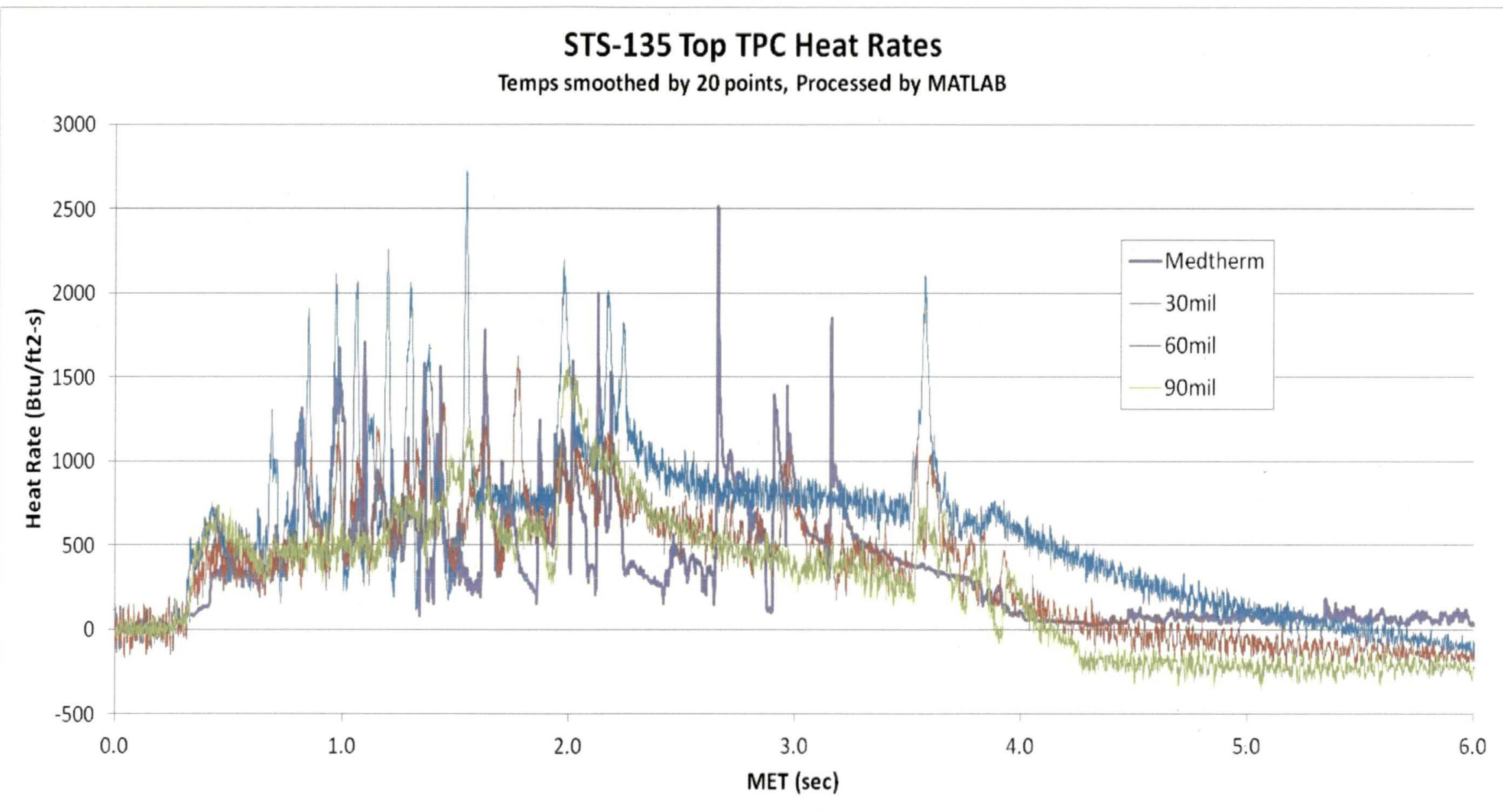

- Thermal spikes were identified with both the Medtherm and Tungsten Piston Calorimeter 


\section{Heat Rates for Three Launches}

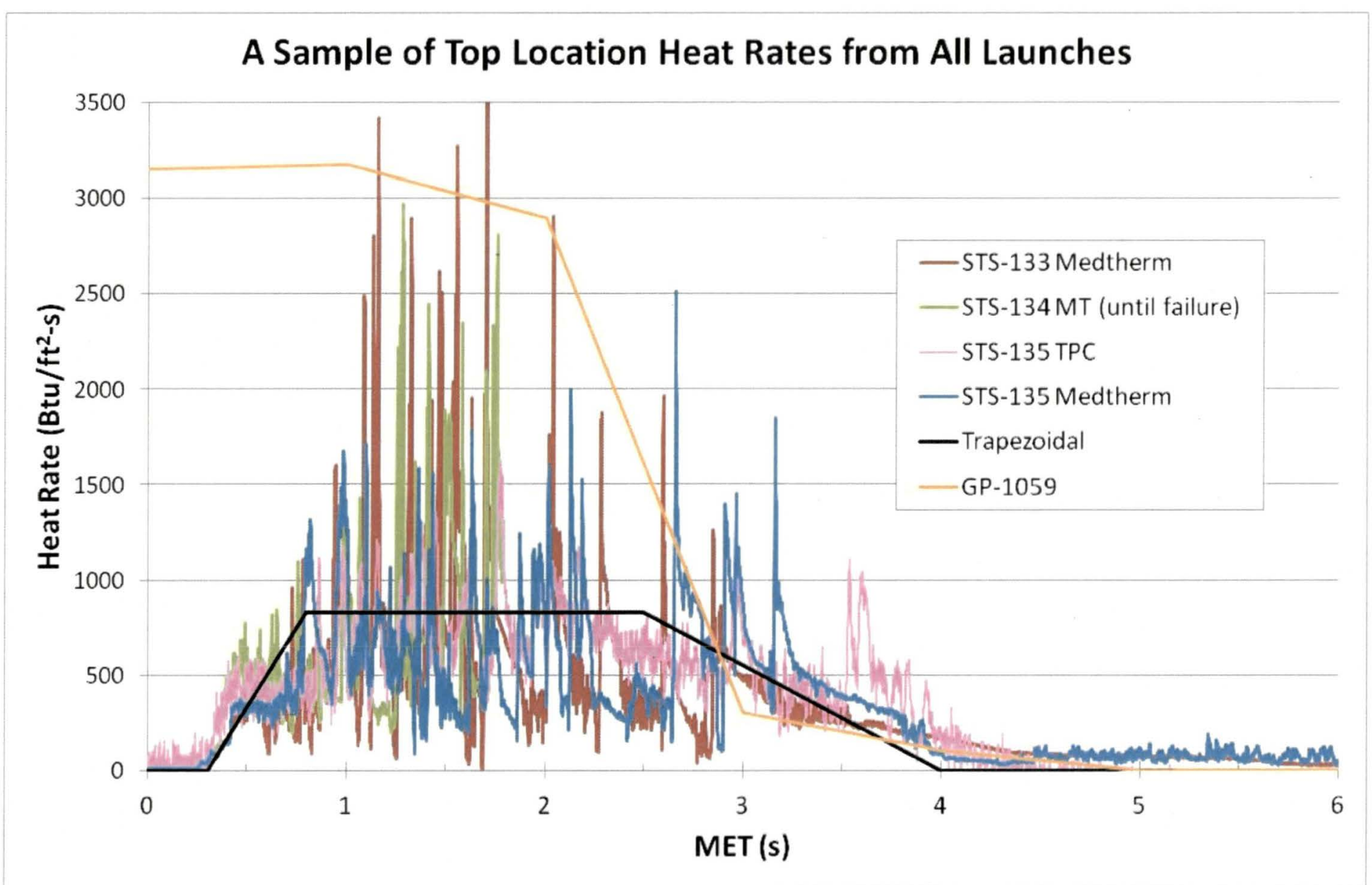

- Trapezoidal heating profile represents the average thermal energy of all the sensors at the top location (2240 Btu/ft²)

- GP-1059 line bounds the thermal spike envelope 


\section{Material Responses}

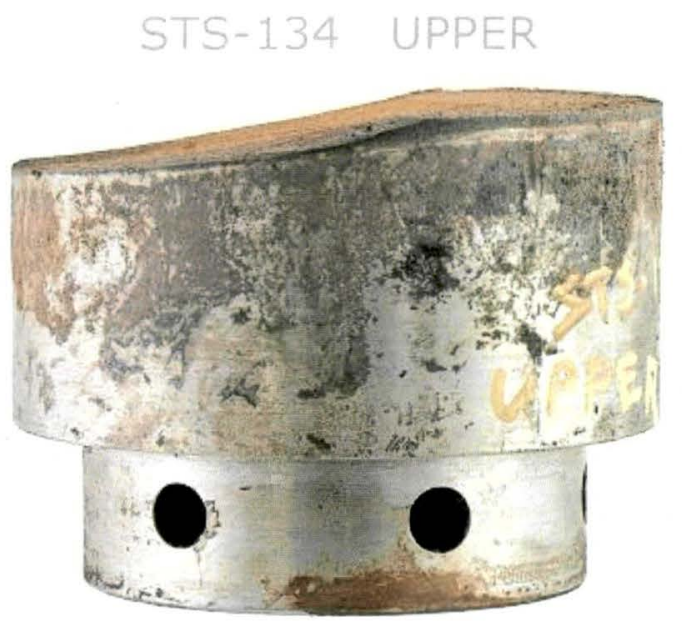

1018 Steel Witness Rod

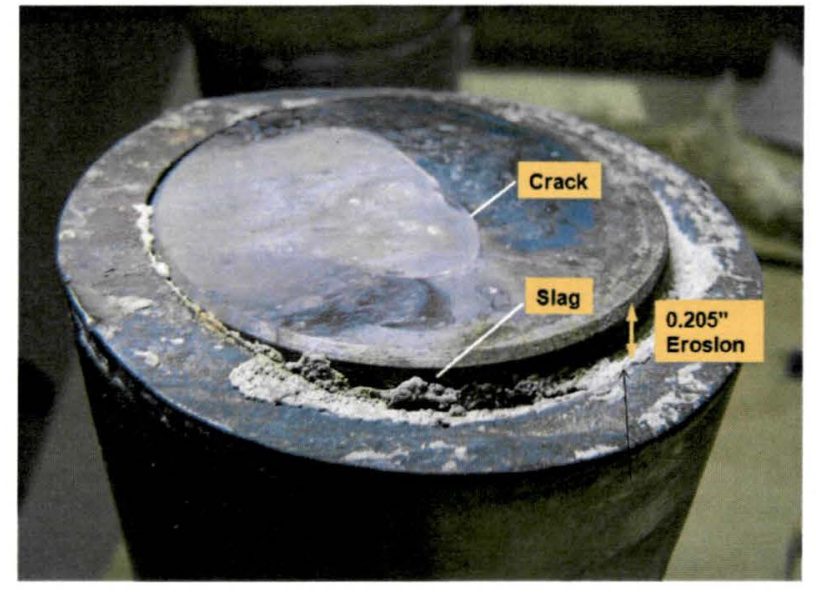

Tungsten Piston within A-286 Housing

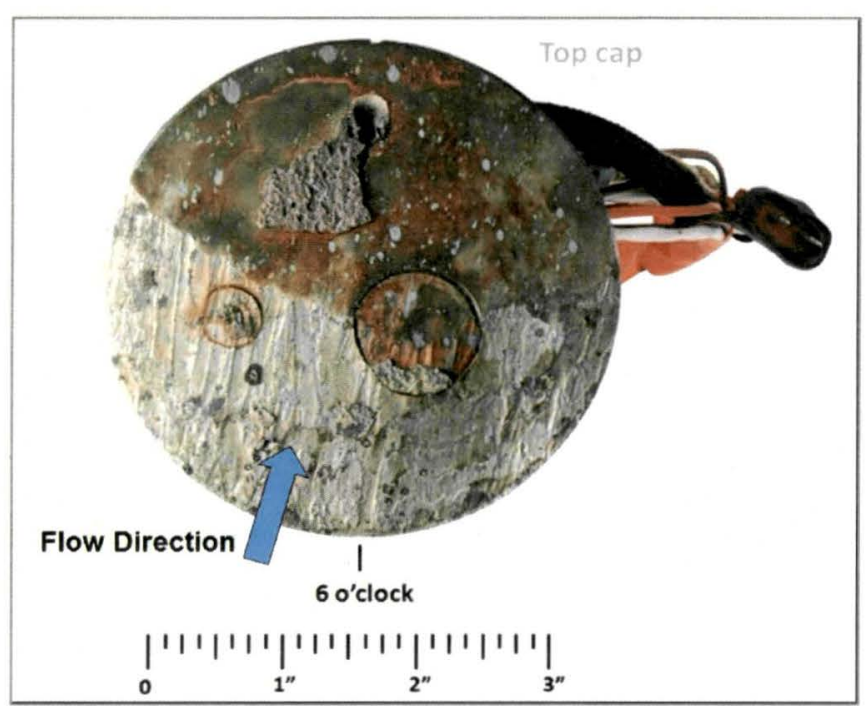

304 Stainless COTS Cap

- Steels with relatively high thermal diffusivities eroded

- Stainless steels with lower thermal diffusivities melted

- Pure tungsten did not erode while the 90-10 tungsten eroded as much as steel

- The most severe environment is located in a relatively small zone near the top of the MFD 


\section{Material Response - STS-134 Top COTS}

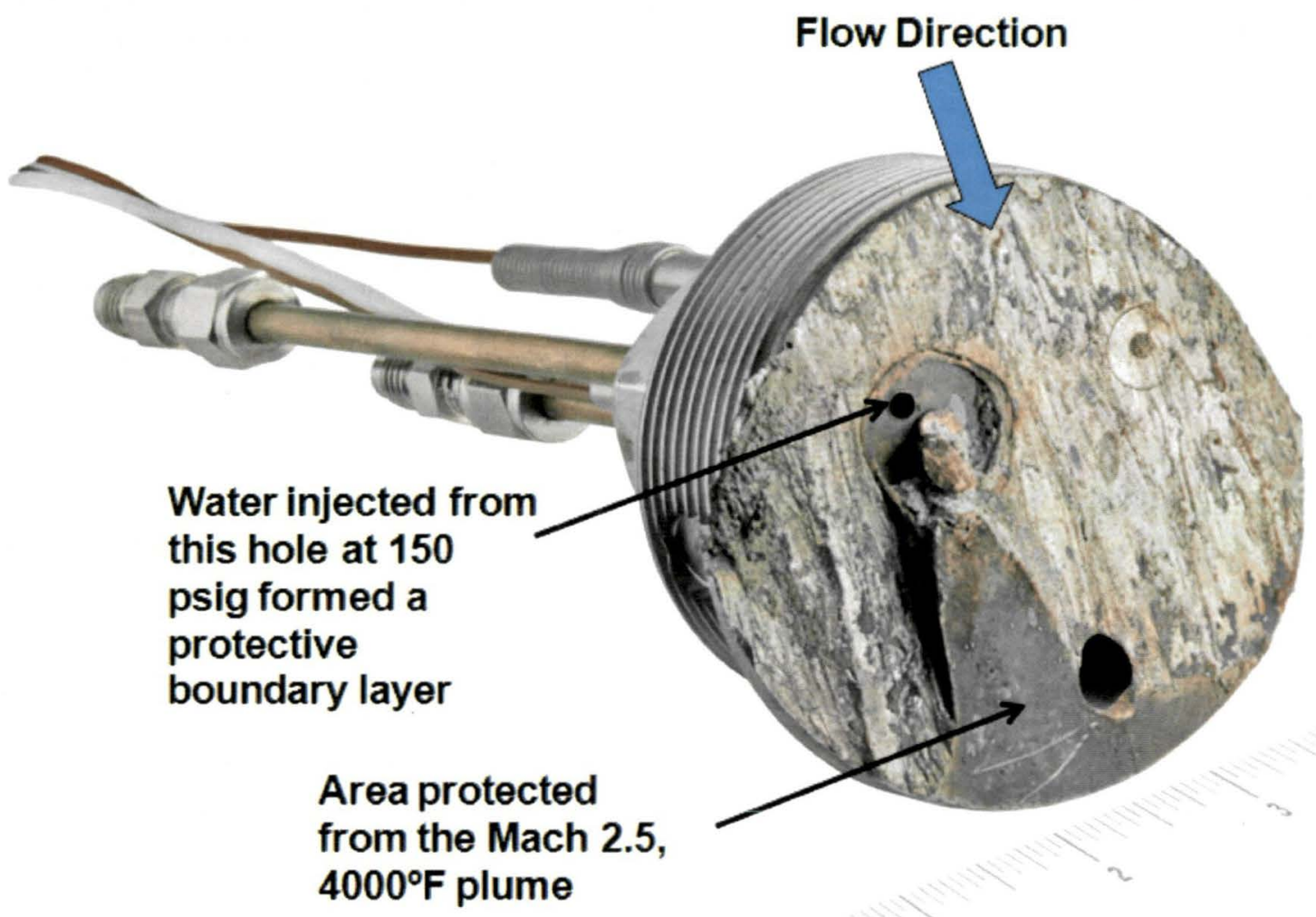

- Top sensors were severely eroded during STS-134

- COTS Medtherm water cooling lines were exposed

- Water injected into boundary layer protected the 304 stainless

- Water can be used on the SRB side of the MFD for protection, similar to Stennis SSME test stand 


\section{Conclusions}

- A Medtherm Calorimeter and Tungsten Piston Calorimeter successfully measured the heat rates of a Shuttle Solid Rocket Motor plume as it impinged upon the Main Flame Deflector

- It was discovered that the particle portion of the plume (slag) produces heating spikes of short duration - hence contribute only about a third of the heat to the surface of the Main Flame Deflector than previously thought

- Pressure Transducers and the Tungsten Piston Calorimeter load cell successfully measured the pressures from a Shuttle Solid Rocket Motor plume impinging on the Main Flame Deflector

- It was discovered that the pressures on the upper portion of the Main Flame Deflector are twice those predicted in previous analyses

- The Tungsten Piston Calorimeter was successfully designed for measuring hot erosive environments

- The COTS sensors performed better than expected. They should be considered for measuring other solid rocket motor plumes. Sensors have improved greatly during the past 25 years.

- Data acquired from this study are currently being used for the calibration of the Computational Fluid Dynamic (CFD) Models for the Space Launch System. 


\section{Space Launch System}

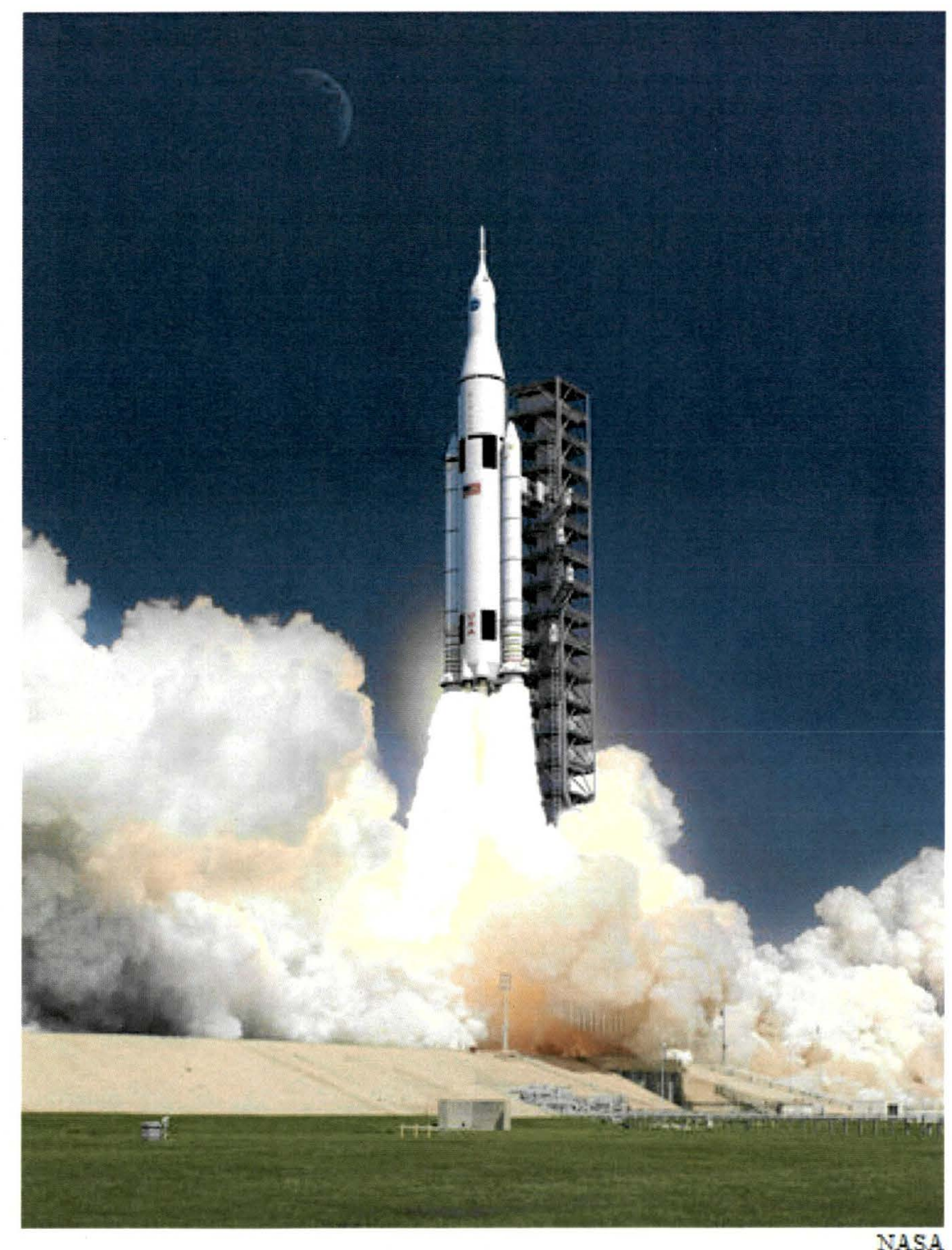

NASA 